1150

S66. $60 \mathrm{dVW}$

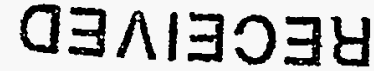

OJLWITNO SI LNבWROOO SIHL JO NOLINBIYLSIC
UOISIMO

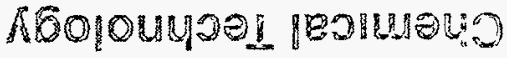

UOIS!n!

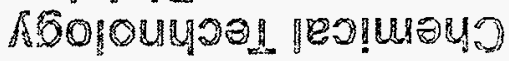

UOHSIRIO

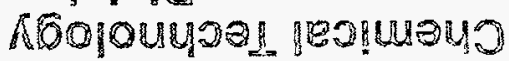
UOISHAO

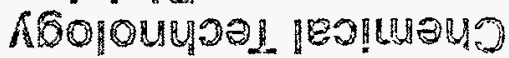

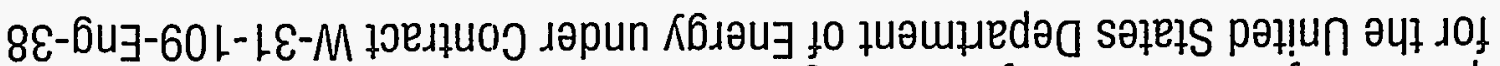

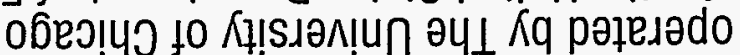

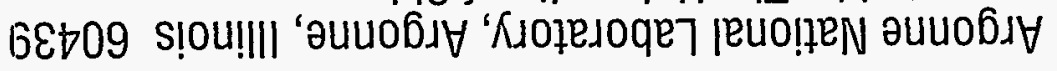

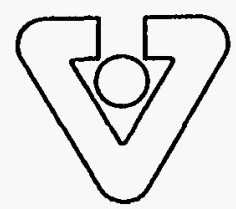

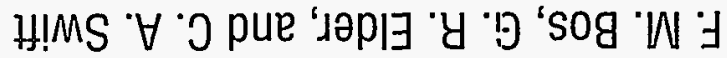

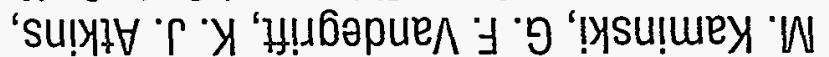

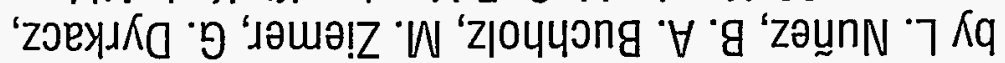

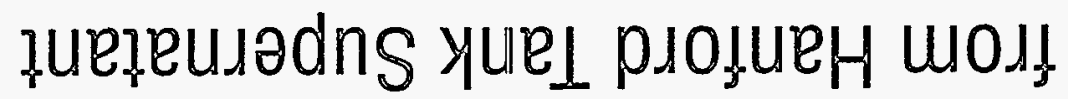

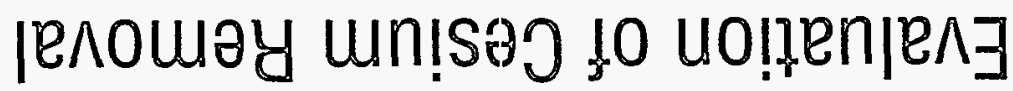
:uolitejedas jeoluayo

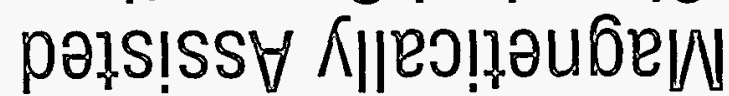

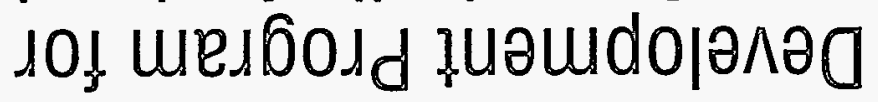

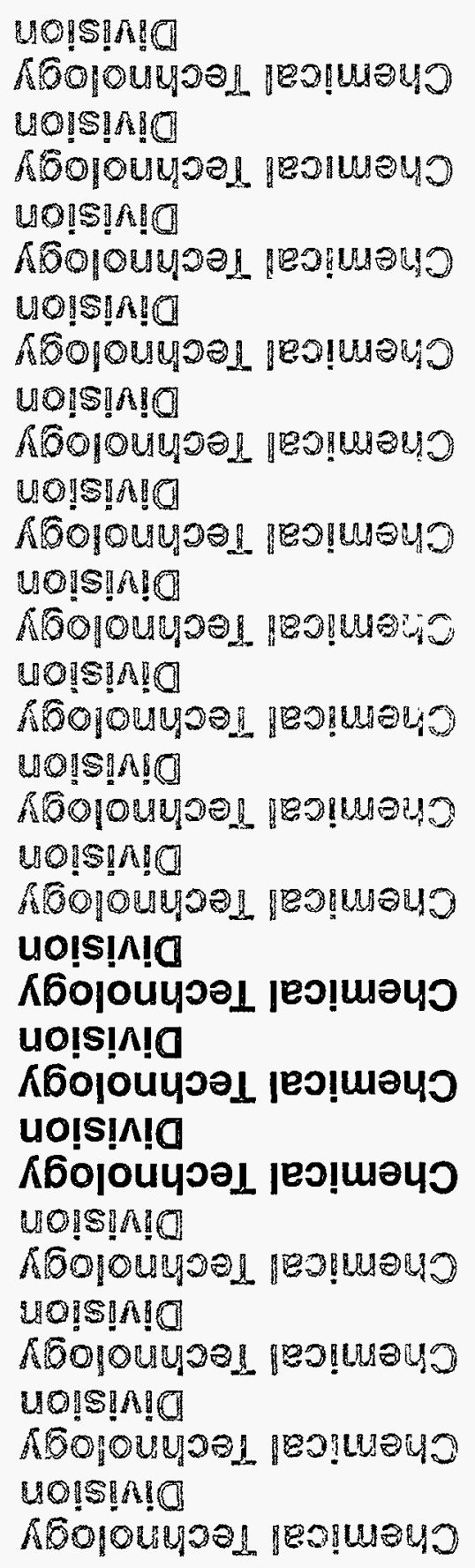

$\angle \nabla / \nabla 6-7 N \forall$ 
Argonne National Laboratory, with facilities in the states of Illinois and Idaho, is owned by the United States government, and operated by The University of Chicago under the provisions of a contract with the Department of Energy.

\section{DISCLAIMER}

This report was prepared as an account of work sponsored by an agency of the United States Government. Neither the United States Government nor any agency thereof, nor any of their employees, makes any warranty, express or implied, or assumes any legal liability or responsibility for the accuracy, completeness, or usefulness of any information, apparatus, product, or process disclosed, or represents that its use would not infringe privately owned rights. Reference herein to any specific commercial product, process, or service by trade name, trademark, manufacturer, or otherwise, does not necessarily constitute or imply its endorsement, recommendation, or favoring by the United States Government or any agency thereof. The views and opinions of authors expressed herein do not necessarily state or reflect those of the United States Government or any agency thereof.

Reproduced from the best available copy.

Available to DOE and DOE contractors from the Office of Scientific and Technical Information

$$
\text { P.O. Box } 62
$$

Oak Ridge, TN 37831

Prices available from (615) 576-8401

Available to the public from the National Technical Information Service

U.S. Department of Commerce 5285 Port Royal Road Springfield, VA 22161 


\section{DISCLAIMER}

Portions of this document may be illegible in electronic image products. Images are produced from the best available original document. 


\author{
$\overline{\text { ANL-94/47 }}$ \\ Argonne National Laboratory \\ 9700 South Cass Avenue \\ Argonne, Illinois 60439
}

\title{
DEVELOPMENT PROGRAM FOR \\ MAGNETICALLY ASSISTED CHEMICAL SEPARATION: \\ EVALUATION OF CESIUM REMOVAL FROM HANFORD TANK SUPERNATANT
}

\section{Principal Investigators}

L. Nuñez, B. A. Buchholz, M. Ziemer,

G. Dyrkacz, M. Kaminski, and G. F. Vandegrift

Argonne National Laboratory

Chemical Technology and Chemistry Divisions

and

K. J. Atkins, F. M. Bos, G. R. Elder, and C. A. Swift

Bradtec, Inc.

Contract No. 31682401

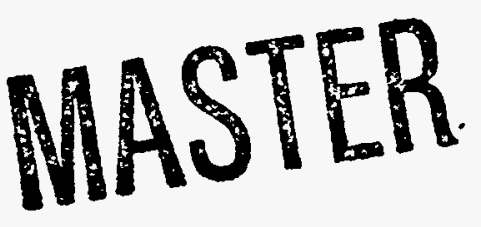

December 1994

DISTRUUTION OE IHIS DOCUMENT IS UNLIMITED

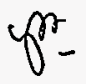


1 


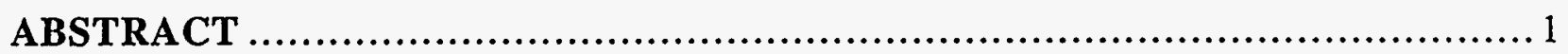

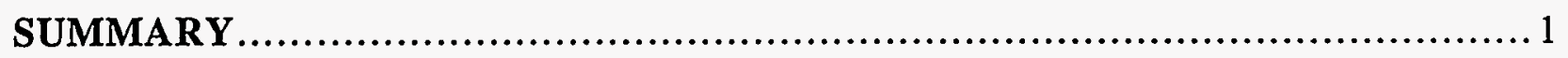

PART ONE. EVALUATION OF CESIUM REMOVAL FROM HANFORD TANKS

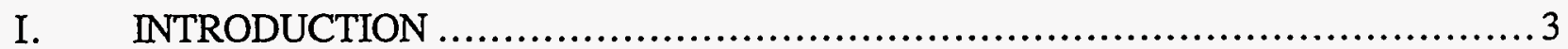

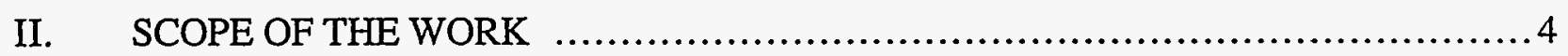

III. METHODOLOGY ............................................................. 6

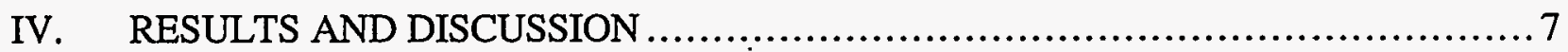

A. Distribution Ratio for Adsorbents before Incorporation into MAG*SEPSM Particle ..................................................... 7

B. Distribution Ratio for MAG*SEPSM Particles with Varying Experimental Conditions ................................................... 7

C. Effect of Gamma Irradiation ............................................... 9

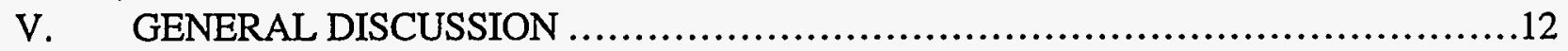

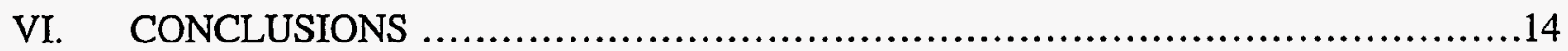

APPENDIX A. Statement of Work and Methodology ....................................15

APPENDIX B. MAG*SEPSM Particle Irradiation Report - Argonne National Laboratory ........25

APPENDIX C. Gamma-Spectrometer Calibration .....................................30

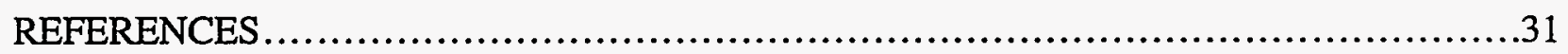

PART TWO. STUDIES OF GAMMA IRRADIATION AND OPTICAL MICROSCOPY ON CESIUM REMOVAL PARTICLES

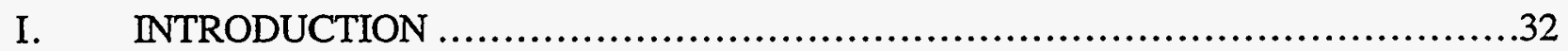

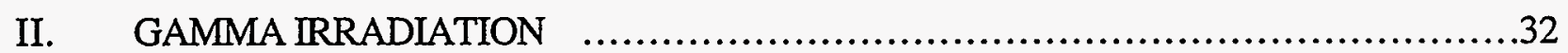

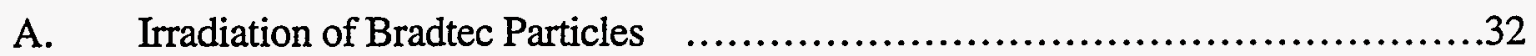

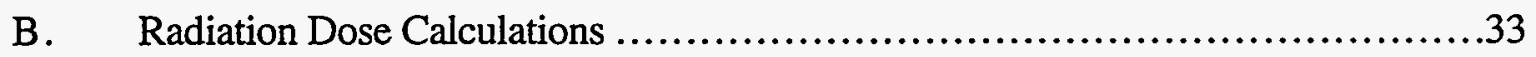


TABLE OF CONTENTS (contd)

$\underline{\text { Page }}$

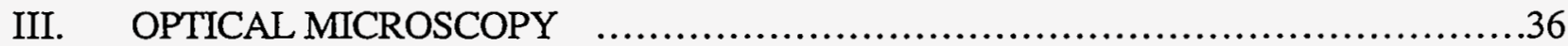

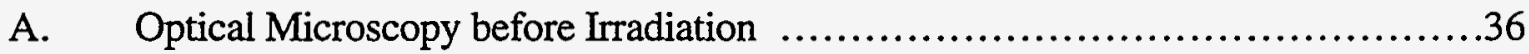

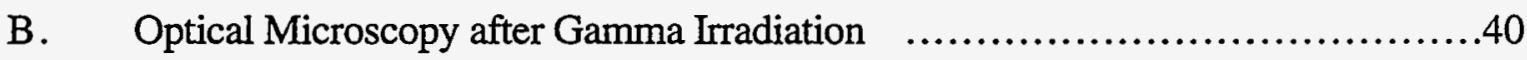

1. Crystalline Silico-Titanate Samples ..................................40

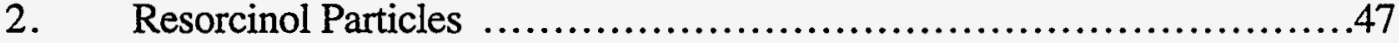

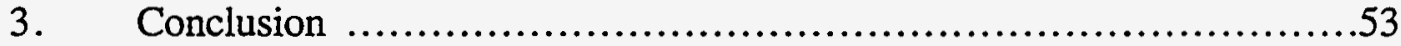

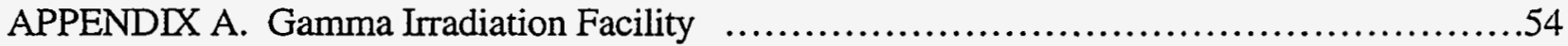

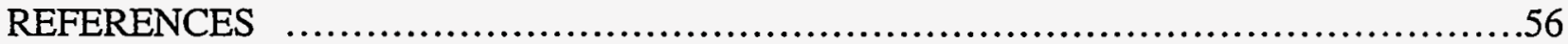




\title{
DEVELOPMENT PROGRAM FOR MAGNETICALLY ASSISTED CHEMICAL SEPARATION: EVALUATION OF CESIUM REMOVAL FROM HANFORD TANK SUPERNATANT
}

\author{
(L. Nuñez, B. A. Buchholz, M. Ziemer, G. Dyrkacz, M. Kaminski,
} G. F. Vandegrift, K. J. Atkins, F. M. Bos, G. R. Elder, and C. A. Swift)

\begin{abstract}
Magnetic particles (MAG*SEPSM) coated with various absorbents were evaluated for the separation and recovery of low concentrations of cesium from nuclear waste solutions. The MAG*SEPSM particles were coated with (1) clinoptilolite, (2) transylvanian volcanic tuff, (3) resorcinol formaldehyde, and (4) crystalline silico-titanate, and then were contacted with a Hanford supernatant simulant. Particles coated with the crystalline silico-titanate were identified by Bradtec as having the highest capacity for cesium removal under the conditions tested (variation of $\mathrm{pH}$, ionic strength, cesium concentration, and absorbent/ solution ratio). The MAG*SEPSM particles coated with resorcinol formaldehyde had high distribution ratios values and could also be used to remove cesium from Hanford supernant simulant.
\end{abstract}

Gamma irradiation studies were performed on the MAG*SEPSM particles with a gamma dose equivalent to 100 cycles of use. This irradiation decreased the loading capacity and distribution ratios for the particles by greater than $75 \%$. The particles demonstrated high sensitivity to radiolytic damage due to the degradation of the polymeric regions. These results were supported by optical microscopy measurements. Overall, use of magnetic particles for cesium separation under nuclear waste conditions was found to be marginally effective.

\section{SUMMARY}

The Magnetically Assisted Chemical (MACS) Separation Program seeks to develop a process that will combine the selectivity afforded by ion exchange and magnetic separation and provide a more efficient chemical separation for transuranics, radionuclides, and heavy metals in nuclear waste solutions. Bradtec, Inc., and Argonne National Laboratory have joined efforts to develop magnetic particles coated with absorbents selective for cesium removal. This report focuses on the feasibility of the separation process for removing cesium from Hanford tank supernatant. This effort is detailed in a two-part report describing Bradtec and ANL tasks separately.

Magnetic (MAG*SEPSM) particles with an absorbed layer of (1) clinoptilolite $(75-200 \mu \mathrm{m}),(2)$ transylvanian volcanic tuff $(100-450 \mu \mathrm{m}),(3)$ resorcinol formaldehyde $(100-450 \mu \mathrm{m})$, and (4) crystalline silico-titanate $(100-450 \mu \mathrm{m})$ were evaluated for recovery of cesium from Hanford supernatant simulant. Particles were tested by varying (1) solution ionic strength, (2) cesium concentration, (3) solution $\mathrm{pH}$, and (4) magnetic particle-to-solution ratios for a simulant of average Hanford tank supernatant. The contact time used for the simulant solutions 
was 15 min and consistent with the requirements of the MAG*SEPSM process; however, this was much shorter than the 17 to $72 \mathrm{~h}$ needed to reach chemical equilibrium. Thus, the distribution ratios $\left(\mathrm{K}_{\mathrm{d}}\right)$ in this report reflect kinetic rate measurements and not equilibrium distributions. The highest $K_{d}$ values were observed for the crystalline silico-titanate when the simulant was diluted in volume by one-fifth the original concentration; these $K_{d}$ values ranged between 350 and 820 . Reduction of the cesium concentration to one-tenth the original simulate composition and the hydroxide concentration to $1 \underline{\mathrm{M}}$ resulted in poor $\mathrm{K}_{\mathrm{d}}$ values ( $<100$ except for silico-titanate, which ranged from 100 to 320 ): for most of the materials and conditions studied, $K_{d}$ values $<300$ were obtained.

Gamma irradiation studies were performed on the MAG*SEPSM particles with a gamma dose equivalent to 100 cycles of use. The particles subjected to gamma irradiation showed a substantial decrease in the capacity for cesium removal. With the original waste supernatant, $\mathrm{K}_{\mathrm{d}}$ values dropped from 100 to 22 for the crystalline silico-titanate particles at $9.7 \mathrm{Mrad}$. With the same type of particles under similar irradiation conditions but with the supernatant solution being one-fifth of the original concentration, the $\mathrm{K}_{\mathrm{d}}$ values dropped from 500 to 130 . Optical microscopy of the crystalline silico-titanate particles showed a drastic increase in the particle size (up to $1000-12,000 \mu \mathrm{m}$ ) due to aggregation. The resulting lower surface area significantly decreased the extraction efficiency. Evidence of fine particles and polymeric unraveling was apparent in all the irradiated materials.

The chemical and physical studies performed in this evaluation indicate that cesium removal using magnetic particles is only marginally effective when compared with more traditional separation techniques. 


\section{PART ONE.}

\section{EVALUATION OF CESIUM REMOVAL FROM HANFORD TANKS \\ (K. J. Atkins, ${ }^{*}$ F. M. Bos, ${ }^{*}$ G. R. Elder,* and C. A. Swift*)}

\section{INTRODUCTION}

The MAG*SEPSM process (patent pending) developed by Bradtec, Inc., allows the selective extraction of ions from solution. The process uses magnetic particles that are chemically engineered to have surface adsorption sites tailored for specific functions. The particles are contacted with the waste stream, where they adsorb the contaminant of interest. Conventional magnetic separation technology may be employed to remove the MAG*SEPSM particles from the waste stream. The fate of the MAG*SEPSM particles is determined by both economic and practical considerations. The MAG*SEPSM particles themselves may become the final waste form in some applications, or alternatively, they could be regenerated, enabling the contaminant to be removed from the waste stream and the "cleaned " particles to be recycled if required.

The MAG*SEPSM technology is being evaluated for several projects where conventional ion exchange methods are not practical or cost effective. These projects include treatment of heavy metals and radionuclides in groundwater and wastewater. ${ }^{1}$

The key element of the technology is the selective adsorption particle. These composite particles consist of a magnetic core, a polymer coating for durability, and either a "functionalized" resin coating or selective seed materials embedded in the polymer coating.

Supernatants stored in the underground storage tanks at the Hanford site contain radioactive $\mathrm{Cs}$ and $\mathrm{Sr}$, and in some cases, low concentrations of transuranics (TRUs). Bradtec has undertaken to demonstrate the feasibility of using the MAG*SEPSM technology for the selective removal of cesium from the Hanford tank supernatant. A simulant waste solution is used since the actual supernatant is not available.

The work discussed in this report describes the testing performed to identify the most promising MAG*SEPSM particle coating in a simulant supernatant while varying (1) solution ionic strength, (2) cesium concentration, (3) solution $\mathrm{pH}$, and (4) magnetic particle-to-solution ratios.

\footnotetext{
${ }^{*}$ Bradtec, Inc.
} 


\section{SCOPE OF THE WORK}

The demonstration of the MAG*SEPSM technology for the selective removal of cesium from Hanford tank supernate simulant involved the testing of four materials for their adsorption characteristics: (1) clinoptilolite, (2) transylvanian volcanic tuff (TVT), (3) resorcinol formaldehyde (resorcinol), and (4) crystalline silico-titanate (CST). Clinoptilolite and TVT are naturally occurring zeolites and were selected because their cation exchange capacities for cesium have been successfully demonstrated in other MAG*SEPSM applications. Resorcinol and CST were chosen for their high selectivity and separation capabilities for cesium in high alkaline and sodium concentrations. The composition of the Hanford waste is summarized in Table II- 1 .

Table II-1. Components of Hanford Simulant Waste Solution

\begin{tabular}{ccc}
\hline Major Components & Component Charge & Concentration, mol/L \\
\hline $\mathrm{Na}$ & 1 & 8.83 \\
$\mathrm{~K}$ & 1 & $9.35 \times 10^{-2}$ \\
$\mathrm{Cs}$ & 1 & $4.88 \times 10^{-5}$ \\
$\mathrm{OH}$ & -1 & 6.54 \\
$\mathrm{NO}_{3}$ & -1 & 1.09 \\
$\mathrm{NO}_{2}$ & -1 & $8.09 \times 10^{-1}$ \\
$\mathrm{Al}(\mathrm{OH})_{4}$ & -1 & $2.06 \times 10^{-2}$ \\
$\mathrm{CO}_{3}$ & -2 & $2.22 \times 10^{-1}$ \\
$\mathrm{CrO}_{4}$ & -2 & $4.37 \times 10^{-3}$ \\
$\mathrm{PO}_{4}$ & -3 & $8.00 \times 10^{-4}$ \\
\hline
\end{tabular}

Two additional materials were originally included in the study, potassium cobalt hexacyanoferrate and sodium cobalt dicarbolide, but were later removed. Potassium cobalt hexacyanoferrate has detrimental waste management implications, and cobalt dicarbolide was found to be too soluble in aqueous solutions to prepare MAG*SEPSM particles.

The four candidate materials were tested for absorption capacity in powder form before the MAG*SEPSM particles were prepared. Next, the adsorption characteristics of the coated particles were determined. The efficiency of the MAG*SEPSM particles were measured by the distribution ratio, $K_{d}$, where $K_{d}=$ [Cs-137] adsorbent per gram/[Cs-137] treated solution per milliliters. Coated particles were then irradiated with a gamma dose equivalent of 10 and 100 cycles (discussed in Part Two of this report), and the adsorption characteristics of the most promising particles were compared with the adsorption prior to irradiation. (The irradiation doses were discussed with Argonne National Laboratory and agreed to by Bradtec and Argonne.)

The contact time between the MAG*SEPSM particles and the simulant waste solutions was 15 min, which is consistent with the needs for the MAG*SEPSM particles. This time is significantly shorter than the 12 to $72 \mathrm{~h}$ normally used to obtain a distribution ratio. Consequently, the term "distribution ratio" here may be more correctly defined as a kinetic rate measurement. It is quite possible that longer contact times would produce higher $\mathrm{K}_{\mathrm{d}}$ values (equilibrated conditions).

Some additional tests to those outlined in the contract requirements were performed to provide a baseline for the behavior of the MAG*SEPSM particles. The solution prepared for these tests contained only cesium and cesium-137 (as a tracer) in deionized water. These tests permitted 
the capacity of the MAG*SEPSM particles to be determined. The capacity of the MAG*SEPSM particles for cesium removal before irradiation was also compared with that after irradiation.

Details of the test program are as follows:

1. Select possible candidate adsorbing materials.

2. Test the candidate adsorbing materials with the Hanford simulant waste solution prepared according to Table II-1.

3. Prepare $M A G * S E P S M$ particles.

4. Perform testing with the MAG*SEPSM particles according to the matrix in Table II-2.

5. Calculate $\mathrm{K}_{\mathrm{d}}$ for cesium for each type of adsorbent and MAG*SEPSM particle.

6. Send the most promising materials to ANL for irradiation testing at a gamma dose equivalent to 10 and 100 cycles of use.

7. Re-test the irradiated particles under the optimum conditions determined from the data obtained in step 5 .

Table II-2. Test Matrix for MACS Testing

\begin{tabular}{ccc}
\hline Experimental Variable & Maximum & Minimum \\
\hline Two ionic strengths & Composition as Table II-1 & $\begin{array}{c}\text { Dilution by water to } 1 / 5 \text { of the above } \\
\text { composition }\end{array}$ \\
Two Cs ${ }^{+}$concentrations & Composition as Table II-1 & $1 / 10$ of the above composition \\
Two OH- concentrations & Composition as Table II-1 & $\begin{array}{c}\mathrm{Approx}^{1} \mathrm{M} \text { with }\left[\mathrm{Na}^{+}\right] \text {kept constant using } \\
\mathrm{NaNO}_{3} \text { and } \mathrm{NaNO}_{2} \text { in their molar ratio given in } \\
\text { Table } \mathrm{II}-1 .\end{array}$ \\
Two adsorbent/solution ratios
\end{tabular}

aIn cases where the quantity of MAG*SEPSM particles was insufficient to permit both adsorbent/solution ratios to be tested, the minimum value was chosen.

${ }^{b}$ Concentration of MAG*SEPSM particles in solution. 


\section{METHODOLOGY} particles:

The following adsorber materials were selected for the preparation of MAG*SEPSM

1. Activated transylvanian volcanic tuff

2. Clinoptilolite (particle size $<75 \mu \mathrm{m}$ to $>45 \mu \mathrm{m}$ )

3. Resorcinol formaldehyde

4. Crystalline silico-titanate

The clinoptilolite and TVT were supplied by Imperial College, London; crystalline silicotitanate was supplied by Norman Brown, Sandia National Laboratories, Albuquerque, NM; and resorsinol formaldehyde was supplied by J. Bibler, Westinghouse Savannah River Co., Aiken, SC.

Prior to testing, the TVT was "activated" by heating at $150^{\circ} \mathrm{C}$ for 24 hours. ${ }^{8}$ The mechanism of "activation" is not clear but may involve the liberation of moisture from active sites within the zeolite.

Clinoptilolite was chosen as a possible adsorber material for cesium removal from Hanford supernatant because MAG*SEPSM particles containing clinoptilolite had been used earlier by Bradtec to remove cesium from contaminated milk. The clinoptilolite was sieved into three fractions with particles in the following ranges: (1) $<180 \mu \mathrm{m}$ and $>75 \mu \mathrm{m},(2)<75 \mu \mathrm{m}$ and $>45 \mu \mathrm{m}$, and $(3)<45 \mu \mathrm{m}$. Tests on all three fractions using the simulant waste stream were performed to determine the optimum particle size for preparation of the MAG*SEPSM particles. Resorcinol formaldehyde and crystalline silico-titanate were used as supplied, and size distribution data are available from microscopy analyses performed at ANL. (see Part Two).

With some of the adsorber materials, the minimum size attainable for the MAG*SEPSM particles was between 106 and $420 \mu \mathrm{m}$. Therefore, for consistency, all the MAG*SEPSM particles used for this study were between 106 and $420 \mu \mathrm{m}$. The MAG*SEPSM particles prepared using activated TVT were re-activated and tested in order to determine whether the process of preparing the particles adversely affected the adsorption capability. The tests showed no significant difference, and consequently, the MAG*SEPSM particles were not reactivated after preparation.

The testing at Bradtec was performed according to the test procedures provided in Appendix A. 


\section{RESULTS AND DISCUSSION}

A. Distribution Ratio for Adsorbents before Incorporation into MAG * SEPSM Particle

Testing was performed on the following types of adsorbent materials before their incorporation into a MAG*SEPSM particle:

1. Powdered TVT

2. Clinoptilolite (particle size $<180 \mu \mathrm{m}>75 \mu \mathrm{m}$ )

2a. Clinoptilolite (particle size $<75 \mu \mathrm{m}>45 \mu \mathrm{m}$ )

2b. Clinoptilolite (particle size $<45 \mu \mathrm{m}$ )

3. Resorcinol formaldehyde

(Note: crystalline silico-titanate was unavailable for testing at this point in the test program.) The results from the testing using the above materials are given in Table IV-1. The calculation used to

Table IV-1. Distribution Ratios for Adsorbent before Incorporation into MAG*SEPSM Particles

\begin{tabular}{lcc}
\hline \multicolumn{1}{c}{ Adsorbent } & ${\text { Sample } \mathrm{A}^{\mathrm{a}}}$ & ${\text { Sample } \mathrm{B}^{\mathrm{a}}}^{\mathrm{c}}$ \\
\hline Powdered TVT & 6 & 7 \\
Clinoptilolite (particle size $<180 \mu \mathrm{m}>75 \mu \mathrm{m}$ ) & 2 & 1 \\
Clinoptilolite (particle size $<75 \mu \mathrm{m}>45 \mu \mathrm{m})$ & 5 & 4 \\
Clinoptilolite (particle size $<45 \mu \mathrm{m})$ & 3 & 1 \\
Resorcinol formaldehyde & 22 & 15 \\
\hline
\end{tabular}

aSamples $\mathrm{A}$ and $\mathrm{B}$ are duplicates.

determine the $\mathrm{K}_{\mathrm{d}}$ values, the raw data for this testing, and the associated statistics are provided in Appendices A and B. Details pertaining to the gamma spectrometer used for the testing are provided in Appendix $\mathrm{C}$.

The results in Table IV-1 show that resorcinol formaldehyde was more selective for cesium under these conditions. Clinoptilolite with a particle size of $>45 \mu \mathrm{m}$ to $<: 75 \mu \mathrm{m}$ showed a small improvement in the $\mathrm{K}_{\mathrm{d}}$ for cesium over the two other samples of clinoptilolite studied. Consequently, clinoptilolite with this size of particles was used to prepare the MAG*SEPSM particles.

B. Distribution Ratio for $M A G * S E P S M$ Particles with Varying Experimental Conditions

The testing using the powdered adsorber materials confirmed that cesium was removed, with varying efficiency, from the Hanford supernant simulant with the composition given in Table II-1. Subsequently, MAG*SEPSM particles were prepared for further testing. Crystalline silico-titanate was received during this period and, therefore, was also tested. After preparation, the silico-titanate particles were examined under a microscope (see Part T'wo of this report), and the particle size was determined to be approximately between $106 \mu \mathrm{m}$ and $420 \mu \mathrm{m}$. However, due to the irregular shape of the particles (i.e., some cylindrical particles may be present) and their tendency to "stick" together as a result of electrostatic charges, the separation of the particles into 
distinct size boundaries using the current equipment was not possible. Thus, the four test materials $(106 \mu \mathrm{m}<$ particle size $<420 \mu \mathrm{m})$ are

\section{Activated TVT MAG*SEPSM}

2. Clinoptilolite $M A G * S E P S M$

3. Resorcinol formaldehyde MAG*SEPSM

4. Silico-titanate MAG*SEPSM

In most cases, insufficient particles were available to permit triplicate tests at the maximum particle-to-solution ratio $(0.05 \mathrm{~g} / \mathrm{mL})$; therefore, in those cases, only the minimum ratio $(0.005 \mathrm{~g} / \mathrm{mL})$ was used.

The $\mathrm{K}_{\mathrm{d}}$ results for the MAG*SEPSM particles with varying experimental conditions are presented in Table IV-2. The calculation used to determine the $\mathrm{K}_{\mathrm{d}}$ values, the raw data for this testing, and the associated statistics are provided in Appendices A and B. Details pertaining to the gamma spectrometer used for the testing are provided in Appendix C.

The results in Table IV-2 show that, with the exception of clinoptilolite, the $K_{d}$ value was the highest for the adsorbers tested when the simulant was diluted by one-fifth. Of these three types of MAG*SEPSM particle, the highest $\mathrm{K}_{d}$ was achieved for the silico-titanate coated particles. As expected, when the concentration of competing species was reduced (condition $B$ in Table IV-2), the $\mathrm{K}_{d}$ increased. The $\mathrm{K}_{d}$ further increased when the higher particle-to-solution ratio $(0.05 \mathrm{~g} / \mathrm{mL})$ was used. Again, as expected, the $\mathrm{K}_{\mathrm{d}}$ was significantly reduced when the cesium concentration was reduced by one-tenth (condition $C$ ). The MAG*SEPSM particles coated with resorcinol formaldehyde and used in a supernatant diluted by one-fifth demonstrated the second highest $\mathrm{K}_{\mathrm{d}}$. When the hydroxide concentration was reduced to $1 \underline{\mathrm{M}}$ (condition $\mathrm{D}$ ), the $\mathrm{K}_{\mathrm{d}}$ was highest for clinoptilolite. This behavior is consistent with clinoptilolite being more soluble in higher concentrations of hydroxide. Hence, for the tests performed in $1.8 \mathrm{M}$ and $8.9 \mathrm{M}$ hydroxide (conditions $A$ to $C$ ), sufficient clinoptilolite may have dissolved from the particle to affect the $\mathrm{K}_{\mathrm{d}}$.

Comparing the results from Tables IV-1 and IV-2 shows that the $\mathrm{K}_{\mathrm{d}}$ was not reduced significantly by incorporating the powdered adsorbents into MAG*SEPSM particles. This is because the exchange process is diffusion limited, and therefore, a large improvement in $K_{d}$ may only be observed if the solution is left in contact with the particles or powder for a considerable time, i.e., $24 \mathrm{~h}$ or more, to allow diffusion and achieve equilibrium. Hence, for the short contact time used in this testing, both the powdered adsorbent and the MAG*SEPSM particles were limited to a surface adsorption mechanism only. Consequently, a large difference in $\mathrm{K}_{d}$ was not expected. In fact, the $\mathrm{K}_{\mathrm{d}}$ values for the MAG*SEPSM particles coated with resorcinol formaldehyde and clinoptilolite were, on average, improved over the tests with the powdered materials, although still of the same order of magnitude.

The Hanford tank waste simulant (Table $\mathrm{II}-1$ ) consisted of $8.8 \mathrm{M} \mathrm{Na} \mathrm{Na}^{+}$and $6.54 \underline{\mathrm{M} \mathrm{OH}^{-}}$. These concentrations are considerably higher than most Hanford simulants, where the $\mathrm{Na}^{+}$ concentration is typically between 5 and $6 \mathrm{M}$ and the $\mathrm{OH}^{-}$concentration is between 1 and $2 \mathrm{M}$. As a consequence, the simulant in this study has a higher viscosity, slower exchange kinetics, and greater competition between $\mathrm{Na}^{+}$and $\mathrm{Cs}^{+}$. 
The combined effect of the higher $\mathrm{Na}^{+}$concentrations, together with the short contact times used for the study, resulted in much lower $\mathrm{K}_{d}$ values than reported elsewhere. ${ }^{3}$ Other factors affecting the $\mathrm{K}_{\mathrm{d}}$ are discussed later.

Table IV-2. Distribution Ratios Obtained for MAG*SEPSM Particles $(0.05$ and $0.005 \mathrm{~g} / \mathrm{mL})$ with Varying Experimental Conditions ${ }^{\mathrm{a}}$

\begin{tabular}{l|cc|cc|cc|cc}
\hline & \multicolumn{2}{|c|}{$\mathrm{A}$} & \multicolumn{2}{c|}{$\mathrm{B}$} & \multicolumn{2}{c|}{$\mathrm{C}$} & \multicolumn{2}{c}{$\mathrm{D}$} \\
\cline { 2 - 9 } & $0.05^{\mathrm{b}}$ & $0.005^{\mathrm{b}}$ & $0.05^{\mathrm{b}}$ & $0.005^{\mathrm{b}}$ & $0.05^{\mathrm{b}}$ & $0.005^{\mathrm{b}}$ & $0.05^{\mathrm{b}}$ & $0.005^{\mathrm{b}}$ \\
\hline Activated TVT MAG*SEPSM & 4 & - & - & 23 & - & 0 & - & 4 \\
& 2 & - & - & 22 & - & 21 & - & 16 \\
& - & - & - & 39 & - & 0 & - & 6 \\
\hline Resorcinol Formaldehyde & - & 39 & - & 136 & - & 168 & - & 0 \\
MAG*SEPSM & & & & & & & & \\
& - & 58 & - & 161 & - & 65 & - & 5 \\
& - & 43 & - & 364 & - & 0 & - & 13 \\
\hline Crystalline Silico-titanate & 49 & 108 & 820 & 353 & - & 53 & - & 278 \\
MAG*SEPSM & & & & & & & & \\
& 64 & 102 & 421 & 685 & - & 81 & - & 320 \\
& - & - & - & 369 & - & 141 & - & 100 \\
\hline Clinoptilolite MAG*SEPSM & - & 0 & - & 54 & - & 3 & - & 100 \\
& - & 11 & - & 76 & - & 30 & - & 73 \\
& - & 20 & - & 41 & - & 113 & - & 63 \\
\hline
\end{tabular}

"Conditions:

$\mathrm{A}=$ Waste solution simulant as given in Table II-1.

$\mathrm{B}=$ Waste solution simulant as given in Table II-1 diluted by one-fifth.

$\mathrm{C}=$ Waste solution simulant with the cesium concentration reduced by one-tenth.

$\mathrm{D}=$ Waste solution simulant with the hydroxide concentration reduced to $1 \mathrm{M}$.

bWeight of MAG*SEPSM in solution, $\mathrm{g} / \mathrm{mL}$.

\section{Effect of Gamma Irradiation}

The capacity of the MAG*SEPSM particles, prior to irradiation, was determined by using a solution of inert cesium containing a trace amount of cesium-137 (baseline solution) and is reported in milliequivalent per gram (meq/g). The minimum particle-to-solution ratio was used for this study, i.e., $0.005 \mathrm{~g}$ of $\mathrm{MAG}^{*} \mathrm{SEPSM}$ particles per milliliter of solution.

The baseline solution was prepared as follows: $0.1065 \mathrm{~g}$ of cesium bromide was dissolved in $500 \mathrm{~mL}$ of deionized water to give a solution containing $1 \mathrm{mM}$ inert cesium. To this solution, $5 \mathrm{kBq}\left(1.35 \times 10^{-7} \mathrm{Ci}\right)$ of Cs-137 was added as a tracer. At a specific activity for Cs-137 of $9.8 \mathrm{Ci} / \mathrm{g}, 5 \mathrm{kBq}$ equates to $1.38 \times 10^{-8} \mathrm{~g}$ or $2 \times 10^{-10} \mathrm{M} \mathrm{Cs}$. Hence, due to the insignificant concentration of Cs-137 tracer present, the effective molarity of cesium in the solution was $1 \mathrm{mM}$. The MAG*SEPSM particles were contacted with the solution for $15 \mathrm{~min}$.

The particles were re-tested after irradiation to a gamma dose equivalent to 100 cycles, and the results were used to assess the effect of irradiating the particles on the cesium capacity. (Note: this testing was performed with particles that had been irradiated with a high gamma dose as a "worst case" scenario.) 
The effect of radiation dose on the cesium capacity of MAG*SEPSM particles is shown in Table IV-3. The MAG*SEPSM particles coated with resorcinol formaldehyde were the least affected ( $15 \%$ reduction of their original capacity), while particles coated with clinoptilolite were the most affected (36\% reduction in capacity). However, the capacity of the clinoptilolite particles may also have been reduced by contact with the supernatant during the irradiation, resulting in the partial dissolution of the clinoptilolite.

Table IV-3. Results for the MAG*SEPSM Particle Capacity for Cesium before and after Irradiation

\begin{tabular}{lcc}
\hline & \multicolumn{2}{c}{ Capacity of MAG*SEPSM Particles, meq/g } \\
\cline { 2 - 3 } & Before Irradiation & Following Irradiation \\
\hline Activated TVT $^{*}$ MAG*SEPSM Particles $^{\mathrm{a}}$ & 0.13 & 0.10 \\
& 0.12 & 0.10 \\
& 0.11 & 0.10 \\
Resorcinol Formaldehyde & 0.20 & 0.17 \\
MAG*SEPSM Particles $^{\mathrm{a}}$ & 0.19 & 0.16 \\
& 0.19 & 0.16 \\
Silico-titanate MAG*SEPSM $^{*}$ & 0.15 & 0.11 \\
Particles $^{\mathrm{b}}$ & & \\
& 0.16 & 0.13 \\
Clinoptilolite $^{*}$ MAG*SEPSM $^{*}$ & 0.16 & - \\
& 0.17 & 0.11 \\
& 0.17 & 0.12 \\
& 0.17 & 0.11 \\
\hline
\end{tabular}

aparticles received a dose of $6.4 \mathrm{Mrad}$.

bParticles received a dose of $9.7 \mathrm{Mrad}$.

From the testing performed to this point, silico-titanate MAG*SEPSM particles were identified as being the most promising material to treat the Hanford supernatant. The irradiated particles, after exposure to a gamma dose equivalent to 100 cycles, were retested with the supernatant at its original concentration and at one-fifth the original concentration. The minimum particle-to-solution ratio was used for this study, i.e., $0.005 \mathrm{~g}$ of $\mathrm{MAG}^{*} \mathrm{SEP}{ }^{\mathrm{SM}}$ particles per milliliter of solution. In Table VI-4, the distribution ratios from this test are compared with the ratios obtained using nonirradiated silico-titanate MAG*SEPSM particles (previously reported in Table VI-2.)

The results presented in Table IV-4 demonstrate a significant reduction in the $\mathrm{K}_{d}$ from the gamma exposure under both conditions tested. Since previous testing at Sandia National Laboratories had shown no degradation in the performance of crystalline silico-titanate after exposure to $10^{9} \mathrm{rad}$ using a Co-60 source, the observed decrease is most likely due to degradation of the organic matrix of the MAG*SEPSM particles and not the adsorber materials themselves. 
Table IV-4. Distribution Ratios for Non-irradiated and Irradiated Silico-titanate MAG*SEPSM Particles

\begin{tabular}{lcc}
\hline & Non-Irradiated Particles & Irradiated Particles $^{\mathbf{a}}$ \\
\hline Supernatant at the original & 102 & 22 \\
concentration & 108 & 28 \\
& & \\
Supernatant at one-fifth of the & 353 & 151 \\
original concentration & 685 & 130 \\
& 369 & - \\
\hline
\end{tabular}

aThe particles received a dose of $9.7 \mathrm{Mrad}$.

A light microscopy study was undertaken to examine any effect on the MAG*SEPSM particles as a consequence of gamma irradiation. The photographs showed the presence of particles much smaller than $100 \mu \mathrm{m}$ and also the presence of fibrous material (refer to Part Two of the report). The observed effects may be attributed to the high $\mathrm{OH}^{-}$concentration in the simulant waste stream present during irradiation, which caused the matrix of the MLAG*SEPSM particles to "unravel."

As a consequence of the effects observed in this study, modification and optimization of the methodology used to prepare the particles will be undertaken to provide more durable MAG*SEPSM particles. 


\section{GENERAL DISCUSSION}

The MAG*SEPSM particles are of two types:

1. A basic core containing an outer surface with a functionalized chemical group.

2. A basic core that has smaller particles of a pre-existing ion exchanger attached to the surface.

The production of particles is often complicated by the materials to be used. Although a functional group or an ion exchange resin may be identified, it is not necessarily a straightforward process to attach these to a magnetic core.

The particles produced for this testing were prepared in a very short period and can only be considered prototypes. Optimization of particle preparation by Bradtec has shown improvements in both the mechanical properties and the ion exchange capacity. It is expected that further work would achieve similar results for any one of the particles used in this work.

In the case of the resorcinol resin, both types of particles ( 1 and 2 above) were produced. The resin produced at the Savannah River Site (SRS) was incorporated as small particles on a magnetic core. A second particle was produced in which the resorcinol grouping was prepared at Bradtec as a functionalized surface on the magnetic particle. Both these particles, as well as the unaltered resin from SRS, were tested for cesium capacity in a solution with no competing ions. The results indicated no differences between the three forms, and so the particles coated with the SRS resin were chosen to use in the test matrix.

It may, at first, appear surprising that a magnetic particle with a coating can have the same capacity as a resin bead. However, it is important to examine the circumstances of the test. The test is conducted to mimic the batch equilibrium which takes place within a very short time. In effect, it is unlikely that the resin and solution have come to equilibrium in such a short period. This results in only the counter ions in the outer layer of the resin bead and particles being exchanged. As this volume of resin is the same for both the particle and the bead, the capacities are equivalent under these test conditions.

For example, the capacity of a typical cation exchange resin is between 1.8 and 2.0 meq per gram of resin. Since the MAG*SEPSM particles contain approximately $30 \%$ adsorber material, this equates to a capacity of 0.6 meq per gram of MAG*SEPSM particles. If, as is the case, the adsorber material is embedded in a binding material on the MAG*SEPSM particle, thus losing approximately one-third of its surface area to the binding material, the capacity is reduced still further, to approximately 0.4 meq per gram. The contact time used in this program of work was $15 \mathrm{~min}$. This time is significantly shorter than is normally used to obtain a distribution ratio, where 12 to $72 \mathrm{~h}$ is more typical. Consequently, the term "distribution ratio" does not correctly describe the results obtained from this study. It may be more correct to consider them as a kinetic rate measurement. The values quoted in Table IV-3 show that the capacities of the MAG*SEPSM particles incorporating the specific adsorber materials studied are comparable with the values that might be expected if a conventional cation exchange resin in the same conditions as described in this report was used to prepare the MAG*SEPSM particles.

The $K_{d} s$ resulting from these tests should be interpreted carefully. The $K_{d}$ reported is for the resin type when associated with a magnetic core. As the calculation of the $K_{d}$ involves the 
concentration of cesium on the mass of beads, any inert material associated with the resin will tend to decrease the $\mathrm{K}_{\mathrm{d}}$ in comparison with pure resin. In addition, production of the resin/bead particle is such that the beads are produced in a wet form. To avoid swelling stresses with untested beads, the particles are used wet, and the weights of particles recorded refer to the wet weight. The calculation of the $K_{d}$ using the wet weight decreases the value. To summarize, the $K_{d}$ for each resin type quoted in Table IV-3 is much lower than reported in the literature or would be determined in a test where the pure resin is used and allowed to come fully to equilibrium with the test solution.

Where MAG*SEPSM technology offers a clear advantage over conventional ion exchange is during the handling of the process stream. The sediment in the bottom of the Hanford tank is composed of very small particles and will be disturbed easily on movement. Hence, it is likely that the supernatant will contain colloidal material and very fine particulate. If conventional ion exchange technology is used to treat this type of waste stream, the resin columns will become blocked very quickly and require frequent back-washing. However, MAG*SEPSM particles can be added to a solution containing particulate and can be removed easily from the solution by using commercially available magnetic recovery systems.

Other important process advantages include a reduction in shielding requirements and residence time and, hence, a reduction of the exposure of the ion exchange resin to the gamma flux. The former problem of shielding is much reduced in the case of MAG*SEPSM, as the process uses only a small quantity of resin at any one time, which is quickly regenerated and reused. The cesium waste can then be treated and stored appropriately. Conventional columns with large amounts of resin become extremely active as they operate and need heavy and costly shielding. Similarly, when used in a continuous short cycle, the ion exchanger is only exposed to the cesium gamma flux for short periods, unlike a column exchanger which is resident in the column for the whole loading cycle.

Regenerative solutions such as ammonia carbonate can be used to good effect with the MAG*SEPSM approach. This solution can be evaporated to concentrate the cesium and condensed for reuse. The concentrated cesium can then be loaded onto an inorganic zeolite, which has good properties for cesium retention and radiation stability and is easily made into a glass for disposal. 


\section{CONCLUSIONS}

- The adsorbents were contacted with the Hanford supernate simulant for 15 min, which is consistent with the needs of the MAG*SEPSM process. Longer contact times may produce higher $\mathrm{K}_{\mathrm{d}}$ values (equilibrated).

- The MAG*SEPSM particles coated with crystalline silico-titanate achieved the highest $\mathrm{K}_{d}$ values for cesium removal from the Hanford tank simulant under the conditions tested. The MAG*SEPSM particles coated with resorcinol formaldehyde had the second highest $\mathrm{K}_{d}$ values.

- For all materials tested, the highest $\mathrm{K}_{\mathrm{d}}$ values were observed when the simulant was diluted by one-fifth.

- The $\mathrm{K}_{\mathrm{d}}$ values of the powdered adsorbents were not reduced by their incorporation into MAG*SEPSM particles.

- The MAG*SEPSM process offers clear advantages over conventional ion-exchange technology in terms of the method of application and handling. The rapid adsorption kinetics enables the particles to be added and removed from a process flowstream, and the magnetic filtration removes the concern of a secondary waste stream if suspended solids are present.

- The results presented in this report demonstrate the viability of using MAG*SEPSM to remove cesium from Hanford tank supernatant. Future work should be performed to further refine the particle manufacture and the appropriate application conditions. This information should be used to develop an economic comparison between MAG*SEPSM and conventional ion exchange. 
APPENDIX A.

\section{STATEMENT OF WORK AND METHODOLOGY}

\section{Background}

The objective of this task is to optimize Bradtec's magnetic separation technology for cesium removal from Hanford tank supernatant. The supernatant is located in underground storage tanks at the Hanford site and contains radioactive $\mathrm{Cs}$ and $\mathrm{Sr}$, and in some cases, low concentrations of transuranics.

Various MAG*SEPSM particle coatings will be tested for their selective removal of cesium from Hanford tank supernatant simulant.

\section{Scope of Work}

Because actual supernatant is not available, a solution will be manufactured to simulate an average composition of the Hanford tanks. Four materials have been identified as possible candidates for cesium removal and have been prepared as MAG*SEPSM particles $(106 \mu \mathrm{m}$ $<$ particle size $<420 \mu \mathrm{m})$ :

\section{Activated TVT MAG*SEPSM}

2. Clinoptilolite $M A G * S E P S M$

3. Resorcinol formaldehyde $M A G * S E P S M$

4. Silico-titanate MAG*SEPSM

The particles will then be tested to determine their ability to adsorb cesium while varying the following:

1. Ionic strength of the solution

2. Cesium concentration

3. Solution $\mathrm{pH}$

4. $M A G^{*} \mathrm{SEP}^{\mathrm{TM}}$ particle-to-solution ratio

\section{Work to Be Performed}

The candidate adsorber materials will be tested, in powder form, for selective removal of cesium from Hanford tank supernatant simulant by measuring the distribution ratio $\left(\mathrm{K}_{\mathrm{d}}=\right.$ [Cs-137] adsorbent per gram/[Cs-137] treated solution per $\left.\mathrm{mL}\right)$ between aqueous solution and adsorber materials. MAG*SEPSM particles containing these adsorber materials will be prepared and tested while varying the parameters (1 through 4 ) above. In addition, the capacity of the MAG*SEPSM particles will be determined with a solution containing no competing ions ("baseline" conditions). The capacity of the particles will be compared before and after irradiation with a gamma ray flux. Once the optimum type of MAG*SEPSM particle and the best conditions have been identified, the $\mathrm{K}_{\mathrm{d}}$ for the particles under these conditions will be compared before and after irradiation with a gamma ray flux. 
The composition of the simulated tank supernatant is given in Table A-1 and the test matrix in Table A-2.

Table A-1. Recipe for Hanford Simulant Waste Stream

\begin{tabular}{ccc}
\hline Major Components & Component Charge & Concentration, mol/L \\
\hline $\mathrm{Na}$ & 1 & 8.83 \\
$\mathrm{~K}$ & 1 & $9.35 \times 10^{-2}$ \\
$\mathrm{Cs}$ & 1 & $4.88 \times 10^{-5}$ \\
$\mathrm{OH}$ & -1 & 6.54 \\
$\mathrm{NO}_{3}$ & -1 & 1.09 \\
$\mathrm{NO}_{2}$ & -1 & $8.09 \times 10^{-1}$ \\
$\mathrm{Al}(\mathrm{OH})_{4}$ & -1 & $2.06 \times 10^{-2}$ \\
$\mathrm{CO}_{3}$ & -2 & $2.22 \times 10^{-1}$ \\
$\mathrm{CrO}_{4}$ & -2 & $4.37 \times 10^{-3}$ \\
$\mathrm{PO}_{4}$ & -3 & $8.00 \times 10^{-4}$ \\
\hline
\end{tabular}

Table A-2. Matrix for MACS Testing

\begin{tabular}{|c|c|c|}
\hline Experimental Variable & Maximum & Minimum \\
\hline Two ionic strengths & Composition as Table A-1 & $\begin{array}{l}\text { Dilution by water to } 1 / 5 \text { of the } \\
\text { above composition }\end{array}$ \\
\hline Two $\mathrm{Cs}^{+}$concentrations & Composition as Table A-1 & $1 / 10$ of the above composition \\
\hline Two $\mathrm{OH}^{-}$concentrations & Composition as Table A-1 & $\begin{array}{l}\text { Approx. } 1 \mathrm{M} \text { with }\left[\mathrm{Na}^{+}\right] \text {kept } \\
\text { constant using } \mathrm{NaNO}_{3} \text { and } \mathrm{NaNO}_{2} \\
\text { in their molar ratio given in } \\
\text { Table A-1 }\end{array}$ \\
\hline Two adsorbent/solution ratios & $0.05 \mathrm{~g} / \mathrm{mL}^{\mathrm{a}}$ & $0.005 \mathrm{~g} / \mathrm{mL}^{\mathrm{a}}$ \\
\hline
\end{tabular}

aparticle-to-solution ratio.

Methodology

A. Preliminary Experiment to Identify Most Promising Adsorbent

Tests are to be performed on the following types of adsorbent:

- $\quad$ Powdered TVT

- Clinoptilolite $(75 \mu \mathrm{m}<$ particle size $<180 \mu \mathrm{m})$

- Clinoptilolite $(45 \mu \mathrm{m}<$ particle size $<75 \mu \mathrm{m})$

- Clinoptilolite $(45 \mu \mathrm{m}<$ particle size)

- Resorcinol formaldehyde

The preliminary tests involved the following steps: 
1. Prepare the Hanford simulant waste solution according to Table A-1 as follows. Prepare $500 \mathrm{~mL}$ of simulant waste solution containing the following but do not make up to the mark of the volumetric flask.

$0.222 \mathrm{M}$ sodium carbonate $\left(\mathrm{Na}_{2} \mathrm{CO}_{3}\right)$

$0.00437 \underline{\mathrm{M}}$ potassium chromate $\left(\mathrm{K}_{2} \mathrm{CrO}_{4}\right)$

$8.00 \times 10^{-4} \underline{\mathrm{M}}$ dipotassium phosphate $\left(\mathrm{K}_{2} \mathrm{HPO}_{4}\right)$

$0.0206 \underline{\mathrm{M}}$ aluminum hydroxide $\left(\mathrm{Al}(\mathrm{OH})_{3} \cdot \mathrm{H}_{2} \mathrm{O}\right)$

$0.0832 \underline{\mathrm{M}}$ potassium chloride $(\mathrm{KCl})$

$6.54 \underline{\mathrm{M}}$ sodium hydroxide $(\mathrm{NaOH})$

$1.09 \mathrm{M}$ sodium nitrate $\left(\mathrm{NaNO}_{3}\right)$

$0.809 \underline{\mathrm{M}}$ sodium nitrite $\left(\mathrm{NaNO}_{2}\right)$

$4.88 \times 10^{-5} \underline{\mathrm{M}}$ cesium chloride ( $\left.\mathrm{CsBr}\right)$

Total $\mathrm{Na}^{+}$burden $=0.444+6.54+1.09+0.809=8.883 \mathrm{M}$

Total $\mathrm{K}^{+}$burden $=0.00874+0.0016+0.0832=0.09354 \underline{\underline{\mathrm{M}}}$

Note: If all the salts do not dissolve, the sollution will require filtering prior to spiking with Cs-137.

2. Add $5 \mathrm{kBq}(135 \mathrm{nCi}) \mathrm{Cs}-137$ to the solution and then make up to $500 \mathrm{~mL}$. This will provide a solution containing $10 \mathrm{~Bq} / \mathrm{mL}(270 \mathrm{pCi} / \mathrm{mL}) \mathrm{Cs}-137$. Store this solution in a plastic bottle.

3. Accurately weigh duplicate aliquots of approximately $1 \mathrm{~g}$ of each of the four types of adsorbent into a screw-top plastic Erlenmeyer flask. Record the weights in QA book.

4. Measure $20 \mathrm{~mL}$ of the Cs-137 spiked simulant solution into each flask and stir for 15 min. Record the actual contact time for each solution in QA book.

5. Decant each solution and filter the solution through a $0.2 \mu \mathrm{m}$ glass microfiber filter.

6. Prepare duplicate $20 \mathrm{~mL}$ aliquots of the original Cs-137 spiked simulant solution.

7. Count the solutions plus one blank (deionized water) on a gamma spectrometer for $2000 \mathrm{~s}$.

8. Determine the $\mathrm{K}_{\mathrm{d}}$ for each type of MAG*SEPSM particle according to the following equation: $K_{d}=[C s-137]$ adsorbent per gram/[Cs-137] treated solution per $\mathrm{mL}$, where [Cs-137] adsorbent $=[$ Cs-137] original solution minus [Cs-137] final solution. 


\section{B. Test Matrix}

Do triplicate tests only if there are sufficient particles; otherwise do duplicates. If insufficient particles are available to perform tests using both weights of particles, use only the $0.005 \mathrm{~g} / \mathrm{mL}$ test.

\section{Ionic Strength as Given in Table A-1}

1. Prepare $500 \mathrm{~mL}$ of simulant waste solution containing the following but do not make up to the mark.

$0.222 \mathrm{M}$ sodium carbonate $\left(\mathrm{Na}_{2} \mathrm{CO}_{3}\right)$

$0.00437 \mathrm{M}$ potassium chromate $\left(\mathrm{K}_{2} \mathrm{CrO}_{4}\right)$

$8.00 \times 10^{-4} \mathrm{M}$ dipotassium phosphate $\left(\mathrm{K}_{2} \mathrm{HPO}_{4}\right)$

$0.020 \mathrm{M}$ aluminum hydroxide $\left[\mathrm{Al}(\mathrm{OH})_{3} \bullet \mathrm{H}_{2} \mathrm{O}\right]$

$0.0832 \mathrm{M}$ potassium chloride $(\mathrm{KCl})$

$6.54 \underline{\mathrm{M}}$ sodium hydroxide $(\mathrm{NaOH})$

$1.09 \mathrm{M}$ sodium nitrate $\left(\mathrm{NaNO}_{3}\right)$

$0.809 \mathrm{M}$ sodium nitrite $\left(\mathrm{NaNO}_{2}\right)$

$4.88 \times 10^{-5} \underline{\mathrm{M}}$ cesium chloride ( $\left.\mathrm{CsBr}\right)$

Total $\mathrm{Na}^{+}$burden $=0.444+6.54+1.09+0.809=8.883 \underline{\mathrm{M}}$

Total $\mathrm{K}^{+}$burden $=0.00874+0.0016+0.0832=0.09354 \mathrm{M}$

Note: If all the salts do not dissolve, the solution will require filtering prior to spiking with Cs-137.

2. Add $5 \mathrm{kBq}(135 \mathrm{nCi}) \mathrm{Cs}-137$ to the solution and then make up to $500 \mathrm{~mL}$. This will provide a solution containing $10 \mathrm{~Bq} / \mathrm{mL}(270 \mathrm{pCi} / \mathrm{mL}) \mathrm{Cs}-137$. Store this solution in a plastic bottle.

3. Where sufficient particles are available, weigh duplicate $1 \mathrm{~g}$ aliquots of each of the following types of MAG*SEPSM particles into screw-top plastic Erlenmeyer flasks (record the weight in QA book). If insufficient particles are available, weigh triplicate $0.1 \mathrm{~g}$ aliquots of the particles.

i. Activated TVT MAG*SEPSM particles $(106 \mu \mathrm{m}<$ particle size $<420 \mu \mathrm{m})$

ii. Clinoptilolite MAG*SEPSM particles $(106 \mu \mathrm{m}<$ particle size $<420 \mu \mathrm{m})$

iii. Resorcinol formaldehyde $\mathrm{MAG}^{*} \mathrm{SEPSM}^{\mathrm{S}}$ particles $(106 \mu \mathrm{m}<$ particle size $<420 \mu \mathrm{m})$

iv. Silico-titanate MAG*SEPSM particles $(106 \mu \mathrm{m}<$ particle size $<420 \mu \mathrm{m})$

4. Measure $20 \mathrm{~mL}$ of the simulant waste solution containing the Cs-137 into each of the flasks containing the MAG*SEPSM particles and stir for $15 \mathrm{~min}$. 
5. Separate the particles from the solution using a magnet and filter through a $0.2 \mu \mathrm{m}$ glass microfiber filter. Retain this solution for analysis in a plastic bottle.

6. Set up the gamma spectrometer and measure the peak area for a $20 \mathrm{~mL}$ aliquot of the simulant waste solution before contact with the MAG*SEPSM particles. Count for 2000 s. Do this measurement on two separate $20 \mathrm{~mL}$ aliquots of the simulant waste solution.

7. Measure each of the solutions from step 5 for $2000 \mathrm{~s}$ to complete the mass balance for Cs-137.

8. Compare the counts obtained for the simulant waste solution before and after exposure to the MAG*SEPSM particles and calculate the distribution ratio $\left(\mathrm{K}_{\mathrm{d}}\right)$ for each of the particle types for Cs-137.

Ionic Strength One-fifth the Composition Given in Table A-1

1. Prepare $500 \mathrm{~mL}$ simulant waste solution containing the following but do not make up to the mark on the volumetric flask.

$0.044 \mathrm{M}$ sodium carbonate $\left(\mathrm{Na}_{2} \mathrm{CO}_{3}\right)$

$8.74 \times 10^{-4} \underline{M}$ potassium chromate $\left(\mathrm{K}_{2} \mathrm{CrO}_{4}\right)$

$1.6 \times 10^{-4} \underline{M}$ dipotassium phosphate $\left(\mathrm{K}_{2} \mathrm{HPO}_{4}\right)$

$4.12 \times 10^{-3} \underline{\mathrm{M}}$ aluminum hydroxide $\left[\mathrm{Al}(\mathrm{OH})_{3} \cdot \mathrm{H}_{2} \mathrm{O}\right]$

$0.0166 \mathrm{M}$ potassium chloride $(\mathrm{KCl})$

$1.308 \mathrm{M}$ sodium hydroxide $(\mathrm{NaOH})$

$0.218 \mathrm{M}$ sodium nitrate $\left(\mathrm{NaNO}_{3}\right)$

$0.1618 \mathrm{M}$ sodium nitrite $\left(\mathrm{NaNO}_{2}\right)$

$9.76 \times 10^{-6} \underline{\mathrm{M}}$ cesium chloride $(\mathrm{CsBr})$

Total $\mathrm{Na}^{+}$burden $=1.7766 \underline{\mathrm{M}}$

Total $\mathrm{K}^{+}$burden $=0.0187 \underline{\mathrm{M}}$

Note: If all the salts do not dissolve, the solution will require filtering prior to spiking with Cs-137.

2. Add $5 \mathrm{kBq}$ (135 $\mathrm{nCi}$ ) $\mathrm{Cs}-137$ to the solution and then make up to $500 \mathrm{~mL}$. This will provide a solution containing $10 \mathrm{~Bq} / \mathrm{mL}(270 \mathrm{pCi} / \mathrm{mL}) \mathrm{Cs}-137$. Store this solution in a plastic bottle.

3. Weigh triplicate $0.1 \mathrm{~g}$ aliquots of each of the following types of MAG*SEPSM particles into screw-top plastic Erlenmeyer flasks (record the accurate weight in QA book).

i. Activated TVT MAG*SEPSM particles $(106 \mu \mathrm{m}<$ particle size $<420 \mu \mathrm{m})$

ii. Clinoptilolite MAG*SEPSM particles $(106 \mu \mathrm{m}<$ particle size $<420 \mu \mathrm{m})$ 
iii. Resorcinol formaldehyde $\mathrm{MAG}^{*} \mathrm{SEPSM}^{\mathrm{S}}$ particles $(106 \mu \mathrm{m}<$ particle size $<420 \mu \mathrm{m})$

iv. Silico-titanate MAG* $^{*}$ SEPSM $^{\text {particles }}(106 \mu \mathrm{m}<$ particle size $<420 \mu \mathrm{m})$

4. Measure $20 \mathrm{~mL}$ of the simulant waste solution containing the $\mathrm{Cs}-137$ into each of the flasks containing the MAG*SEPSM particles and stir for $15 \mathrm{~min}$.

5. Separate the particles from the solution using a magnet and filter through a $0.2 \mu \mathrm{m}$ glass microfiber filter. Retain this solution for analysis in a plastic bottle.

6. Set up the gamma spectrometer and measure the peak area for a $20 \mathrm{~mL}$ aliquot of the simulant waste solution before contact with the MAG*SEPSM particles. Count for $2000 \mathrm{~s}$. Do this measurement on two separate $20 \mathrm{~mL}$ aliquots of the simulant waste solution.

7. Measure each of the solutions from step 5 for $2000 \mathrm{~s}$ to complete the mass balance for Cs-137.

8. Compare the counts obtained for the simulant waste solution before and after exposure to the MAG*SEPSM particles and calculate the distribution ratio $\left(\mathrm{K}_{\mathrm{d}}\right)$ for each of the particle types for Cs-137.

\section{Cesium Concentration One-Tenth of Composition in Table A-1}

1. Prepare $500 \mathrm{~mL}$ simulant waste solution containing the following but do not make up to the mark on the volumetric flask.

$0.222 \mathrm{M}$ sodium carbonate $\left(\mathrm{Na}_{2} \mathrm{CO}_{3}\right)$

$0.00437 \underline{\mathrm{M}}$ potassium chromate $\left(\mathrm{K}_{2} \mathrm{CrO}_{4}\right)$

$8.00 \times 10^{-4} \underline{\mathrm{M}}$ dipotassium phosphate $\left(\mathrm{K}_{2} \mathrm{HPO}_{4}\right)$

$0.0206 \mathrm{M}$ aluminum hydroxide $\left[\mathrm{Al}(\mathrm{OH})_{3} \cdot \mathrm{H}_{2} \mathrm{O}\right]$

$0.0832 \underline{\mathrm{M}}$ potassium chloride $(\mathrm{KCl})$

$6.54 \underline{\mathrm{M}}$ sodium hydroxide $(\mathrm{NaOH})$

$1.09 \mathrm{M}$ sodium nitrate $\left(\mathrm{NaNO}_{3}\right)$

$0.809 \mathrm{M}$ sodium nitrite $\left(\mathrm{NaNO}_{2}\right)$

$4.88 \times 10^{-6} \underline{\mathrm{M}}$ cesium chloride ( $\left.\mathrm{CsBr}\right)$

Note: If all the salts do not dissolve, the solution will require filtering prior to spiking with Cs-137.

Repeat steps 2 through 8 as given above.

$\underline{\text { Hydroxide Concentration } 1 \mathrm{M} \text { with }\left[\mathrm{Na}^{+}\right] \text {Kept Constant }}$

1. Prepare $500 \mathrm{~mL}$ simulant waste solution containing the following but do not make up to the mark on the volumetric flask. 
$0.222 \underline{\mathrm{M}}$ sodium carbonate $\left(\mathrm{Na}_{2} \mathrm{CO}_{3}\right)$

$0.00437 \mathrm{M}$ potassium chromate $\left(\mathrm{K}_{2} \mathrm{CrO}_{4}\right)$

$8.00 \times 10^{-4} \underline{\mathrm{M}}$ dipotassium phosphate $\left(\mathrm{K}_{2} \mathrm{HPO}_{4}\right)$

$0.0206 \mathrm{M}$ aluminum hydroxide $\left[\mathrm{Al}(\mathrm{OH})_{3} \cdot \mathrm{H}_{2} \mathrm{O}\right]$

$0.0832 \mathrm{M}$ potassium chloride $(\mathrm{KCl})$

$1.0 \mathrm{M}$ sodium hydroxide $(\mathrm{NaOH})$

$4.25 \underline{\mathrm{M}}$ sodium nitrate $\left(\mathrm{NaNO}_{3}\right)$

$3.15 \underline{\mathrm{M}}$ sodium nitrite $\left(\mathrm{NaNO}_{2}\right)$

$4.88 \times 10^{-5} \underline{\mathrm{M}}$ cesium chloride ( $\left.\mathrm{CsBr}\right)$

Note: If all the salts do not dissolve, the solution will require filtering prior to spiking with Cs-137.

Repeat steps 2 through 8 as given above.

C. Capacity of MAG*SEPSM Particles before and after Irradiation

Prepare a "baseline" solution containing only inert cesium and a Cs-137 tracer as follows:

1. Weigh $0.1065 \mathrm{~g}$ of cesium bromide in $500 \mathrm{~mL}$ of deionized water to provide a solution containing $1 \mathrm{mM}$ cesium. Spike this solution with $5 \mathrm{kBq}\left(1.35 \times 10^{-7} \mathrm{Ci}\right)$ of Cs-137 to provide $10 \mathrm{~Bq}$ per $\mathrm{mL}$ of solution.

2. Accurately weigh triplicate aliquots containing approximately $0.1 \mathrm{~g}$ of each of the following MAG*SEPSM particles into screw-top plastic Erlenmeyer flasks (record the weight in QA book).

i. Activated TVT MAG*SEPSM particles $(106 \mu \mathrm{m}<$ particle size $<420 \mu \mathrm{m})$

ii. Clinoptilolite MAG*SEPSM particles $(106 \mu \mathrm{m}<$ particle size $<420 \mu \mathrm{m})$

iii. Resorcinol formaldehyde MAG*SEPSM particles $(106 \mu \mathrm{m}<$ particle size $<420 \mu \mathrm{m}$ )

iv. Silico-titanate MAG*SEPSM particles $(106 \mu \mathrm{m}<$ particle size $<420 \mu \mathrm{m})$

3. Measure $20 \mathrm{~mL}$ of the baseline solution containing the Cs-137 into each of the flasks containing the $\mathrm{MAG}^{*} \mathrm{SEP}{ }^{\mathrm{TM}}$ particles and stir for $15 \mathrm{~min}$.

4. Separate the particles from the solution using a magnet and filter through a $0.2 \mu \mathrm{m}$ glass microfiber filter. Retain this solution for analysis in a plastic bottle.

5. Set up the gamma spectrometer and measure the peak area for a $20 \mathrm{~mL}$ aliquot of the baseline solution containing the Cs-137 before contact with the MAG*SEPSM particles. Count for $2000 \mathrm{~s}$. Do this measurement on two separate $20 \mathrm{~mL}$ aliquots of the baseline solution. 
6. Measure each of the solutions from step 5 for $2000 \mathrm{~s}$ to complete the mass balance for Cs-137.

7. Compare the counts obtained for the baseline solution before and after exposure to the MAG*SEPSM particles and calculate the capacity for each of the particle types for Cs137.

8. Send the particles for irradiation with a gamma flux to Argonne National Laboratory.

9. Repeat the testing as described in steps 1 through 8 on the MAG*SEPSM particles which have received the highest dose of gamma irradiation.

10. Compare the capacities of the MAG*SEPSM particles before and after irradiation.

D. Distribution Ratio $\left(\mathrm{K}_{\mathrm{d}}\right)$ before and after Irradiation

1. Repeat the test matrix (as described earlier) using only the Hanford simulant waste at the original concentration and at one-fifth the original concentration, on duplicate aliquots of approximately $0.1 \mathrm{~g}$ of irradiated crystalline silico-titanate particles. Use the particles which have been irradiated with the highest gamma flux.

2. Calculate the $\mathrm{K}_{\mathrm{d}}$ for the particles and compare with the $\mathrm{K}_{\mathrm{d}}$ obtained for the particles prior to irradiation.

\section{Collation of the Raw Data}

Notes to accompany data spreadsheets (see Appendix B):

i. Samples p-tvt-1 to resorcinol-2 = tests using powdered adsorbents only (Table IV-1).

ii. Samples tvt-mag*sep-A1 to cl-mag*sep-D3 = test matrix using MAG*SEPSM particles (Table IV-2).

iii. Samples tvt-mag*sep-E1 to cl-irr-mag*-E3 = capacity testing on nonirradiated and irradiated MAG*SEPSM particles (Table IV-3).

iv. Samples st-mag*sep-A1 to st-irr-mag*-B2 = testing on nonirradiated and irradiated MAG*SEPSM particles coated with crystalline silico-titanate (Table IV-4).

v. Column entitled "sample counts" = counts obtained for samples corrected for background.

vi. Column entitled "standard counts" = counts obtained for solutions of the simulant waste stream and baseline prior to testing and corrected for background. The data are the average of duplicate measurements. 
vii. Column entitled "standard activity $\mathrm{Bq} / \mathrm{mL}^{\text {" }}=$ activity in solutions of the simulant waste stream and baseline prior to testing and is equal to the amount of standard Cs-137 used to spike the solutions.

viii. Description of the solutions (final two digits in sample ID):

$\mathrm{A}=$ simulant waste stream at the original composition.

$\mathrm{B}=$ simulant waste stream at one-fifth of the original composition.

$\mathrm{C}=$ simulant waste stream containing one-tenth of the cesium concentration; the remaining components are present in their original concentration.

$\mathrm{D}=$ simulant waste stream containing 1 molar hydroxide; the remaining components are present in their original concentration.

$\mathrm{E}=$ "baseline solution," containing only inert cesium and Cs- 137 .

ix. The final digit in the sample $\mathrm{ID}(1$ to 3$)$ is the number of tests performed under these conditions and, hence, the number of samples analyzed, i.e., $\mathrm{A} 1$ to $\mathrm{A} 3=$ test samples 1,2, and 3 for condition $\mathrm{A}$.

$\mathrm{x}$. MAG*SEPSM particle description:

tvt $=$ transylvanian volcanic tuff

rf $=$ resorcinol formaldehyde

st $=$ crystalline silico-titanate

$\mathrm{cl} /$ clino $=$ clinoptilolite

irr $=$ irradiated particles

Calculation of $\mathrm{K}_{\mathrm{d}}$

The experimental program depended on the measurement of ${ }^{137} \mathrm{Cs}$ in solution before and after contact with the ion exchange beads. The $K_{d}$ was determined from the following equation ${ }^{4}$ :

$$
\mathrm{K}_{\mathrm{d}}=\frac{\text { concentration of } \mathrm{Cs}^{137} \text { in the particles }}{\text { concentration of } \mathrm{Cs}^{137} \text { in solution }}\left(\frac{\mathrm{Bq} \mathrm{g}^{-1}}{\mathrm{~Bq} \mathrm{~mL}^{-1}}\right)
$$

where concentration of cesium on MAG*SEPSM particles = becquerels of cesium in original solution minus becquerels of cesium remaining in treated solution, all divided by the weight of MAG*SEPSM particles used in the test; and concentration of cesium remaining in solution = becquerels of cesium remaining in the treated solution divided by the milliliters of solution tested. This relationship is derived by mass balance arguments.

E. Statistical Evaluation of $\mathrm{K}_{\mathrm{d}}$

In calculating $\mathrm{K}_{\mathrm{d}}$, the following approach has been taken in assessing the uncertainty associated with the final result (from Ref. 5). The experimental $\mathrm{K}_{d}$ was calculated as:

$$
\frac{\text { initial sol. activity }- \text { final sol. • sample volume }}{\text { weight of resin }} / \text { final sol. activity }
$$


The activity of the initial spiked sample was counted in the measurement geometry to act as a secondary standard.

The sample activity was counted twice, and the uncertainty associated with the mean count is given as:

$$
\begin{aligned}
& \qquad \sigma_{\mathrm{x}}=\sqrt{\frac{\overline{\mathrm{x}}}{\mathrm{N}}} \\
& \sigma_{\mathrm{x}}=\text { standard deviation of } \overline{\mathrm{X}} \\
& \overline{\mathrm{x}}=\text { mean of independent counts } \\
& \mathrm{N}=\text { number of independent counts }
\end{aligned}
$$

The activity of the final solution was measured by a single count with uncertainty:

$$
\sigma_{\gamma}=\sqrt{Y}
$$

The activity was calculated as:

$$
\text { activity } Y=\frac{Y \text { counts }}{\bar{X} \text { counts }}(\text { activity of } \bar{X})
$$




\section{APPENDIX B. \\ MAG*SEPSM PARTICLE IRRADIATION REPORT ARGONNE NATIONAL LABORATORY}

The following irradiated materials were used for capacity and testing:

Vial ID B-1 Clinoptilolite MAG*SEPSM particles - dose $6.4 \mathrm{Mrad} \pm 15 \%$

B-3 Clinoptilolite MAG*SEPSM particles - dose $6.4 \mathrm{Mrad} \pm 15 \%$

B-5 Activated TVT MAG*SEPSM particles - dose $6.4 \mathrm{Mrad} \pm 15 \%$

B-6 Activated TVT MAG*SEPSM particles - dose $6.4 \mathrm{Mrad} \pm 15 \%$

B-13 Resorcinol formaldehyde MAG*SEPSM particles - dose 6.4 Mrad $\pm 15 \%$

B-14 Resorcinol formaldehyde MAG*SEPSM particles - dose $6.4 \mathrm{Mrad} \pm 15 \%$

B-19 Silico-titanate MAG*SEPSM particles - dose $9.7 \mathrm{Mrad} \pm 30 \%$

B-20 Silico-titanate MAG*SEPSM particles - dose $9.7 \mathrm{Mrad} \pm 30 \%$

The table that follows summarizes the data obtained from testing these samples. 


\begin{tabular}{|c|c|c|c|c|c|c|c|c|c|c|c|c|}
\hline \multicolumn{13}{|c|}{ MAGNETICALLY ASSISTED CHEMICAL SEPARATION DEVELOPMENT PROGRAM } \\
\hline $\begin{array}{c}\text { Sample } \\
\text { Identification }\end{array}$ & $\begin{array}{l}\text { Sample } \\
\text { Counts }\end{array}$ & $\begin{array}{c}\text { Sample } \\
\text { Assoc. 1s } \\
\text { error }+1-\end{array}$ & $\begin{array}{c}\text { Standard } \\
\text { Activity } \\
\text { Bq/mL }\end{array}$ & $\begin{array}{l}\text { Standard } \\
\text { Counts }\end{array}$ & $\begin{array}{l}\text { Two Ind. } \\
\text { Measures } \\
\text { Assoc 1s } \\
\text { error }+1-\end{array}$ & $\begin{array}{c}\text { Standard } \\
\text { to Sample } \\
\text { Ratio }\end{array}$ & $\begin{array}{l}\text { Ratio } \\
\text { Assoc. } \\
\text { error +/- }\end{array}$ & $\begin{array}{c}\text { Sample } \\
\text { Activity } \\
\text { Bq/mL }\end{array}$ & $\begin{array}{c}\text { Sample } \\
\text { Assoc. 1s } \\
\text { error }+1-\end{array}$ & $\begin{array}{l}\text { Particle } \\
\text { Weight } \\
\text { grams }\end{array}$ & $\begin{array}{c}\text { Calculated } \\
\mathrm{Kd}\end{array}$ & $\begin{array}{l}\text { Kd Assoc. } \\
\text { is errort } 1-\end{array}$ \\
\hline & & & & & & & & & & & & \\
\hline$p \cdot \operatorname{tvt} 1$ & 393 & 19.82 & 10 & 516 & 16.06 & 0.76 & 0.05 & 7.62 & 0.39 & 1.023 & 6 & 1.35 \\
\hline$p \cdot t v i-2$ & 385 & 19.62 & 10 & 516 & 16.06 & 0.75 & 0.05 & 7.46 & 0.37 & 1.000 & 7 & 1.39 \\
\hline clino-75.180. & 407 & 20.17 & 10 & 450 & 15.00 & 0.90 & 0.06 & 9.04 & 0.56 & 1.027 & 2 & 141 \\
\hline clino-75-180-2 & 428 & 20.69 & 10 & 450 & 15.00 & 0.95 & 0.06 & 9.51 & 0.61 & 1.053 & 1 & 1.39 \\
\hline clino-45-7 4-1 & 362 & 19.03 & 10 & 450 & 15.00 & 0.80 & 0.06 & 8.04 & 0.46 & 1.040 & 5 & 1.40 \\
\hline clino-45-74-2 & 378 & 19.44 & 10 & 450 & 15.00 & 0.84 & 0.06 & 8.40 & 0.49 & 1.012 & 4 & 143 \\
\hline clino $<45-1$ & 388 & 19.70 & 10 & 450 & 15.00 & 0.86 & 0.06 & 8.62 & 0.52 & 1.032 & 3 & 1.40 \\
\hline clino $<4 \overline{5}-2$ & 426 & 20.64 & 10 & 450 & 15.00 & 0.95 & 0.06 & 9.47 & 0.61 & 1.036 & 1 & 1.41 \\
\hline resorcinai $-\overline{1}$ & 212 & 14.56 & 10 & 450 & 15.00 & 0.47 & 0.04 & 4.71 & 0.18 & 1.005 & 22 & 2.15 \\
\hline resorcinal-2- & 251 & 15.84 & 10 & 450 & 15.00 & 0.56 & 0.04 & 5.58 & 0.25 & 1.026 & 15 & 1.77 \\
\hline tvi-mag'sep-A1 & 425 & 20.62 & 10 & 517 & 16.08 & 0.82 & 0.05 & 8.22 & 0.44 & 1.012 & 4 & 1.34 \\
\hline ivt-mag sep-A2 & 465 & 21.56 & 10 & 517 & 16.08 & 0.90 & 0.06 & 8.99 & 0.52 & 1.019 & 2 & 1.33 \\
\hline tvt-mag*sep-B1 & 343 & 18.52 & 10 & 411 & 14.34 & 0.83 & 0.06 & 8.35 & 0.51 & 0.101 & 39 & 15.02 \\
\hline tvi-mag"sep-82 & 370 & 19.24 & 10 & 411 & 14.34 & 0.90 & 0.06 & 9.00 & 0.58 & 0.102 & 22 & 14.94 \\
\hline tvi-mag'sep-B3 & 368 & 19.18 & 10 & 411 & 14.34 & 0.90 & 0.06 & 8.95 & 0.58 & 0.100 & 23 & 15.09 \\
\hline Ivt-mag sep-C1 & 400 & 20.00 & 10 & 394 & 14.04 & 1.02 & 0.07 & 10.15 & 0.73 & 0.101 & -3 & -15.95 \\
\hline $\mid$ ivt-mag sep-c2 & 397 & 19.92 & 10 & 394 & 14.04 & 2.01 & 0.07 & 10.08 & 0.72 & 0.101 & -1 & -15.84 \\
\hline ivi-mag'sep-C3 & 356 & 18.87 & 10 & 394 & 14.04 & 0.90 & 0.07 & 9.04 & 0.60 & 0.101 & 21 & 15.35 \\
\hline tvi-mag*sep-D & 416 & 20.40 & 10 & 424 & 14.56 & 0.98 & 0.07 & 9.81 & 0.66 & 0.100 & 4 & 15.25 \\
\hline tvi-mag'sep-02 & 393 & 19.82 & 10 & 424 & 14.56 & 0.93 & 0.06 & 9.27 & 0.60 & 0.100 & 16 & 14.97 \\
\hline ivi-mag sep-D3 & 411 & 20.27 & 10 & 424 & 14.56 & 0.97 & 0.07 & 9.69 & 0.65 & 0.100 & 6 & 15.15 \\
\hline il.magsep-A1 & 388 & 19.70 & 10 & 465 & 15.25 & 0.83 & 0.06 & 8.34 & 0.48 & 0.101 & 39 & 14.09 \\
\hline ri.mag'sep-A 2 & 360 & 18.97 & 10 & 465 & 15.25 & 0.77 & 0.05 & 7.74 & 0.42 & 0.100 & 58 & 14.40 \\
\hline if-mag sep-A3 & 381 & 19.52 & 10 & 465 & 15.25 & 0.82 & 0.06 & 8.19 & 0.46 & 0.102 & 43 & 14.00 \\
\hline If-magosep-B 1 & 244 & 15.62 & 10 & 411 & 14.34 & 0.59 & 0.05 & 5.94 & 0.28 & 0.101 & 136 & 17.73 \\
\hline 11-mag'sep-B? & 2.26 & 15.03 & 10 & 411 & 14.34 & 0.55 & 0.05 & 5.50 & 0.25 & 0.102 & 161 & 18.84 \\
\hline 11.mag sep-B33 & 145 & $1 \overline{2} . \overline{4}$ & 10 & 411 & 14.34 & 0.35 & 0.03 & 3.53 & 0.12 & 0.101 & 364 & $30 . \overline{3}$ \\
\hline rl-mag $\overline{\operatorname{sep}-\bar{C} i}$ & 208 & 14.42 & 10 & 394 & 14.04 & 0.53 & 0.05 & 5.28 & 0.24 & 0.106 & 168 & 1903 \\
\hline
\end{tabular}

$\cdot$ Value represents an average of daily measurements 


\begin{tabular}{|c|c|c|c|c|c|c|c|c|c|c|c|c|}
\hline \multicolumn{13}{|c|}{ MAGNETICALLY ASSISTED CHEMICAL SEPARATION DEVELOPMENT PROGRAM } \\
\hline $\begin{array}{c}\text { Sample } \\
\text { Identification }\end{array}$ & $\begin{array}{l}\text { Sample } \\
\text { Counts }\end{array}$ & $\begin{array}{c}\text { Sample } \\
\text { Assoc. 1s } \\
\text { error }+1-\end{array}$ & $\begin{array}{c}\text { Slandard } \\
\text { Activity } \\
\text { Bq/mL }\end{array}$ & $\begin{array}{l}\text { Standard } \\
\text { Counts }\end{array}$ & $\begin{array}{l}\text { Two Ind. } \\
\text { Measures } \\
\text { Assoc is } \\
\text { error }+1-\end{array}$ & $\begin{array}{c}\text { Standard } \\
\text { to Sample } \\
\text { Ratio }\end{array}$ & $\begin{array}{c}\text { Ratio } \\
\text { Assoc. } \\
\text { error +/- }\end{array}$ & $\begin{array}{c}\text { Sample } \\
\text { Activity } \\
\text { Bq/mL }\end{array}$ & $\begin{array}{c}\text { Sample } \\
\text { Assoc. 1s } \\
\text { error }+1-\end{array}$ & $\begin{array}{c}\text { Particle } \\
\text { Weight } \\
\text { grams }\end{array}$ & $\begin{array}{c}\text { Calculated } \\
\mathrm{Kd}\end{array}$ & $\begin{array}{l}\mathrm{Kd} \text { Assoc. } \\
\text { is errort } 1 \text { - }\end{array}$ \\
\hline 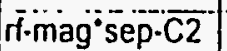 & 296 & 17.20 & 10 & 394 & 14.04 & 0.75 & 0.06 & 7.51 & 0.43 & 0.101 & 65 & 15.58 \\
\hline ff-mag*sep-C3 & 398 & 19.95 & 10 & 394 & 14.04 & 1.01 & 0.07 & 10.10 & 0.73 & $0: 100$ & -2 & -15.97 \\
\hline fi-mag'sep-D1 & 414 & 20.35 & 10 & 424 & 14.56 & 0.98 & 0.07 & 9.76 & 0.66 & 0.104 & 5 & 14.66 \\
\hline f $-\mathrm{mag}^{\circ} \operatorname{sep}-\mathrm{D} 2$ & 398 & 19.95 & 10 & 424 & 14.56 & 0.94 & 0.07 & 9.39 & 0.61 & 0.102 & 13 & 14.74 \\
\hline $\mathrm{r}$-mag ${ }^{\circ} \operatorname{sep}-03$ & 398 & 19.95 & 10 & 424 & 14.56 & 0.94 & 0.07 & 9.39 & 0.61 & 0.103 & 13 & 14.61 \\
\hline si-magosep-A1 & 117 & 10.82 & 10 & 419 & 14.47 & 0.28 & 0.03 & 2.79 & 0.08 & 1.055 & 49 & $=3.72$ \\
\hline si-mag sep-A2 & 99 & 9.95 & 10 & 419 & 14.47 & 0.24 & 0.03 & 2.36 & 0.06 & 1.013 & 64 & .4 .65 \\
\hline si-mag'sep-A3 & 256 & 16.00 & 10 & 419 & 14.47 & 0.61 & 0.05 & 6.11 & 0.30 & 0.118 & 108 & 14.65 \\
\hline si-mag'sep-A4 & 262 & 16.19 & 10 & 419 & 14.47 & 0.63 & 0.05 & 6.25 & 0.31 & 0.118 & 102 & 14.46 \\
\hline st-mag'sep-B1 & 148 & 12.17 & 10 & 411 & 14.34 & 0.36 & 0.03 & 3.60 & 0.12 & 0.101 & 353 & 29.64 \\
\hline st-mag ${ }^{7} \operatorname{sep}-\overline{B 2}$ & 91 & 9.54 & 10 & 411 & 14.34 & 0.22 & 0.03 & 2.21 & 0.06 & 0.103 & 685 & 49.63 \\
\hline st-mag'sep-B3 & 142 & 11.92 & 10 & 411 & 14.34 & 0.35 & 0.03 & 3.45 & 0.12 & 0.103 & 369 & 30.41 \\
\hline st-mag'sep-B4 & 10 & 3.16 & 10 & 423 & 14.54 & 0.02 & 0.01 & 0.24 & 0.00 & 1.007 & 820 & 50.24 \\
\hline st-mag*sep-B5 & 19 & 4.36 & 10 & 423 & 14.54 & 0.04 & 0.01 & 0.45 & 0.47 & 1.010 & 421 & 26.31 \\
\hline st-mag ${ }^{\circ}$ sep-C1 & 310 & 17.61 & 10 & 394 & 14.04 & 0.79 & 0.06 & 7.87 & 0.39 & 0.103 & 53 & .15 .09 \\
\hline st-mag ${ }^{*}$ sep-c2 & 279 & 16.70 & 10 & 394 & 14.04 & 0.71 & 0.06 & 7.08 & 0.28 & 0.102 & 81 & 15.95 \\
\hline st-mag ${ }^{\circ} \operatorname{sep}-\mathrm{C} 3$ & 227 & 15.07 & 10 & 394 & 14.04 & 0.58 & 0.05 & 5.76 & 0.28 & 0.105 & 141 & 17.89 \\
\hline si-mag sep-D1 & 174 & 13.19 & 10 & 424 & 14.56 & 0.41 & 0.04 & 4.10 & 0.15 & 0.103 & 278 & 24.77 \\
\hline st-mag'sep-D2 & 162 & 12.73 & 10 & 424 & 14.56 & 0.38 & 0.04 & 3.82 & 0.13 & 0.101 & 320 & 27.37 \\
\hline st-mag sep-D3 & 278 & 16.67 & 10 & 424 & 14.56 & 0.66 & 0.05 & 6.56 & 0.33 & 0.105 & 100 & 15.57 \\
\hline cl-mag'sep-A1 & 440 & 20.98 & 10 & 465 & 15.25 & 0.95 & 0.06 & 9.46 & 0.60 & 0.100 & 11 & 14.38 \\
\hline ci-mag sep.A2 & 460 & 21.66 & 10 & 465 & 15.25 & 1.01 & 0.07 & 10.09 & 0.67 & 0.101 & -2 & $-14 \overline{16}$ \\
\hline ci-mag ${ }^{\circ} \operatorname{sep}-A 3$ & 422 & 20.54 & 10 & 465 & 15.25 & 0.91 & 0.06 & 9.08 & 0.55 & 0.101 & 20 & $\overline{14.19}$ \\
\hline cl-magosep-B1 & 324 & 18.00 & 10 & 411. & 14.34 & 0.79 & 0.06 & 7.88 & 0.46 & 0.100 & 54 & 15.22 \\
\hline$c i-m a{ }^{\circ} \operatorname{sep}-B 2$ & 297 & 17.23 & 10 & 411 & 14.34 & 0.72 & 0.06 & 7.23 & 0.40 & .0 .101 & 76 & 15.56 \\
\hline $\mathrm{cl} \cdot \mathrm{mag}^{\circ} \operatorname{sep} \cdot \mathrm{B3}$ & 341 & 18.47 & 10 & 411 & 14.34 & 0.83 & 0.06 & 8.30 & 0.50 & 0.100 & 41 & 15.13 \\
\hline cl-mag sep-C1 & 389 & 19.72 & 10 & 394 & 14.04 & 0.99 & 0.07 & 9.87 & 0.70 & 0.100 & 3 & 15.81 \\
\hline ci-mag'sep.c2 & 341 & 18.47 & 10 & 394 & 14.04 & 0.87 & 0.06 & 8.65 & 0.55 & 0.105 & 30 & 14.74 \\
\hline
\end{tabular}

- Value represents an average of daily measurements 


\begin{tabular}{|c|c|c|c|c|c|c|c|c|c|c|c|c|}
\hline \multicolumn{13}{|c|}{ MAGNETICALLY ASSISTED CHEMICAL SEPARATION DEVELOPMENT PROGRAM } \\
\hline $\begin{array}{c}\text { Sample } \\
\text { Identification }\end{array}$ & $\begin{array}{l}\text { Sample } \\
\text { Counts }\end{array}$ & $\begin{array}{c}\text { Sample } \\
\text { Assoc. 1s } \\
\text { error +/- }\end{array}$ & $\begin{array}{c}\text { Slandard } \\
\text { Activity } \\
\text { Bq/mL }\end{array}$ & $\begin{array}{l}\text { Standard } \\
\text { Counts* }\end{array}$ & $\begin{array}{l}\text { Two Ind. } \\
\text { Measures } \\
\text { Assoc 1s } \\
\text { error +l- }\end{array}$ & $\begin{array}{c}\text { Standaro } \\
\text { to Sample } \\
\text { Ratio }\end{array}$ & $\begin{array}{l}\text { Ratio } \\
\text { Assoc. } \\
\text { error +/- }\end{array}$ & $\begin{array}{l}\text { Sample } \\
\text { Activity } \\
\text { Bq/mL }\end{array}$ & $\begin{array}{l}\text { Sample } \\
\text { Assoc. 1s } \\
\text { error }+1-\end{array}$ & $\begin{array}{c}\text { Particle } \\
\text { Weight } \\
\text { grams }\end{array}$ & $\begin{array}{c}\text { Calculated } \\
\mathrm{Kd}\end{array}$ & $\begin{array}{l}\text { Kd Assoc. } \\
\text { 1s errort-1- }\end{array}$ \\
\hline ci-mag sep-c3 & 251 & 15.84 & 10 & 394 & 14.04 & 0.64 & 0.05 & 6.37 & 0.33 & 0.100 & 113 & 17.20 \\
\hline cl-mag*sep-D1 & 282 & 16.79 & 10 & 424 & 14.56 & 0.67 & 0.05 & 6.65 & 0.34 & 0.101 & 100 & 16.03 \\
\hline cl-mag'sep-D2 & 306 & 17.49 & 10 & 424 & 14.56 & 0.72 & 0.05 & 7.22 & 0.39 & 0.105 & 73 & 14.70 \\
\hline cl-mag ${ }^{*}$ sep-D3 & 318 & 17.83 & 10 & 424 & 14.56 & 0.75 & 0.06 & 7.50 & 0.42 & 0.105 & 63 & 14.50 \\
\hline tvt-mag'sep-E1 & 168 & 12.96 & 10 & 460 & 15.17 & 0.37 & 0.03 & 3.65 & 0.12 & 0.101 & 346 & 28.21 \\
\hline IVt-mag*sep-E2 & 178 & 13.34 & 10 & 460 & 15.17 & 0.39 & 0.03 & 3.87 & 0.13 & 0.101 & 314 & 26.36 \\
\hline ivi-mag sep-E3 & 202 & 14.21 & 10 & 460 & 15.17 & 0.44 & 0.04 & 4.39 & 0.16 & 0.101 & 252 & 22.81 \\
\hline vt-irr-mag*-E1 & 205 & 14.32 & 10 & 392 & 14.00 & 0.52 & 0.05 & 5.23 & 0.24 & 0.132 & 138 & 15.47 \\
\hline Ivt-irr-mag -E2 & 196 & 14.00 & 10 & 392 & 14.00 & 0.50 & 0.04 & 5.00 & 0.22 & 0.137 & 146 & 15.64 \\
\hline tvt-irr-mag-E3 & 226 & 15.03 & 10 & 392 & 14.00 & 0.58 & 0.05 & 5.77 & 0.28 & 0.110 & 13 & 17.01 \\
\hline f-mag'sep-El & 24 & 4.90 & 10 & 460 & 15.17 & 0.05 & 0.01 & 0.52 & 0.01 & 0.106 & 3441 & 213.54 \\
\hline f-mag'sep-E2 & 30 & 5.48 & 10 & 460 & 15.17 & 0.07 & 0.01 & 0.65 & 0.01 & 0.101 & 2847 & 178.24 \\
\hline ff-mag'sep-E3 & 32 & 5.66 & 10 & 460 & 15.17 & 0.07 & 0.01 & 0.70 & 0.01 & 0.102 & 2635 & 165.48 \\
\hline i-irr-mag ${ }^{*}-\mathrm{E} 1$ & 64 & 8.00 & 10 & 392 & 14.00 & 0.16 & 0.02 & 1.63 & 0.04 & 0.101 & 1019 & 70.59 \\
\hline rifr-mag ${ }^{\circ} \cdot E 2$ & 72 & 8.49 & 10 & 392 & 14.00 & 0.18 & 0.02 & 1.84 & 0.04 & 0.100 & 886 & 62.80 \\
\hline f-irr-mag ${ }^{\circ}-\mathrm{E} 3$ & 72 & 8.49 & 10 & 392 & 14.00 & 0.18 & 0.02 & 1.84 & 0.04 & 0.100 & 887 & 62.86 \\
\hline st-magosep-Ei & 125 & 11.18 & 10 & 460 & 15.17 & 0.27 & 0.03 & 2.72 & 0.07 & 0.102 & 526 & 38.76 \\
\hline st-mag sep-E2 & 85 & 9.22 & 10 & 460 & 15.17 & 0.18 & 0.02 & 1.85 & 0.04 & 0.105 & 838 & 57.19 \\
\hline st-mag sep-E3 & 99 & 9.95 & 10 & 460 & 15.17 & 0.22 & 0.02 & 2.15 & 0.05 & 0.103 & 711 & 49.76 \\
\hline sl-irr-mag E1 & 174 & 13.19 & 10 & 392 & 14.00 & 0.44 & 0.04 & 4.44 & 0.18 & 0.112 & 224 & 21.64 \\
\hline si-irr-mag ${ }^{\circ} E 2$ & $13 \overline{6}$ & 11.66 & 10 & 392 & 14.00 & 0.35 & 0.03 & 3.47 & 0.12 & 0.116 & 326 & 27.34 \\
\hline ci-mag'sep-E1 & 72 & 8.49 & 10 & 460 & 15.17 & 0.16 & 0.02 & 1.57 & 0.03 & 0.101 & 1065 & 71.12 \\
\hline cl-mag"sep-E2 & 68 & 8.25 & 10 & 460 & 15.17 & 0.15 & 0.02 & 1.48 & 0.03 & 0.101 & 1143 & 75.81 \\
\hline cl-mag sep-E3 & 60 & 7.75 & 10 & 460 & 15.17 & 0.13 & 0.02 & 1.30 & 0.02 & 0.102 & 1311 & 85.87 \\
\hline$c^{i}$ irr-mag $-\bar{E}{ }^{-}$ & 185 & 13.60 & 10 & 392 & 14.00 & 0.47 & 0.04 & 4.72 & 0.20 & 0.124 & 181 & 18.33 \\
\hline cl-irr-mag $-\overline{E 2}$ & 159 & 12.61 & 10 & 392 & 14.00 & 0.41 & 0.04 & 4.06 & 0.15 & 0.128 & 229 & 20.82 \\
\hline $\mathrm{cl}$-irr-mag $=\overline{\mathrm{E}} \overline{3}^{-}$ & 185 & 13.60 & 10 & 392 & 14.00 & 0.47 & 0.04 & 4.72 & 0.20 & 0.101 & 221 & 22.43 \\
\hline sl-mag sep-Ai & 256 & 16.00 & 10 & 419 & 14.47 & 0.61 & 0.05 & 6.11 & 0.30 & 0.118 & 108 & 14.65 \\
\hline
\end{tabular}

$\because$ Value represents an average of daily measurements 


\begin{tabular}{|c|c|c|c|c|c|c|c|c|c|c|c|c|}
\hline \multicolumn{13}{|c|}{ MAGNETICALLY ASSISTED CHEMICAL SEPARATION DEVELOPMENT PROGRAM } \\
\hline $\begin{array}{c}\text { Sample } \\
\text { Identificalion }\end{array}$ & $\begin{array}{l}\text { Sample } \\
\text { Counts }\end{array}$ & $\begin{array}{c}\text { Sample } \\
\text { Assoc. Is } \\
\text { error +/- }\end{array}$ & $\begin{array}{c}\text { Standard } \\
\text { Activity } \\
\text { Bq/mL }\end{array}$ & $\begin{array}{l}\text { Standard } \\
\text { Counts* }\end{array}$ & $\begin{array}{l}\text { Two Ind. } \\
\text { Measures } \\
\text { Assoc 1s } \\
\text { error }+1-\end{array}$ & $\begin{array}{c}\text { Standard } \\
\text { to Sample } \\
\text { Ratio }\end{array}$ & $\begin{array}{c}\text { Ratio } \\
\text { Assoc. } \\
\text { error +/- }\end{array}$ & $\begin{array}{c}\text { Sample } \\
\text { Aclivity } \\
\text { Bq/mL }\end{array}$ & $\begin{array}{c}\text { Sample } \\
\text { Assoc. 1s } \\
\text { error +1- }\end{array}$ & $\begin{array}{c}\text { Particle } \\
\text { Weight } \\
\text { grams }\end{array}$ & $\begin{array}{c}\text { Calculated } \\
\mathrm{Kd}\end{array}$ & $\begin{array}{l}\text { Kd Assoc. } \\
\text { 1s errortl- }\end{array}$ \\
\hline & & & & & & & & & & & & \\
\hline si-mag'sep-A $\overline{2}$ & 262 & 16.19 & 10 & 419 & 14.47 & 0.63 & 0.05 & 6.25 & 0.31 & 0.118 & 102 & 14.46 \\
\hline st-irr-mag $-A 1$ & 361 & 19.00 & 10 & 419 & 14.47 & 0.86 & 0.06 & 8.62 & 0.53 & 0.117 & 28 & 12.81 \\
\hline st-irr-mag"-A2 & 372 & 19.29 & 10 & 419 & 14.47 & 0.89 & 0.06 & 8.88 & 0.56 & 0.115 & 22 & 13.08 \\
\hline st-mag'sep-B1 & 148 & 12.17 & 10 & 411 & 14.34 & 0.36 & 0.03 & 3.60 & $0: 12$ & 0.101 & 353 & 29.64 \\
\hline st-mag sep-B2 & 91 & 9.54 & 10 & 411 & 14.34 & 0.22 & 0.03 & 2.21 & 0.06 & 0.103 & 685 & 49.63 \\
\hline $\mathrm{st}-\mathrm{mag}{ }^{\circ} \mathrm{sep}-\mathrm{B} 3$ & 142 & 11.92 & 10 & 411 & 14.34 & 0.35 & 0.03 & 3.45 & 0.12 & 0.103 & 369 & 30.41 \\
\hline st-irr-mag $-\overline{81}$ & 225 & 15.00 & 10 & 423 & 14.54 & 0.53 & 0.04 & 5.32 & 0.23 & 0.117 & 151 & -16.74 \\
\hline si-irr-mag'- 82 & 240 & 15.49 & 10 & 423 & 14.54 & 0.57 & 0.05 & 5.67 & 0.26 & 0.118 & 130 & 1564 \\
\hline
\end{tabular}

- Value represents an average of daily measurements 
APPENDIX C.

GAMMA-SPECTROMETER CALIBRATION

Apparatus: Canberra 7000 Series

$\mathrm{Ge}(\mathrm{Li})$ Spectrometer Systems

Detector Model: 7222 S/N 113

Cryostat Model: 7500 S/N 113

Preamplifier Model: $1408 \mathrm{C}$ special S/N 1230

A certified Cs-137 standard is counted for a known period of time (normally $1 \mathrm{~h}$ ). The data from the activity of the source and the counting time are then fed to an analysis software program (spectra-AT CISE 526). The calibration graph is then calculated by computer.

For each new experiment, two samples of the solution prior to contact with MAG*SEPSM particles are counted. The volume of these samples must be the same as the volume of the treated solution samples. Also, the geometry of the samples must be exactly the same.

The gamma-spectrometer system was checked (in February 1992) using a mixture of certified radionuclide standards. The efficiency and accuracy of the apparatus were examined. The apparatus is more efficient at low energy levels. The efficiency for Cs-137 is very low, but the accuracy is very good for all the radionuclides, with Cs- 137 being one of the most accurate radionuclides. 


\section{REFERENCES}

1. D. Bradbury, G. R. Elder, P. M. Tucker, and M. J. Dunn, "Treatment of Heavy Metals and Radionuclides in Groundwater and Wastewater by Magnetic Separation," ER '92 Symposium, p. 439 (September 1992).

2. D. White, Personal Communication, Department of Chemical Engineering, Imperial College, London.

3. S. F. Marsh, Z. V. Svitra, and S. M. Bowen, Distribution of 14 Elernents on 60 Selected Absorbers from Two Simulant Solutions (Acid - Dissolved Sludge and Alkaline Supernate for Hanford HLW Tank 102 - SY), Los Alamos National Laboratory Report LA-12654 (October 1993).

4. F. Helfferich, Ion Exchange, McGraw-Hill, New York (1962).

5. G. F. Knoll, Radiation Detection and Measurement, 2nd Ed., John Wiley \& Son, New York (1989).

6. J. C. Miller and J. N. Miller, Statistics for Analytical Chemistry, 3rd Ed., Prentice Hall, London (1993). 
PART TWO.

\author{
STUDIES OF GAMMA IRRADIATION AND OPTICAL MICROSCOPY ON \\ CESIUM REMOVAL PARTICLES \\ (L. Nuñez, ${ }^{*}$ B. A. Buchholz, ${ }^{*}$ M. Ziemer,* G. Dyrkacz, ${ }^{* *}$ \\ M. Kaminski,* and G. F. Vandegrift*)
}

\title{
I. INTRODUCTION
}

Coated magnetic particles prepared by Bradtec were contacted with simulated Hanford supernatant and irradiated with a gamma dose equivalent to 10 and 100 cycles of use. These irradiated particles were then returned to Bradtec and re-tested for their absorption characteristics. We also performed optical microscopy of the Bradtec particles before and after irradiation equivalent to 10 and 100 cycles of use. The results were provided to Bradtec (see Part One).

\section{GAMMA IRRADIATION}

\section{A. Irradiation of Bradtec Particles}

Coated magnetic particles prepared by Bradtec (absorber material composed of clinoptilolite, resorcinol formaldehyde, and crystalline silico-titanate) were irradiated with a gamma dose equivalent to 10 and 100 cycles of use. A safety review was submitted and accepted by the CMT Safety Review Committee; the samples were irradiated in the Co-60 hot cell in the ANL Chemistry Division (diagram and information on source in Appendix A). Approximately $0.5 \mathrm{~g}$ of each irradiated sample was sealed in quartz tubes with $1.5 \mathrm{~mL}$ of the simulated supernatant solution (Part One, Table I-1). Dose estimates were computed on the basis of the size of the particles, estimates of the likely time needed to complete an irradiation cycle, and the following assumptions:

1. Average path length of radiation in magnetic particles is $80 \mu \mathrm{m}$.

2. Average values for the atomic number, atomic mass, and density of the magnetic particles are 14,28 , and $2.7 \mathrm{~g} / \mathrm{cm}^{3}$, respectively.

3. Contact time per extraction is $2 \mathrm{~h}$.

These factors yield estimated doses of $6.79 \times 10^{5} \mathrm{rad}$ and $6.79 \times 10^{6} \mathrm{rad}$ for 10 and 100 cycles of use, respectively (see Sec. II.B).

Table II-1 contains information on the actual dose absorbed by the magnetic particles in the experiments.

\footnotetext{
*Argonne National Laboratory, Chemical Technology Division.

**Argonne National Laboratory, Chemistry Division.
} 
Table II-1. Dose to Bradtec-Provided Samples of Coated Magnetic Particles

\begin{tabular}{|c|c|c|c|c|}
\hline Vial & $\begin{array}{l}\text { Bradtec } \\
\text { ID }\end{array}$ & $\begin{array}{l}\text { Mass, } \\
\quad \mathrm{g}\end{array}$ & $\begin{array}{l}\text { Dose, } \\
\text { Mrad }\end{array}$ & Comments \\
\hline B-1 & clinoptilolite & 0.5961 & 6.4 & Beads absorbed liquid prior to irradiation. \\
\hline B-2 & clinoptilolite & 0.4917 & 0.56 & \\
\hline B-3 & clinoptilolite & 0.4686 & 6.4 & \\
\hline B-4 & clinoptilolite & 0.5217 & 0.56 & \\
\hline B-5 & activated TVT & 0.4976 & 6.4 & Sample B-15 contained $2 \mathrm{~mL}$ of solution. \\
\hline B-6 & activated TVT & 0.6163 & 6.4 & \\
\hline B-7 & activated TVT & 0.5548 & 0.55 & \\
\hline B-8 & activated TVT & 0.5133 & 0.55 & \\
\hline B-9 & resorcinol-formaldehyde UK form ${ }^{\mathfrak{a}}$ & 0.5549 & 6.4 & Solution changed color from yellow to deep \\
\hline B-10 & resorcinol-formaldehyde UK form & 0.5316 & 6.4 & red upon contact with beads. Samples B-9 to \\
\hline B-11 & resorcinol-formaldehyde UK form & 0.4678 & 0.55 & B-16 appeared to behave similarly. \\
\hline B-12 & resorcinol-formaldehyde UK form & 0.5474 & 0.55 & \\
\hline B-13 & resorcinol-formaldehyde US form ${ }^{b}$ & 0.5192 & 6.4 & Beads floated on top of solution when sealed. \\
\hline B-14 & resorcinol-formaldehyde US form & 0.5897 & 6.4 & Beads absorbed liquid prior to irradiation. \\
\hline B-15 & resorcinol-formaldehyde US form & 0.5900 & 0.56 & \\
\hline B-16 & resorcinol-formaldehyde US form & 0.4806 & 0.56 & \\
\hline B-17 & crystalline silico-titanate & 0.5354 & 0.55 & Solution changes color from yellow to rust on \\
\hline B-18 & crystalline silico-titanate & 0.4980 & 0.55 & contact. Liquid adsorbed prior to irradiation. \\
\hline B-19 & crystalline silico-titanate & 0.5236 & 9.7 & Rotor failure during irradiation. \\
\hline B-20 & crystalline silico-titanate & 0.5061 & 9.7 & \\
\hline
\end{tabular}

aPrepared by Bradtec, Ltd. (UK).

bPrepared by Bradtec, Inc. (US).

The doses absorbed by samples have an uncertainty of $\pm 10-15 \%$. The irradiation of two crystalline silico-titanate samples has a larger uncertainty in the dose (approximately $\pm 30-35 \%$ ) due to the failure of the mechanical rotors used to rotate the test tubes containing samples. Hence, the dose to samples B-19 and B-20 is given as $9.7 \pm 3.2 \mathrm{Mrad}$. The irradiated samples were returned to Bradtec for analysis (Part One). All the samples swelled after contact with the simulant supernatant. Those samples that entirely absorbed the solution showed the greatest swelling.

\section{B. Radiation Dose Calculations}

In order to approximate a real gamma dose, it is necessary to determine the time required for a complete cycle of the magnetic separation process. This estimation will determine the time necessary for gamma irradiation studies. This section discusses the method used to calculate the dose absorbed by the cesium-specific magnetic particles from Bradtec.

The particles provided by Bradtec were $100-400 \mu \mathrm{m}$. Since the kinetic energy of the emitted B-particles is deposited over a short range, the dose absorbed by large particles is significantly higher than that absorbed by smaller particles. The doses anticipated to be absorbed by the cesium-specific magnetic particles were calculated by considering the $B$-particle and $\gamma$-ray 
emitted by $\mathrm{Cs}-137$. The $B$-particles are expected to deposit much more energy per unit path length than do the $\gamma$-rays. The emitted $B$-particle and a neutrino share $514 \mathrm{keV}$, producing an energy spectrum of emitted B-particles. The most probable kinetic energy of the $B$-particle is $1 / 3 \mathrm{E}_{\max }$, or $171 \mathrm{keV}$. This energy is typically used when computing doses from B-particles. Ionization of target atoms is the principal mechanism for energy deposition.

The energy deposited in the magnetic particles was determined by using an expression for the loss in kinetic energy per unit path length (Eq. II-1) and approximating the energy deposited by $\gamma$-rays using an attenuation coefficient (Eq. II-2). ${ }^{1}$ The energy deposited by the B-particle is given by

$$
\frac{\mathrm{dE}}{\mathrm{dX}}=\frac{2 \pi \mathrm{q}^{4} \mathrm{NZ}\left(3 \times 10^{9}\right)^{4}}{\mathrm{E}_{\mathrm{m}} \beta^{2}\left(1.6 \times 10^{-6}\right)^{2}}\left\{\ln \left[\frac{\mathrm{E}_{\mathrm{m}} \mathrm{E}_{\mathrm{k}} \beta^{2}}{\mathrm{I}^{2}\left(1-\beta^{2}\right)}\right]-\beta^{2}\right\} \frac{\mathrm{MeV}}{\mathrm{cm}}
$$

where

$\mathrm{q}=$ charge of an electron $=1.6 \times 10^{-19} \mathrm{C}$,

$\mathrm{N}=$ number of absorber atoms per $\mathrm{cm}^{3}$,

$\mathrm{Z}$ = atomic number of absorber,

$\mathrm{NZ}=$ electron density of absorber, in electrons $/ \mathrm{cm}^{3}$

$E_{\mathrm{m}}=$ rest energy of a $\beta$-particle $=0.511 \mathrm{MeV}$,

$E_{k}=$ kinetic energy of the $\beta$-particle, in eV

$\beta=\mathrm{v} / \mathrm{c}$ (where $\mathrm{v}=$ velocity of $\beta$-particle, $\mathrm{cm} / \mathrm{s}$; and $\mathrm{c}=$ speed of light, $\mathrm{cm} / \mathrm{s}$ )

$\mathrm{I}=$ mean ionization and excitation potential of absorber $=\mathrm{Z} \cdot 13.5 \mathrm{eV}$.

The numerical factors in Eq. II-1 are used to produce convenient units (MeV/cm). The absorption and attenuation coefficients for the magnetic particles are approximately equal. Equation I-2 gives an expression for the intensity (I) of $\gamma$-rays having passed through an absorber of thickness $x(\mathrm{~cm})$ and absorption coefficient $\mu\left(\mathrm{cm}^{-1}\right)$ compared to the initial intensity $I_{0}$ :

$$
I=I_{0}[1-\exp (-\mu x)]
$$

The ratio $I I_{0}$ gives the fraction of $\gamma$-rays absorbed when passing through the absorber. It was assumed that any $\gamma$-ray that interacted with the particles deposited all its energy. Since the magnetic particles are relatively transparent to $660 \mathrm{keV}$ photons, the $\gamma$-rays deposited much less energy than did the B-particles.

The electron density of the target must be determined to compute the absorbed dose. Since Bradtec was unable to provide detailed information regarding particle density, average atomic number, and average atomic mass, several values within a reasonable range were used to compute estimates.

The Bradtec particles were larger than expected, and since the dose absorbed depends on the path length of the ionizing radiation through the particle, they received a large dose. The assumptions used when calculating doses are as follows: 
1. Half of the B-particles are emitted into solution, resulting in no energy deposited to the magnetic particles.

2. Beta-particles interact with only one magnetic particle.

3. All $\boldsymbol{\gamma}$-rays interact with magnetic particles.

4. The energy deposited by $\gamma$-rays depends solely on the attenuation of the ${ }^{137} \mathrm{Cs}$ gamma ray.

5. All cesium in the supernatant solution absorbed on particles.

6. One gram of particles was assumed per liter of solution.

7. The concentration of Cs-137 in the supernatant is $4.88 \times 10^{-5} \mathrm{~mol} / \mathrm{L}$.

Using these assumptions and the equations above for energy deposition as a function of path length, the dose to the magnetic particles was estimated for different path lengths, atomic numbers, atomic masses, and densities, and the results are presented in Table II-2. The results were used as the basis for ${ }^{60} \mathrm{Co}$ gamma irradiation of the particles.

Table II-2. Calculated Dose Absorbed by Cesium-Specific Magnetic Particles

\begin{tabular}{|c|c|c|c|c|c|c|c|c|}
\hline \multirow{2}{*}{$\begin{array}{c}\text { Path } \\
\text { Length, } \\
\mu \mathrm{m}\end{array}$} & \multirow{2}{*}{$\begin{array}{c}\text { Target } \\
\mathbf{Z} \\
\end{array}$} & \multirow{2}{*}{$\begin{array}{c}\text { Target } \\
\text { A }\end{array}$} & \multirow{2}{*}{$\begin{array}{c}\text { Target } \\
\text { Density, } \\
{\mathrm{g} / \mathrm{cm}^{3}}\end{array}$} & \multirow{2}{*}{$\begin{array}{c}\text { Beta } \\
\text { Energy, } \\
\mathrm{MeV}\end{array}$} & \multirow{2}{*}{$\begin{array}{c}\text { Gamma } \\
\text { Energy, } \\
\mathrm{MeV}\end{array}$} & \multirow{2}{*}{$\begin{array}{c}\text { Contact } \\
\text { Time, } \\
\text { h }\end{array}$} & \multicolumn{2}{|c|}{ Dose, rad } \\
\hline & & & & & & & 10 Contacts & 100 Contacts \\
\hline 20 & 12 & 24 & 2.5 & $6.26 \mathrm{E}+03$ & $2.65 E+02$ & 0.5 & $4.02 E+04$ & $4.02 E+05$ \\
\hline 40 & 12 & 24 & 2.5 & $1.25 \mathrm{E}+04$ & $5.29 E+02$ & 0.5 & $8.04 E+04$ & $8.04 E+05$ \\
\hline 60 & 12 & 24 & 2.5 & $1.88 \mathrm{E}+04$ & $7.94 \mathrm{E}+02$ & 0.5 & $1.21 E+05$ & $1.21 \mathrm{E}+06$ \\
\hline 80 & 12 & 24 & 2.5 & $2.51 \mathrm{E}+04$ & $1.06 \mathrm{E}+03$ & 0.5 & $1.61 E+05$ & $1.61 E+06$ \\
\hline 100 & 12 & 24 & 2.5 & $3.13 E+04$ & $1.32 E+03$ & 0.5 & $2.01 E+05$ & $2.01 E+06$ \\
\hline 20 & 14 & 28 & 2.7 & $6.62 \mathrm{E}+03$ & $2.65 E+02$ & 0.5 & $4.24 \mathrm{E}+04$ & $4.24 \mathrm{E}+05$ \\
\hline 40 & 14 & 28 & 2.7 & $1.32 \mathrm{E}+04$ & $5.29 \mathrm{E}+02$ & 0.5 & $8.48 E+04$ & $8.48 E+05$ \\
\hline 60 & 14 & 28 & 2.7 & $1.99 \mathrm{E}+04$ & $7.94 E+02$ & 0.5 & $1.27 \mathrm{E}+05$ & $1.27 E+06$ \\
\hline 80 & 14 & 28 & 2.7 & $2.65 \mathrm{E}+04$ & $1.06 E+03$ & 0.5 & $1.70 \mathrm{E}+05$ & $1.70 \mathrm{E}+06$ \\
\hline 100 & 14 & 28 & 2.7 & $3.31 E+04$ & $1.32 \mathrm{E}+03$ & 0.5 & $2.12 E+05$ & $2.12 E+06$ \\
\hline 20 & 12 & 24 & 2.5 & $6.26 E+03$ & $2.65 E+02$ & 1 & $8.04 E+04$ & $8.04 E+05$ \\
\hline 40 . & 12 & 24 & 2.5 & $1.25 E+04$ & $5.29 E+02$ & 1 & $1.61 \mathrm{E}+05$ & $1.61 E+06$ \\
\hline $60^{\circ}$ & 12 & 24 & 2.5 & $1.88 E+04$ & $7.94 \mathrm{E}+02$ & 1 & $2.41 E+05$ & $2.41 E+06$ \\
\hline 80 & 12 & 24 & 2.5 & $2.51 E+04$ & $1.06 E+03$ & 1 & $3.22 \mathrm{E}+05$ & $3.22 E+06$ \\
\hline 100 & 12 & 24 & 2.5 & $3.13 E+04$ & $1.32 E+03$ & 1 & $4.02 E+05$ & $4.02 E+06$ \\
\hline 20 & 14 & 28 & 2.7 & $6.62 E+03$ & $2.65 \mathrm{E}+02$ & 1 & $8.48 \mathrm{E}+04$ & $8.48 E+05$ \\
\hline 40 & 14 & 28 & 2.7 & $1.32 E+04$ & $5.29 E+02$ & 1 & $1.70 \mathrm{E}+05$ & $1.70 E+06$ \\
\hline 60 & 14 & 28 & 2.7 & $1.99 \mathrm{E}+04$ & $7.94 \mathrm{E}+02$ & 1 & $2.54 \mathrm{E}+05$ & $2.54 \mathrm{E}+06$ \\
\hline 80 & 14 & 28 & 2.7 & $2.65 E+04$ & $1.06 \mathrm{E}+03$ & 1 & $3.39 E+05$ & $3.39 E+06$ \\
\hline 100 & 14 & 28 & 2.7 & $3.31 E+04$ & $1.32 \mathrm{E}+03$ & 1 & $4.24 E+05$ & $4.24 E+06$ \\
\hline 20 & 12 & 24 & 2.5 & $6.26 \mathrm{E}+03$ & $2.65 E+02$ & 2 & $1.61 E+05$ & $1.61 E+06$ \\
\hline 40 & 12 & 24 & 2.5 & $1.25 \mathrm{E}+04$ & $5.29 \mathrm{E}+02$ & 2 & $3.22 \mathrm{E}+05$ & $3.22 E+06$ \\
\hline 60 & 12 & 24 & 2.5 & $1.88 \mathrm{E}+04$ & $7.94 \mathrm{E}+02$ & 2 & $4.83 E+05$ & $4.83 E+06$ \\
\hline 80 & 12 & 24 & 2.5 & $2.51 E+04$ & $1.06 \mathrm{E}+03$ & 2 & $6.44 E+05$ & $6.44 \mathrm{E}+06$ \\
\hline 100 & 12 & 24 & 2.5 & $3.13 E+04$ & $1.32 \mathrm{E}+03$ & 2 & $8.04 E+05$ & $8.04 E+06$ \\
\hline 20 & 14 & 28 & 2.7 & $6.62 E+03$ & $2.65 E+02$ & 2 & $1.70 E+05$ & $1.70 E+06$ \\
\hline 40 & 14 & 28 & 2.7 & $1.32 E+04$ & $5.29 E+02$ & 2 & $3.39 \mathrm{E}+05$ & $3.39 E+06$ \\
\hline 60 & 14 & 28 & 2.7 & $1.99 E+04$ & $7.94 \mathrm{E}+02$ & 2 & $5.09 \mathrm{E}+05$ & $5.09 E+06$ \\
\hline 80 & 14 & 28 & 2.7 & $2.65 E+04$ & $1.06 \mathrm{E}+03$ & 2 & $6.79 \mathrm{E}+05$ & $6.79 \mathrm{E}+06$ \\
\hline 100 & 14 & 28 & 2.7 & $3.31 E+04$ & $1.32 \mathrm{E}+03$ & 2 & $8.48 E+05$ & $8.48 E+06$ \\
\hline
\end{tabular}

aDeposit decay. 


\section{OPTICAL MICROSCOPY}

\section{A. Optical Microscopy before Irradiation}

Upon contact of the Bradtec particles with the Hanford supernatant simulant, the liquid was completely absorbed by the particles, and in some cases, the solution color changed. The large size of these particles precluded them as candidates for transmission electron microscopy (TEM). However, we were able to observe the particles (before irradiation) under an optical microscope and determine general features and size distributions. Results are given below for the analyses of crystalline silico-titanate, resorcinol, clinoptilolite, and transylvanian volcanic tuff particles.

Photographs of all samples were taken using a light microscope. One micrograph was made for each of the samples, and an additional micrograph was taken and included a physical scale to be used in size determination. The pictures obtained were then digitized and analyzed by two different computer programs: National Institute of Health Image 1.49 and Ultimage/24 2.1. The digitized pictures were then enhanced. The first step was to physically white-out the background, leaving behind only the particle images. Next, the programs were used to find the maximum diameter of each particle. These results are present in the form of a histogram. Particle distributions are given in Figs. III-1 to III-4 and micrographs in Figs. III-5 to III-8.

The particles in the crystalline silico-titanate sample did not seem to align themselves with the induced magnetic field from the transformer of the microscope, as some of the others did. Most of the particles were smaller than $300 \mu \mathrm{m}$ in diameter (Fig. III-1). The particles appeared to be original particles and not chips. The particles were round and did not appear to be fractured larger particles. This sample also contained a number of thread-like structures. The thread-like structures appeared to be fibers that had entered the sample during production. They could possibly be fibers from filters. (We looked at another sample after the microscope was cleaned and verified that the threads were in the sample, not on the lens or eyepiece of the microscope).

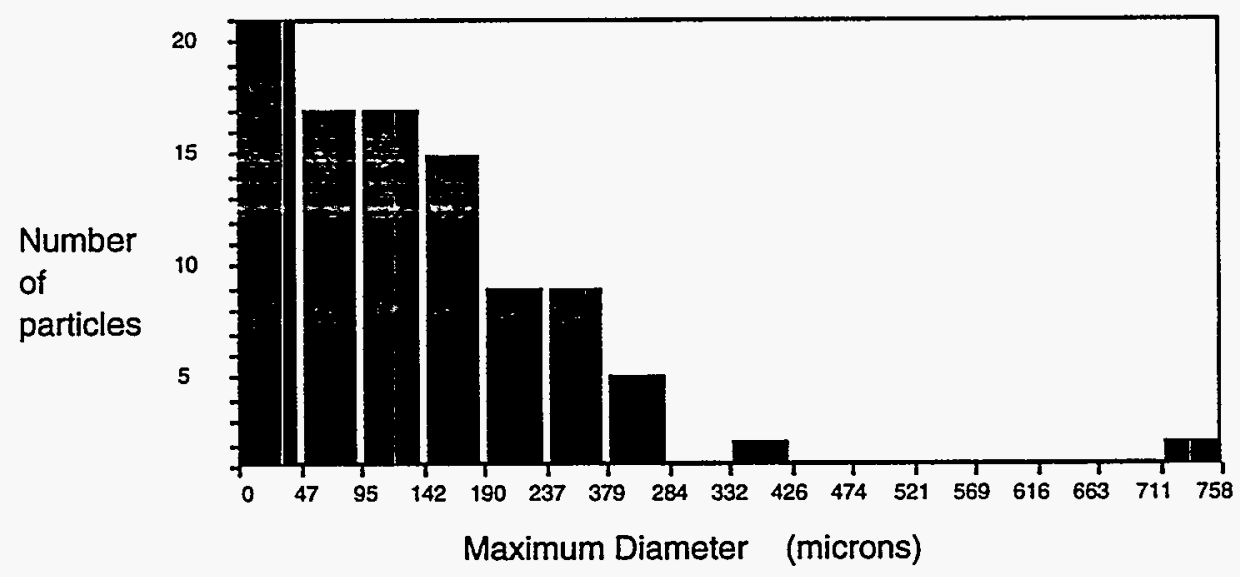

Fig. III-1. Particle Distribution of Crystalline Silico-Titanate Particles (number of particles, 90; mean diameter, $132.6 \mu \mathrm{m}$ )

The resorcinol (US form) sample (Fig. III-2) was composed of a few particles over $500 \mu \mathrm{m}$ and numerous others smaller than $100 \mu \mathrm{m}$. This sample also contained a number of thread-like structures. 


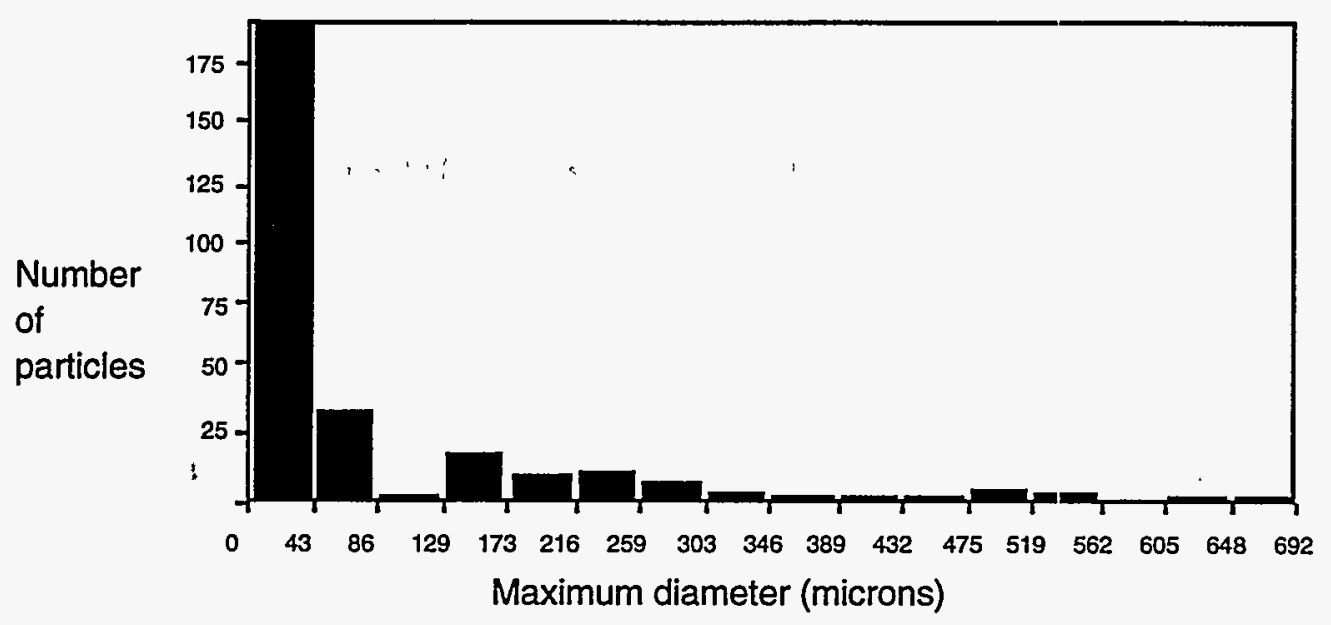

Fig. III-2. Particle Distribution of Resorcinol (US form) Particles (number of particles, 307; mean diameter, $83.8 \mu \mathrm{m}$ )

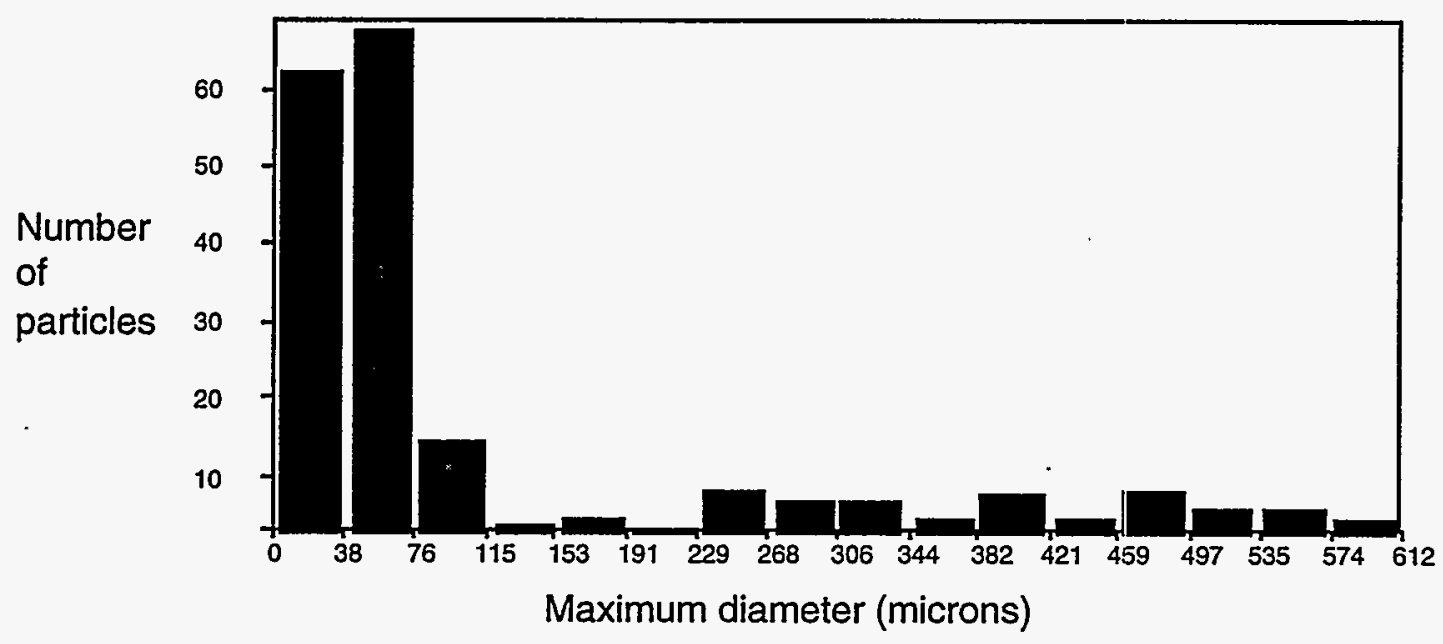

Fig. III-3. Particle Distribution of Resorcinol (UK form) Particles (number of particles, 189; mean diameter, $110.5 \mu \mathrm{m}$ )

The resorcinol (UK form) sample (Fig. III-3) was composed of a number of particles with diameters greater than $300 \mu \mathrm{m}$, as well as numerous others with diameters less than $100 \mu \mathrm{m}$. Very few particles were found with diameters in the 100 to $300 \mu \mathrm{m}$ range. The micrograph (Fig. III-7) suggests that there may be some attraction between the larger particles.

For the clinoptilolite sample (Fig. III-4), the magnetic particles aligned themselves with the magnetic field induced by the transformer used to provide the light for the microscope. This led to some inaccuracy in counting the particles. Analyzing the particles required that a white line be drawn between them. The smaller particles, in the 0 to $50 \mu \mathrm{m}$ range, did not align themselves with the larger ones. This suggests that the smaller particles may not contain magnetite, or at least that the particles do not contain enough magnetite for the field produced by the transformer to have an effect, but this would not discern if small particles are in contact with larger particles. 


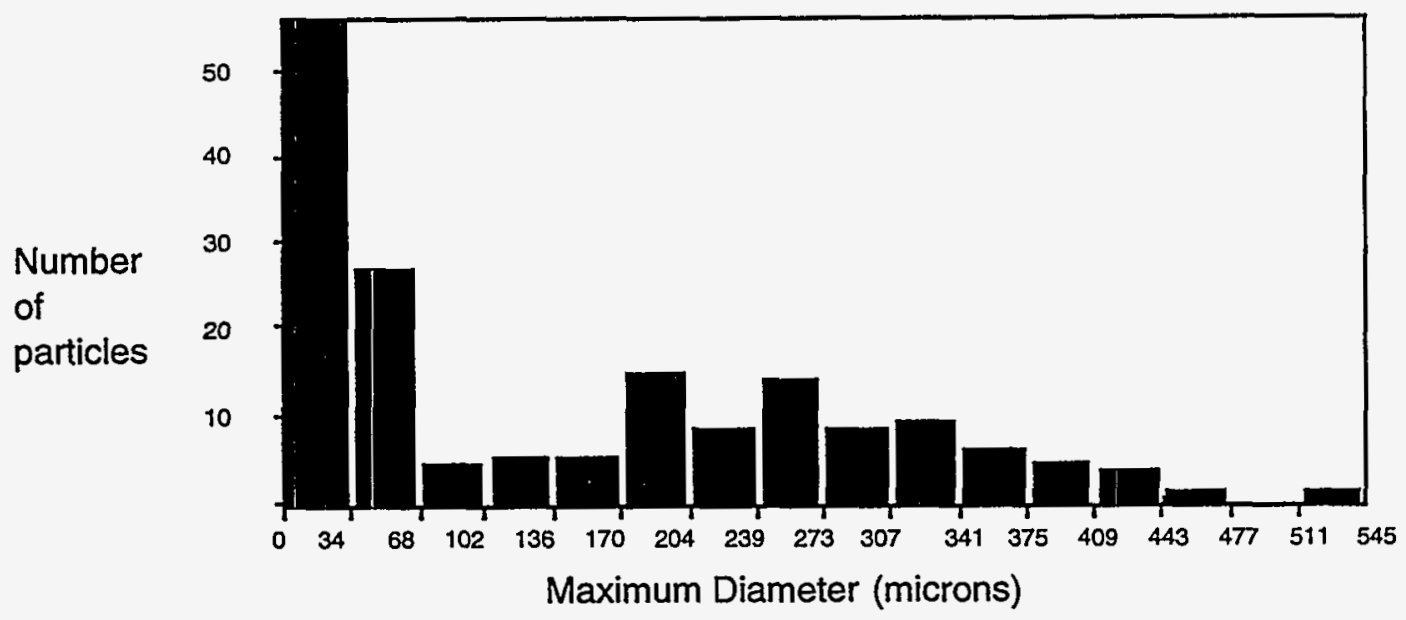

Fig. III-4. Particle Distribution of Clinoptilolite Particles (number of particles, 185; mean diameter, $150.0 \mu \mathrm{m}$ )

The particles of the activated transylvanian volcanic tuff samples were aligned in chains; however, the photograph was too dark to be analyzed using the software available (figures therefore not included). The particles appear to be in the 200 to $300 \mu \mathrm{m}$ region. There are also a number of particles less than $50 \mu \mathrm{m}$ in diameter scattered throughout the sample. This micrograph showed a large thread-like structure, perhaps composed of a few smaller strands.

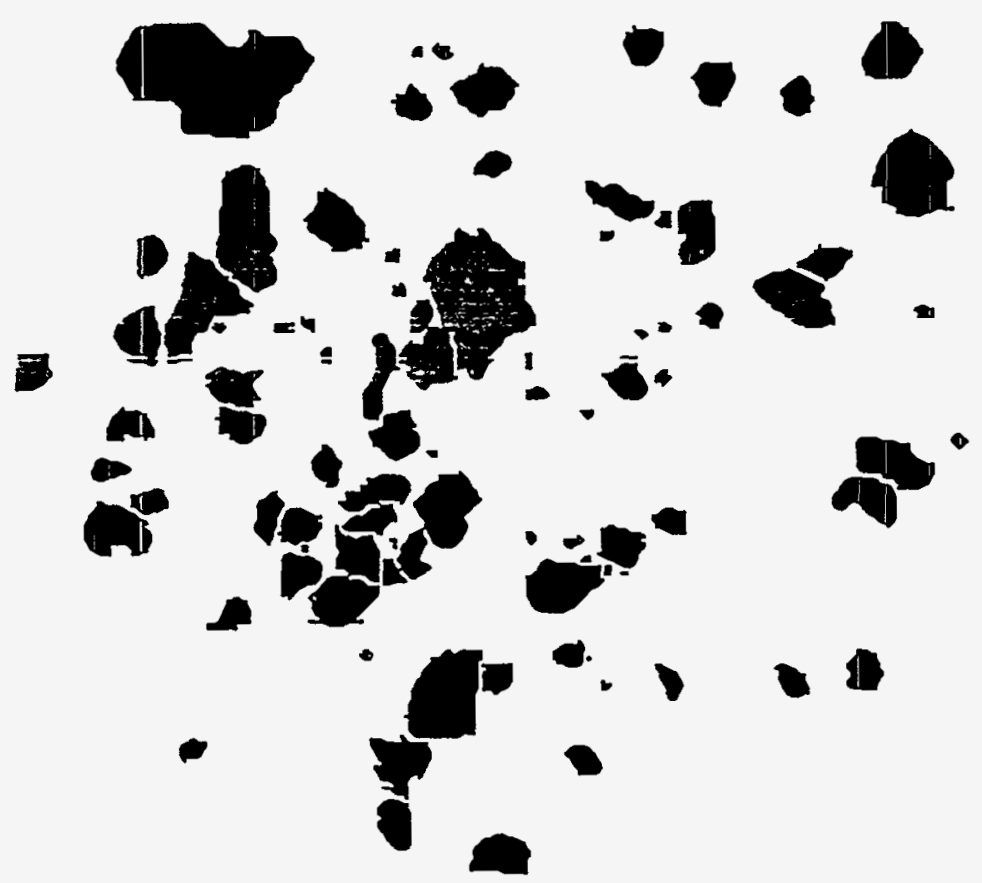

Fig. III-5. Micrograph of Crystalline Silico-Titanate Particles 
Figures III-5 through III-8 show the micrographs obtained with the whited-out background and Ultimage/24 analysis. In Fig. III-5, the random alignment of the silico-titanate particles is apparent. The particles did not appear to be fragmentations from larger particles. Figure III-6 shows the prominence of fines in the presence of larger particles $(>500 \mu \mathrm{m})$ for the resorcinol

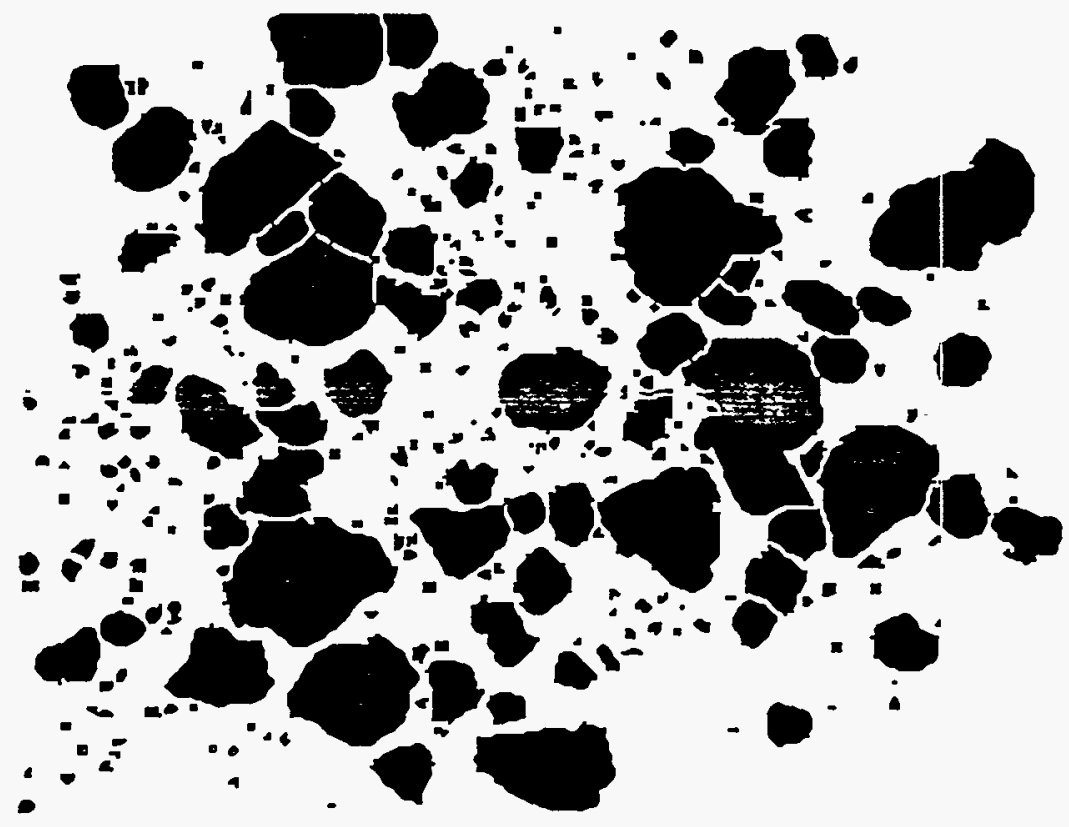

Fig. III-6. Micrograph of Resorcinol (US form) Particles

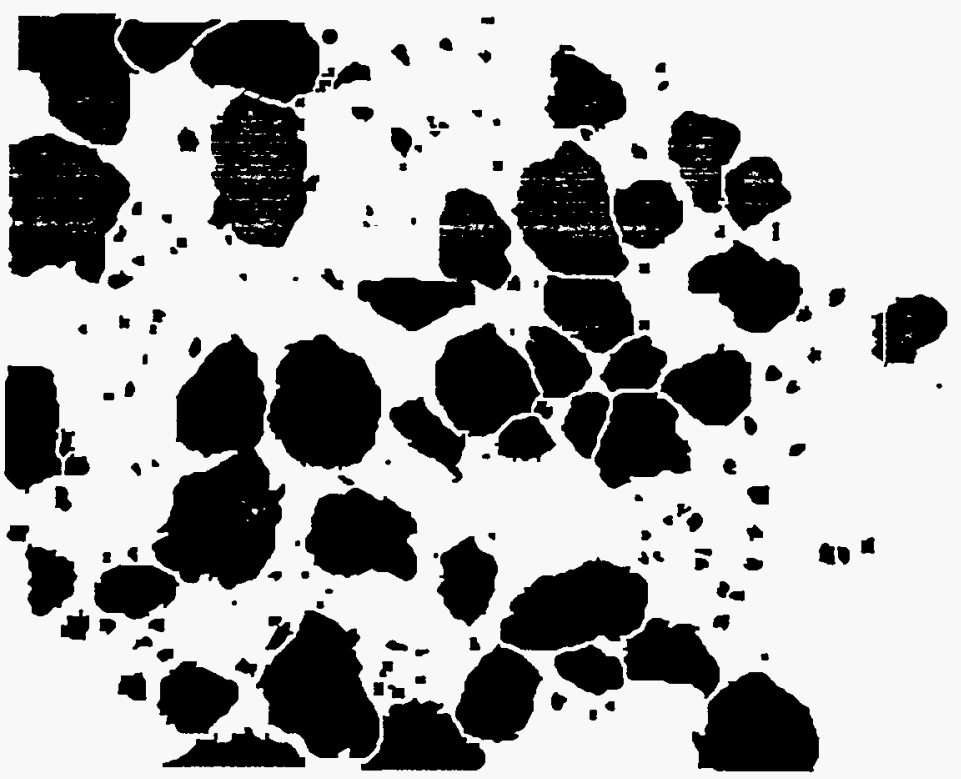

Fig. III-7. Micrograph of Resorcinol (UK form) Particles 
(US form) sample. Figure III-7 shows the presence of a large number of particles smaller than $100 \mu \mathrm{m}$ and larger than $300 \mu \mathrm{m}$ in the resorcinol (UK form) sample. The alignment of the clinoptilolite particles with the induced magnetic field is well illustrated in Fig. III-8. The closepacking led to estimates on the position of the natural breaks between particles.

In general, the majority of the particles were smaller than $100 \mu \mathrm{m}$, with the largest ones being over $700 \mu \mathrm{m}$. All of the samples displayed a distribution between these two values.

Standard deviations (not included in this report), which were much greater than the mean values in all cases, demonstrated the large variation in the particle sizes. The resolution at the magnification used was $13 \mu \mathrm{m}$. All of the photographs also showed the presence of tiny particles (less than $50 \mu \mathrm{m})$ scattered throughout the samples.

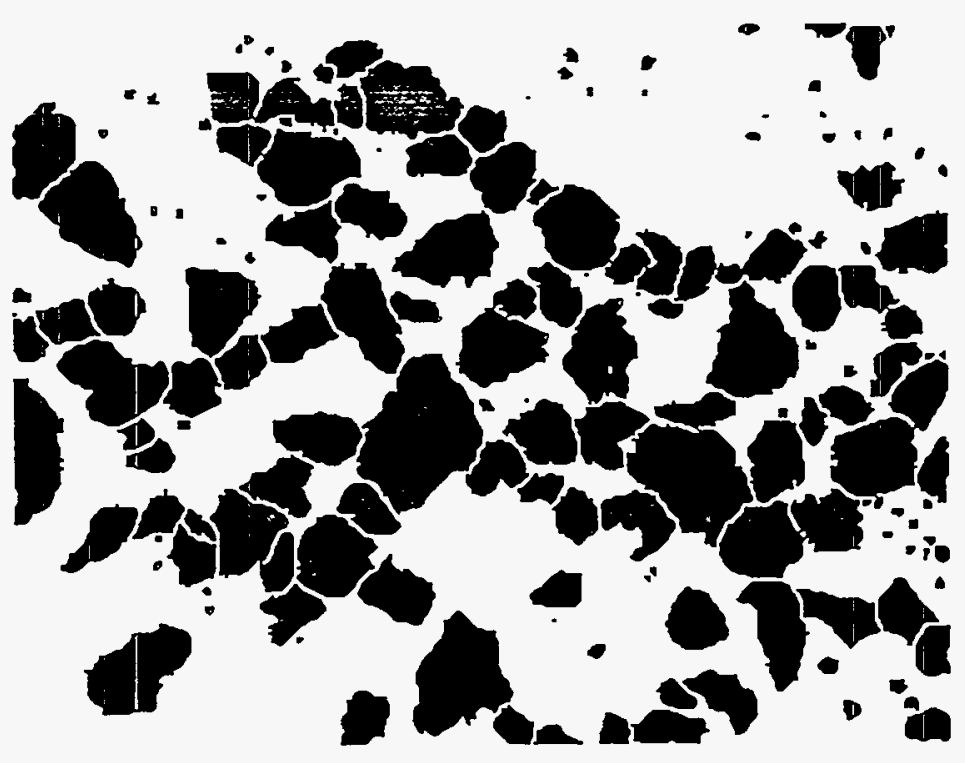

Fig. III-8. Micrograph of Clinoptilolite Particles

\section{B. Optical Microscopy after Gamma Irradiation}

Optical micrographs were taken to help determine the effect of radiation on two sets of particles provided by Bradtec: crystalline silico-titanate and resorcinol. The micrographs were taken with a Leitz light microscope at 32 times magnification. The images were then digitized with a Hewlett Packard scanner and Ofoto software. All of the micrographs were edited according to the procedure described in the previous section. The distribution of particles according to maximum diameter and total area is included along with each micrograph.

\section{Crystalline Silico-Titanate Samples}

Figure III-9 is the micrograph obtained before irradiation of crystalline silicotitanate contacted by supernatant. The particles did not appear to align themselves with a magnetic field, as did some of the other particle types. Most of the particles were smaller than $300 \mu \mathrm{m}$ in diameter but probably still contained iron particles (Figs. III-10 and III-11). This sample also contained a number of thread-like structures of unknown origin. These were recognized as being of a different composition than the polymer that constitutes the silico-titanate particle core. We 
looked at another sample after the microscope was cleaned and verified that the threads were in the sample, not on the lens or eyepiece of the microscope.

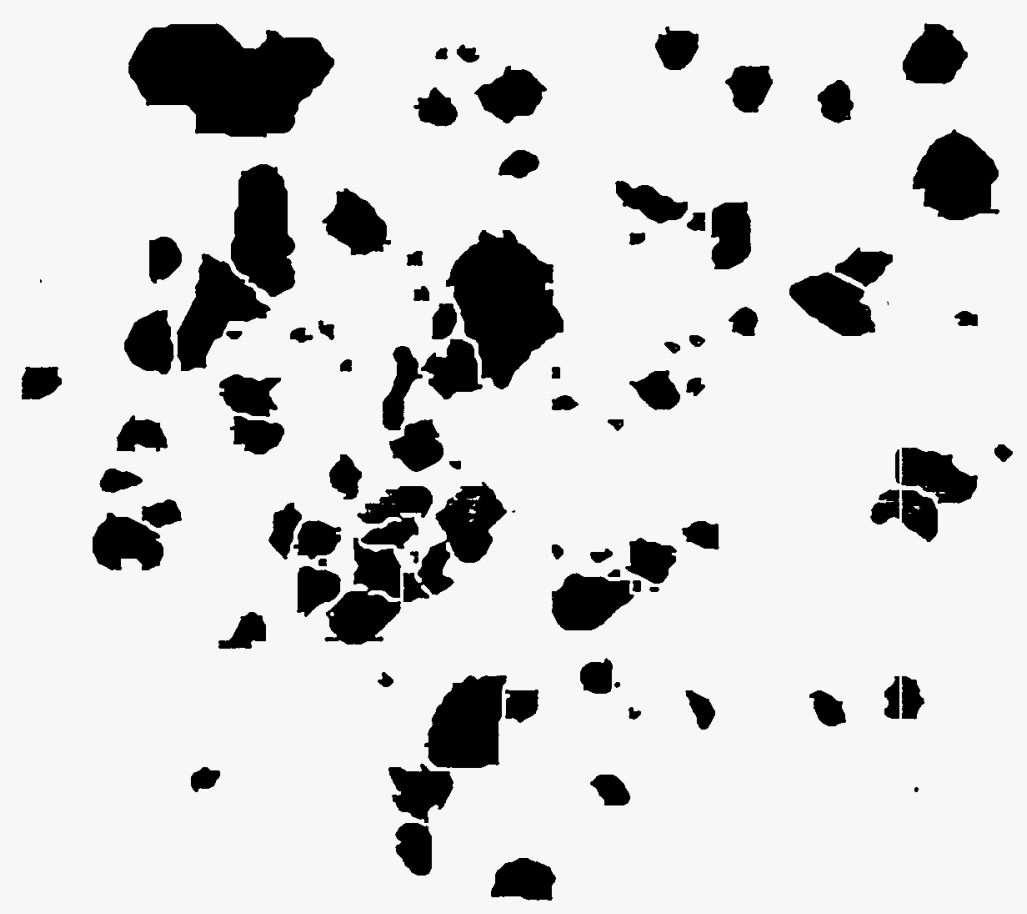

Fig. III-9. Micrograph of Crystalline Silico-titanate Particles before Irradiation

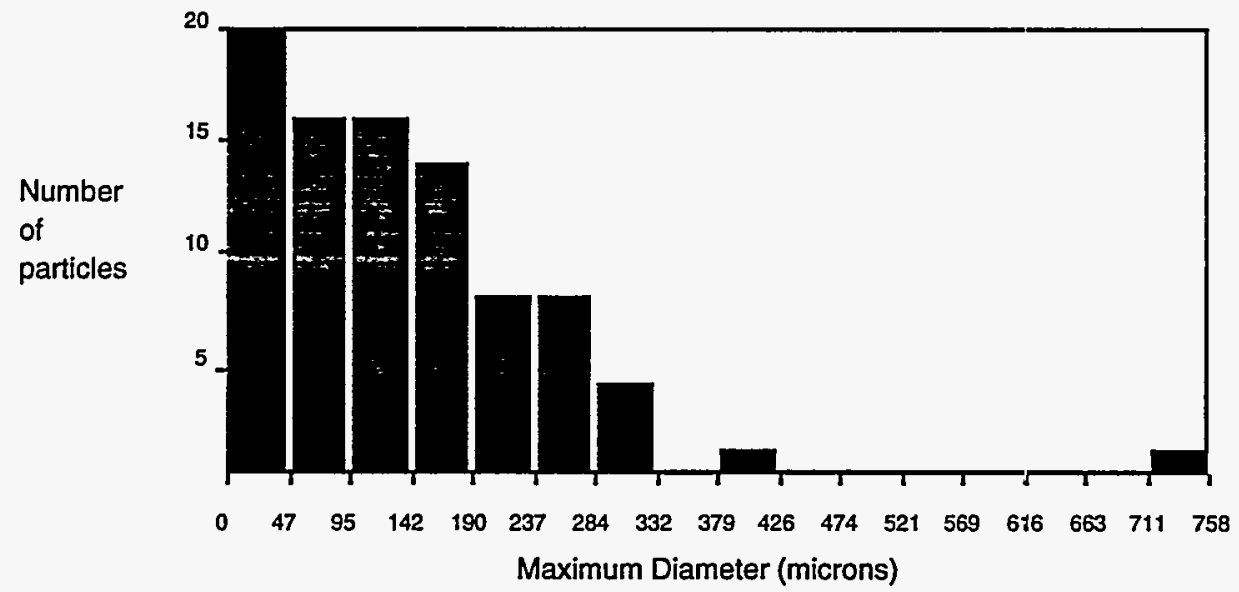

Fig. III-10. Distribution of Crystalline Silico-titanate Particles in

Fig. III-9 as Function of Diameter (average value, $133 \mu \mathrm{m}$ )

In Fig. III-12, the supernatant waste simulant has been added to the particles, and swelling has occurred. In the comparison between this micrograph and Fig. III-9, the average particle diameter increased by approximately $100 \mu \mathrm{m}$ (Figs. III-13 and III-14). This sample also contained some material that appeared to be glass particles, which were bound to the silico-titanate resin and appear as fine particles in the figure. It was concluded that this material must be the 


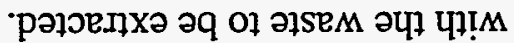

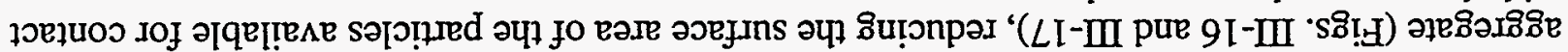

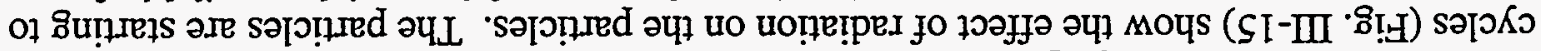
OI јо ұนәГе

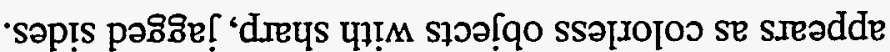

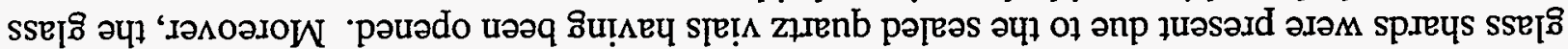

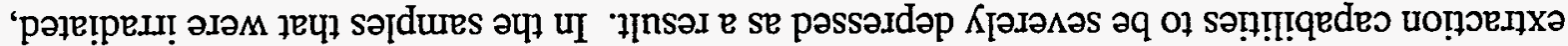

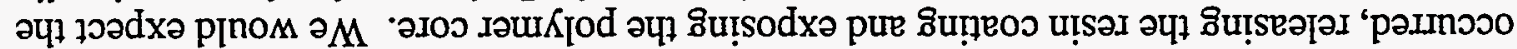

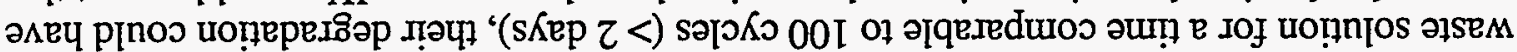

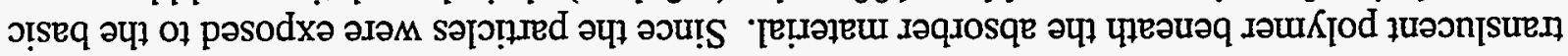

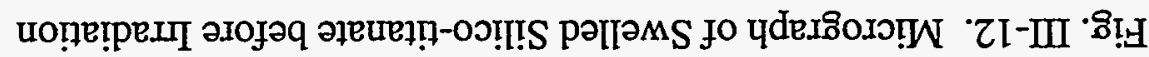

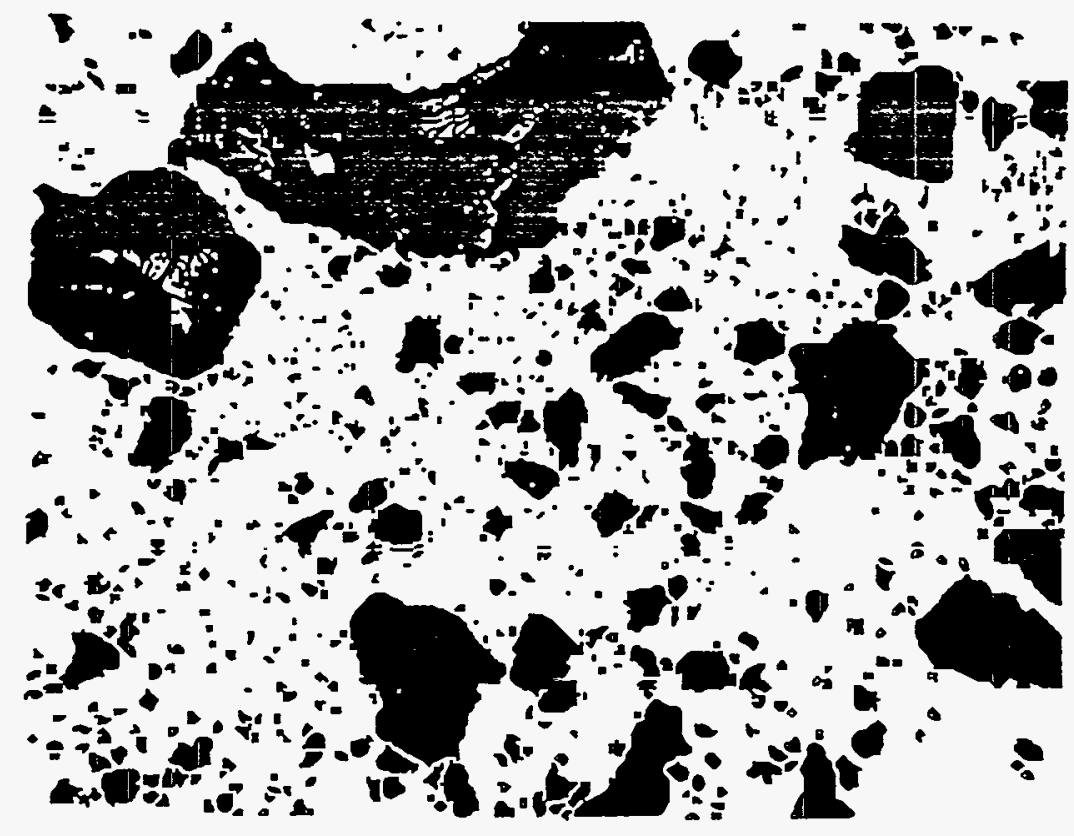

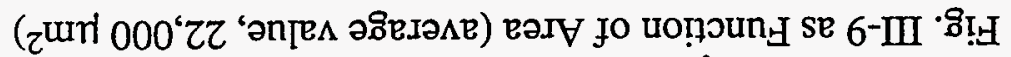

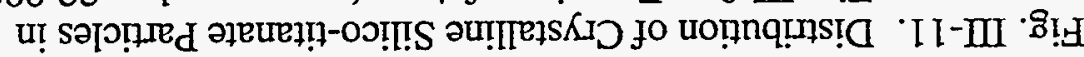

(suodọu ·bs 000l) eady

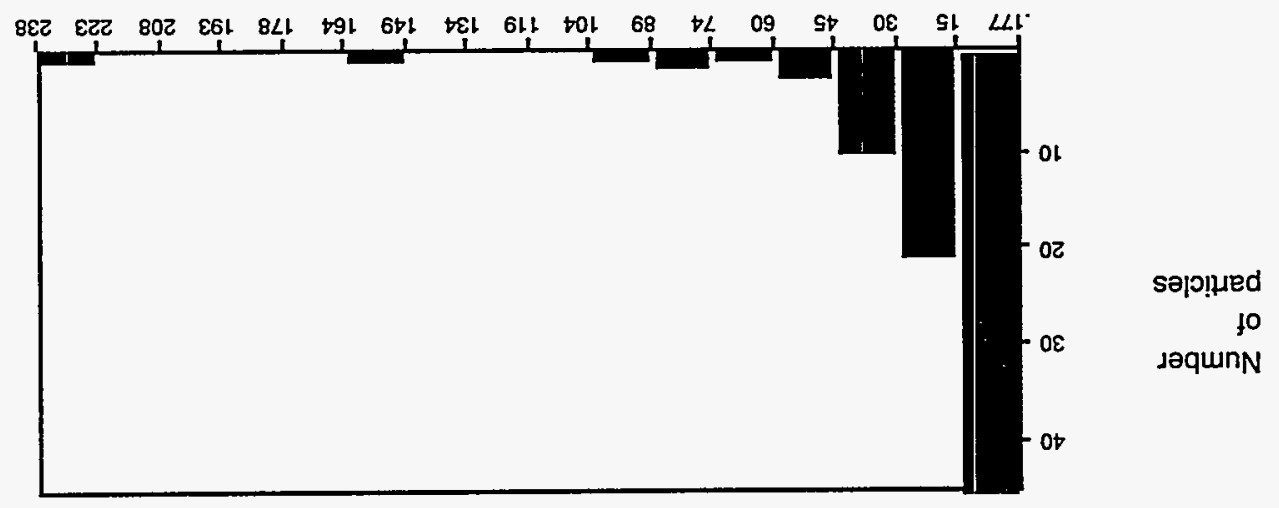




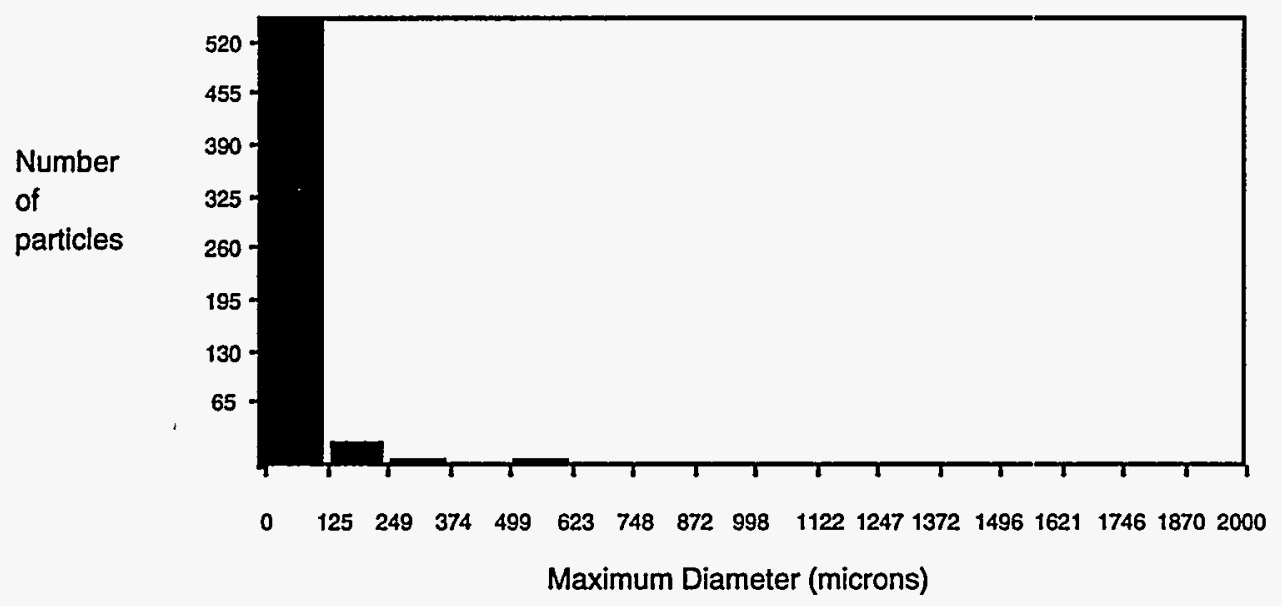

Fig. III-13. Particle Distribution for Silico-titanate Sample in Fig. III-12 as Function of Diameter (average value, $55 \mu \mathrm{m}$ )

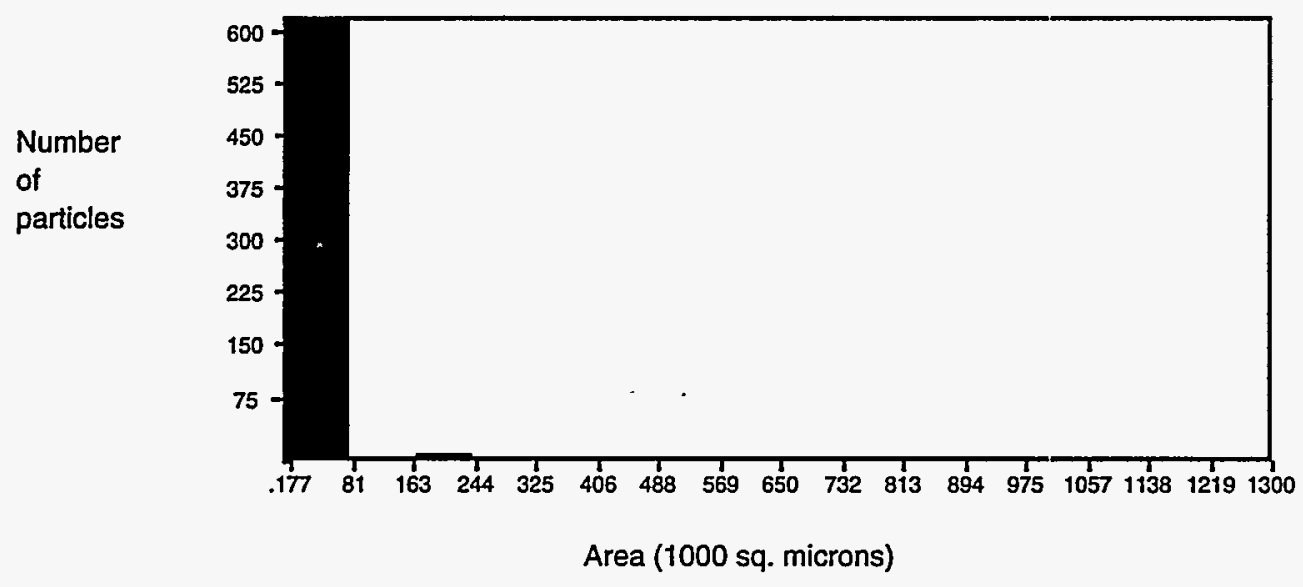

Fig. III-14. Particle Distribution for Silico-titanate Sample in Fig. III-12 as Function of Area (average value, $8200 \mu \mathrm{m}^{2}$ )

The micrograph of the silico-titanate sample irradiated for 100 cycles (Fig. III-18) continues the trend that began with low radiation doses. The particles are forming larger aggregates, 1000 to $1200 \mu \mathrm{m}$ in diameter. Once again, some glass was found in the sample but is not visible in the figures presented (Figs. III-19 and III-20). The tremendous decrease in surface area indicated by this micrograph provides a possible answer to the low $K_{d}$ values recorded (see Part One), since it is the silico-titanate on the surface of the particles which complexes the waste. 


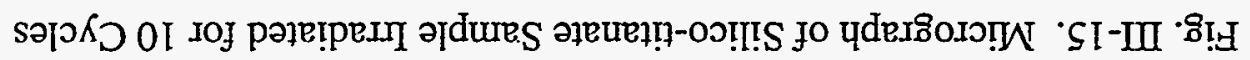

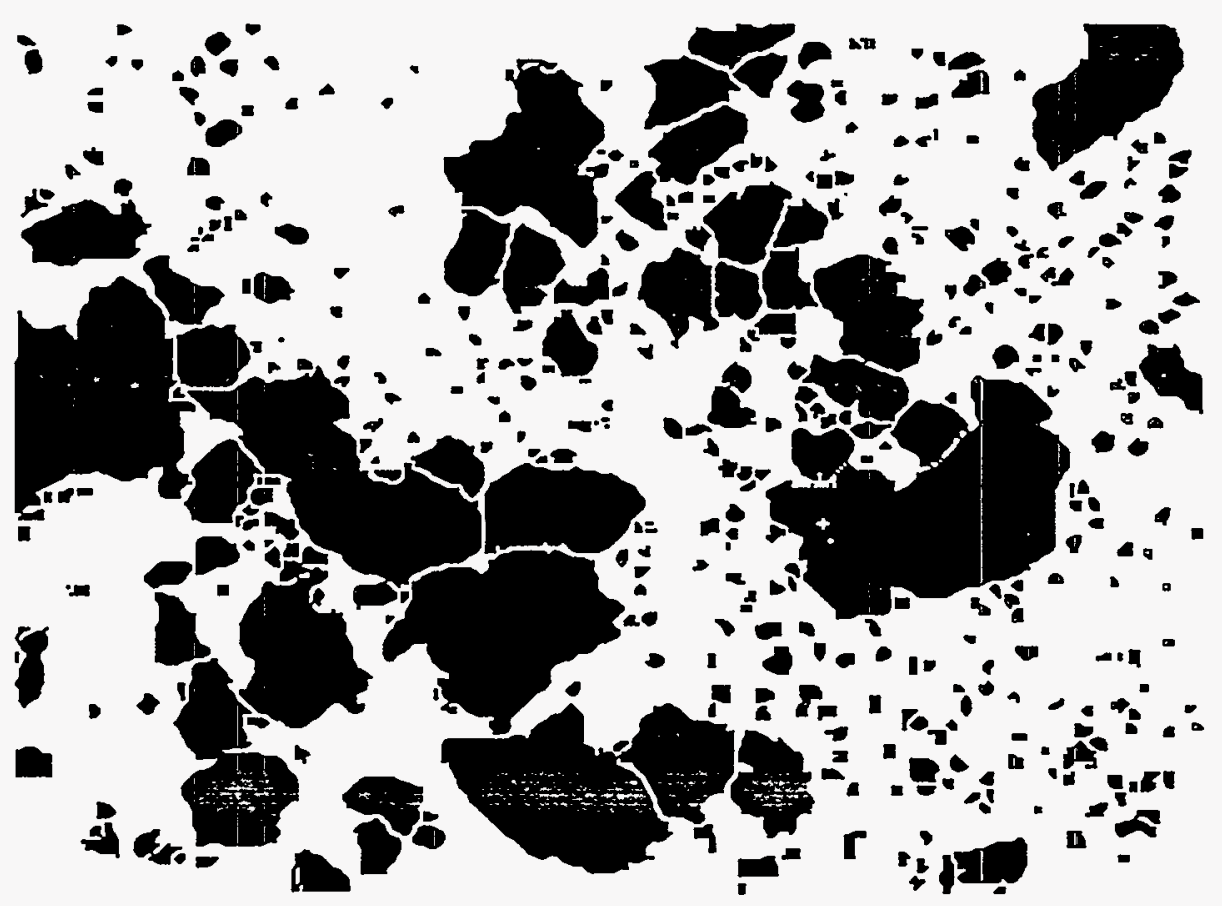




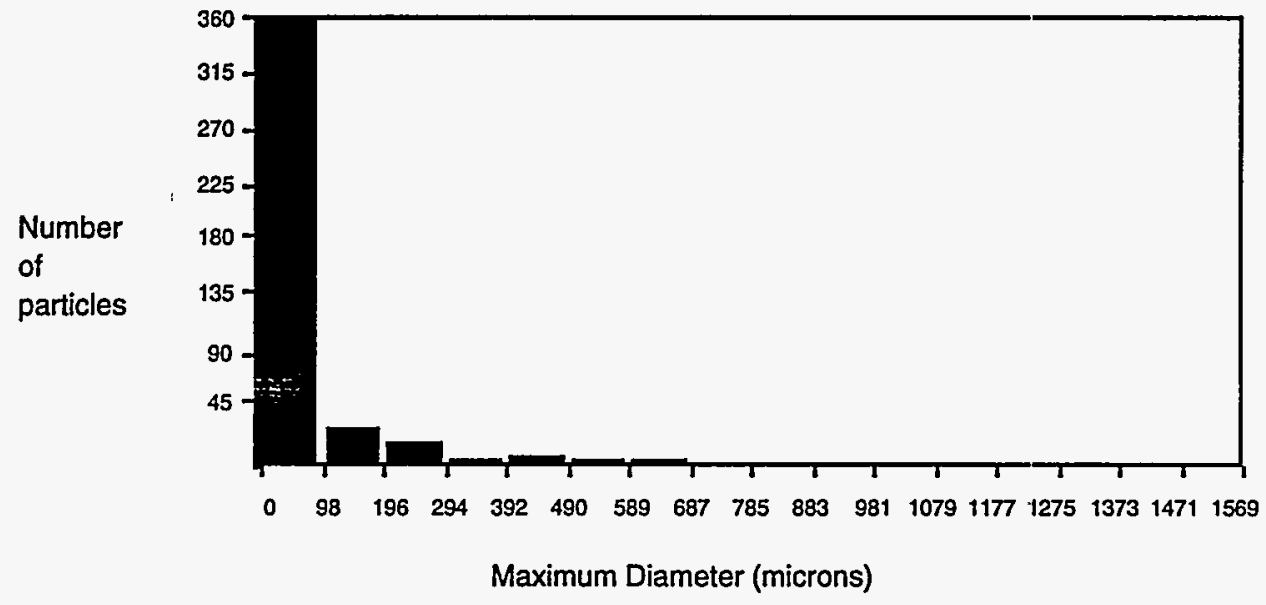

Fig. III-16. Particle Distribution for Silico-titanate Sample in Fig. III-15 as Function of Diameter (average value, $71 \mu \mathrm{m}$ )

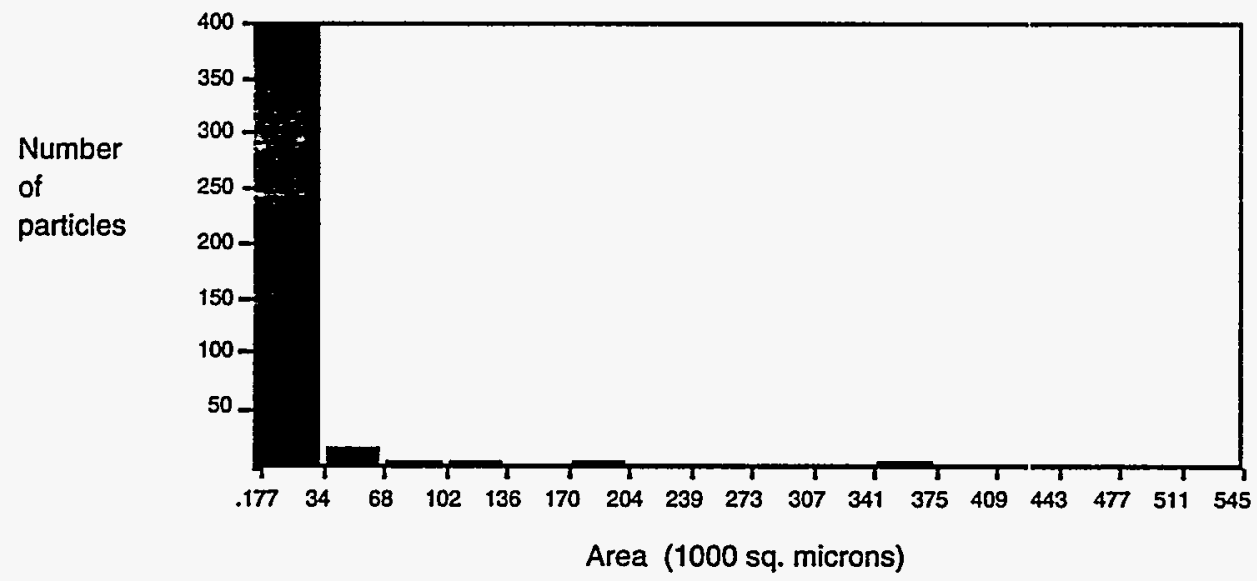

Fig. III-17. Particle Distribution for Silico-titanate Sample in Fig. III-15 as Function of Area (average value, $12,000 \mu \mathrm{m}^{2}$ ) 


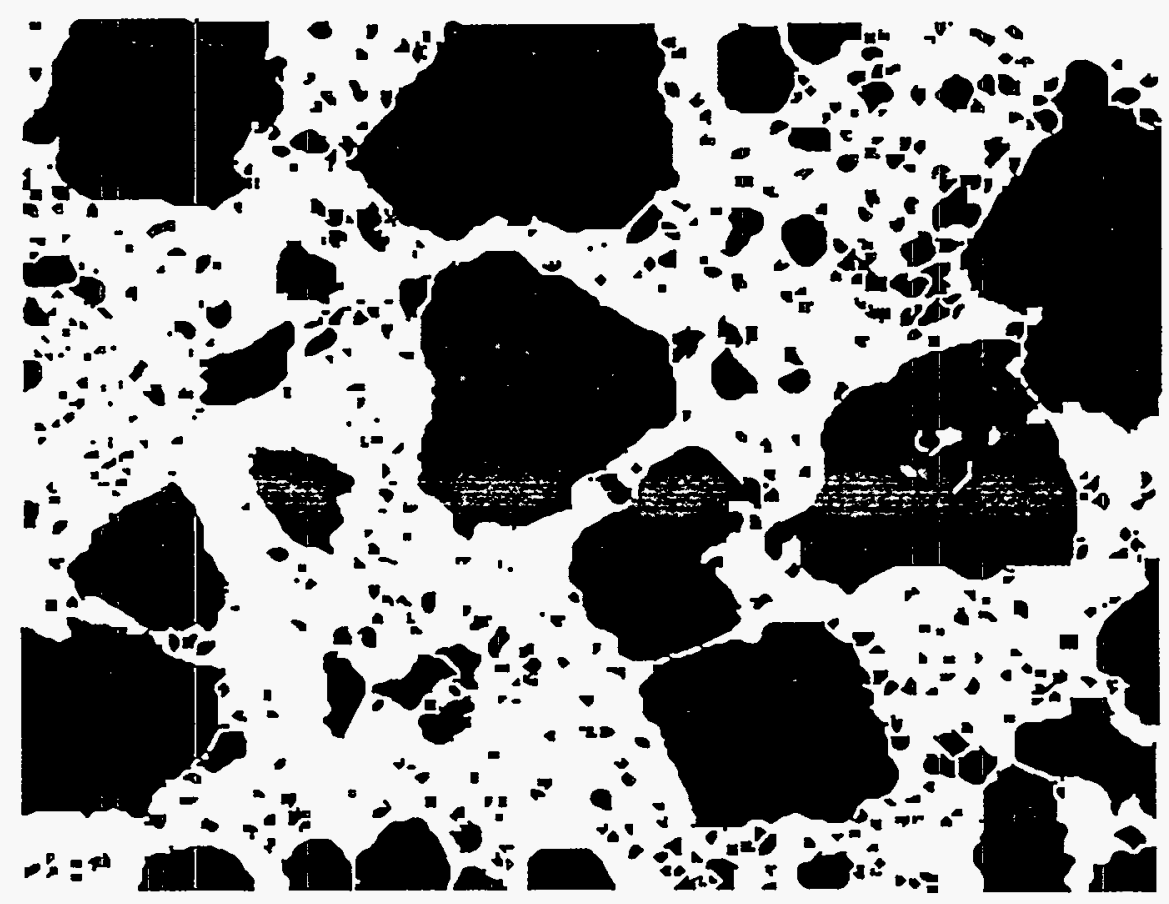

Fig. III-18. Micrograph of Silico-titanate Sample Irradiated for 100 Cycles

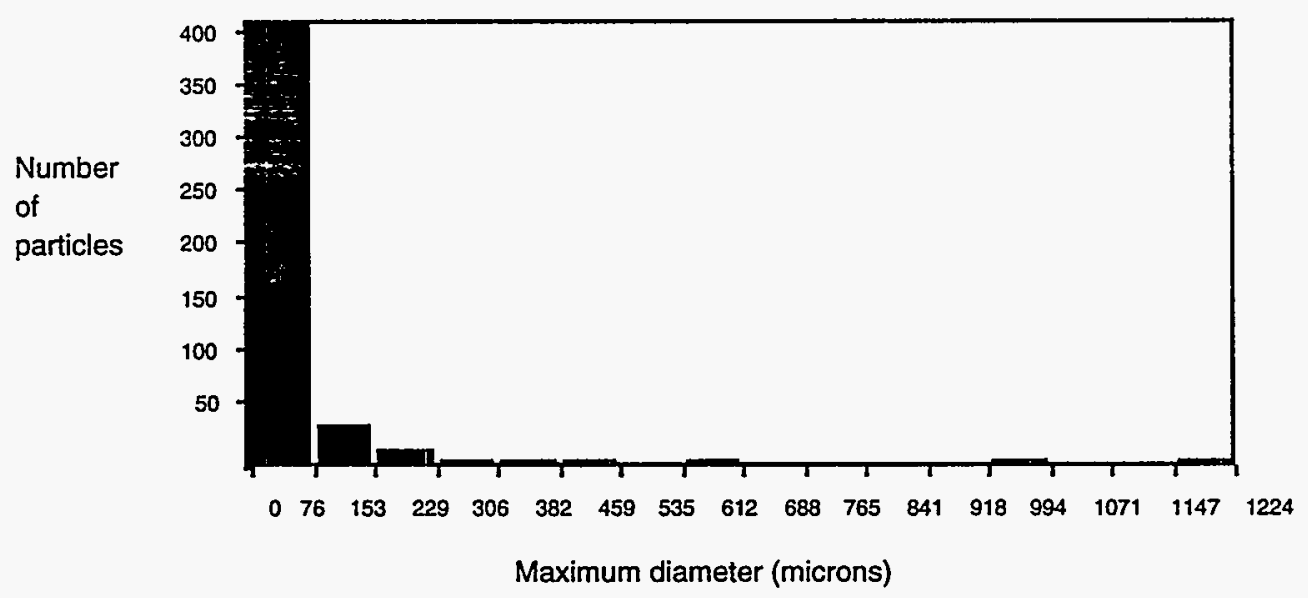

Fig. III-19. Particle Distribution of Silico-titanate Sample in Fig. III-18 as Function of Diameter (average value, $64 \mu \mathrm{m}$ ) 


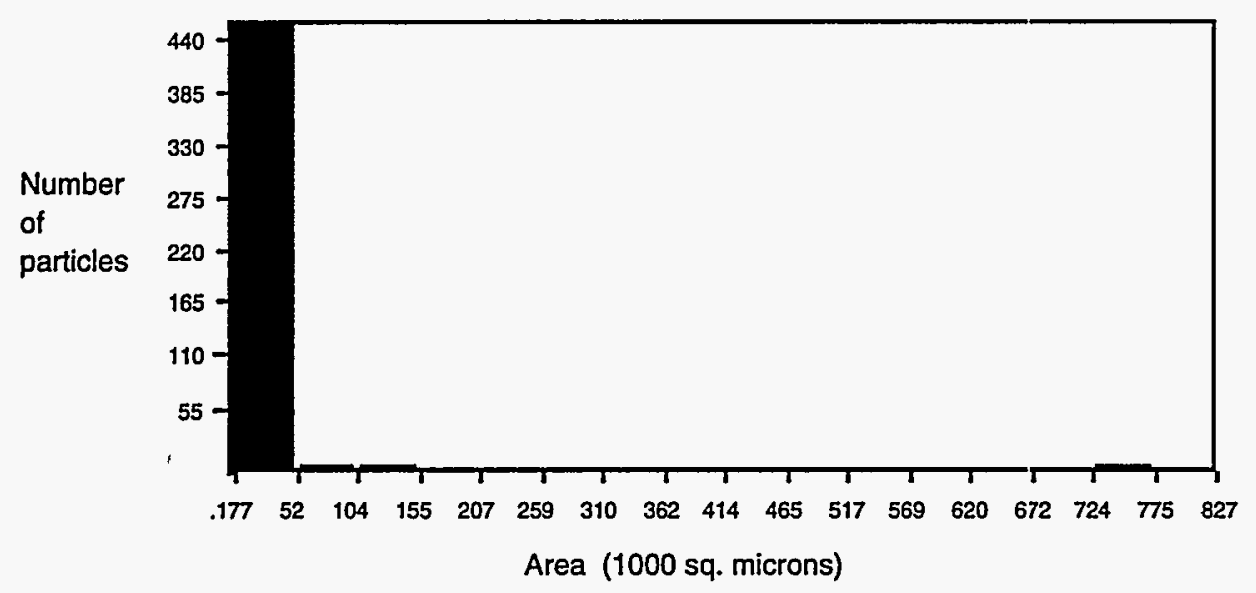

Fig. III-20. Particle Distribution of Silico-titanate Sample in Fig. III-18 as Function of Area (average value, $150,000 \mu \mathrm{m}^{2}$ )

\section{Resorcinol Particles (US Form)}

The micrograph of a resorcinol sample irradiated for 100 cycles (Fig. III-21) was composed of a few particles over $500 \mu \mathrm{m}$ and numerous others smaller than $100 \mu \mathrm{m}$ (Figs. III-22 and III-23). This sample also contained a number of thread-like structures.

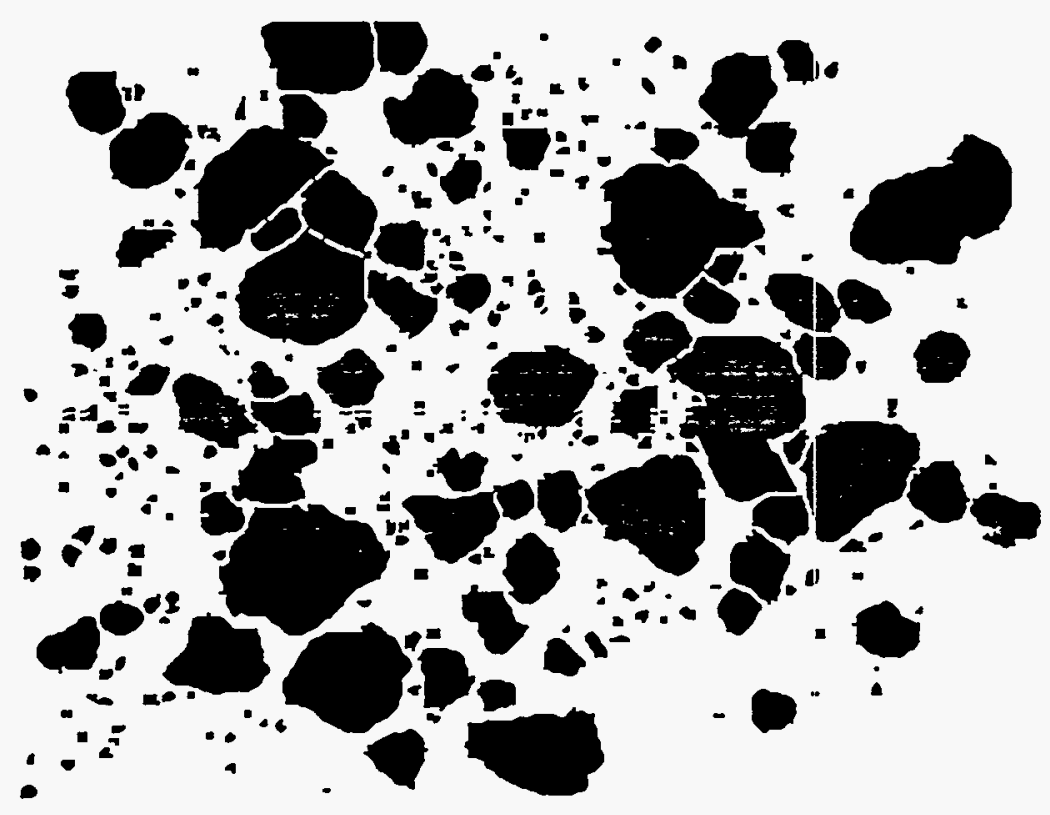

Fig. III-21. Micrograph of Resorcinol (US form) Sample before Irradiation 


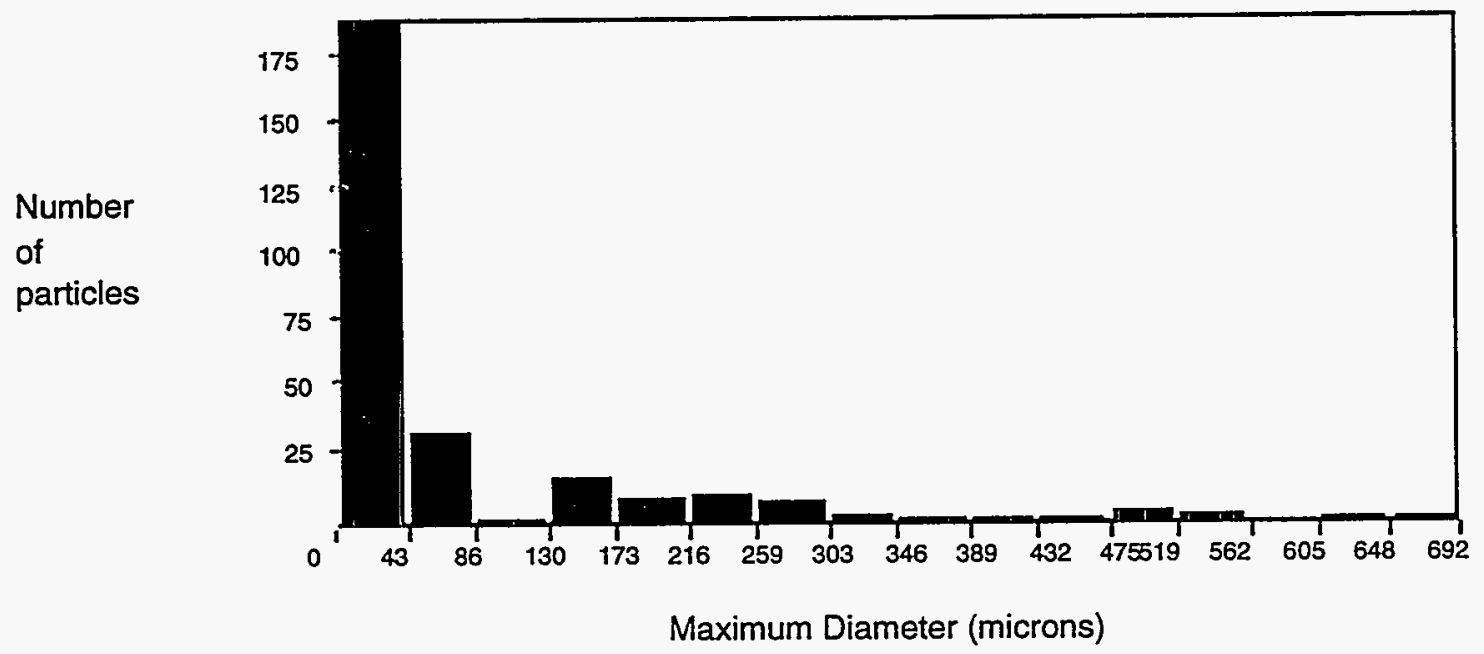

Fig. III-22. Particle Distribution of Resorcinol Sample in Fig. II-21 as Function of Diameter (average value, $84 \mu \mathrm{m}$ )

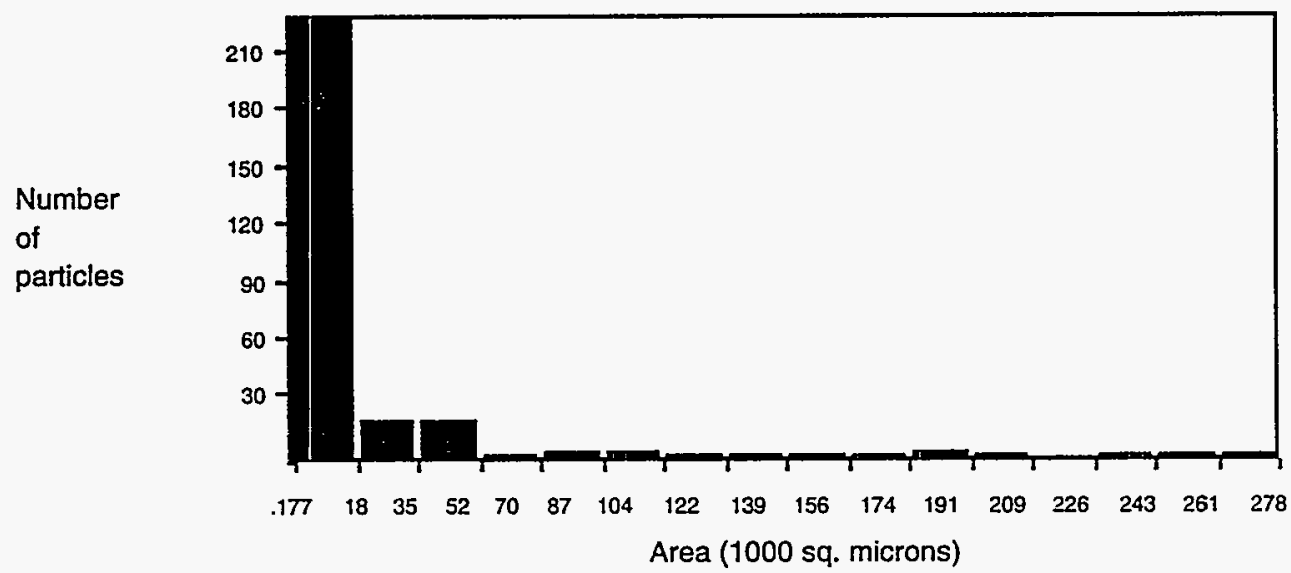

Fig. III-23. Particle Distribution of Resorcinol Sample in Fig. III-21 as Function of Area (average value, $16,000 \mu \mathrm{m}^{2}$ )

In the micrograph (Fig. III-24) and particle distribution (Figs. III-25 and III-26), it appears that the particles have swelled. The sizes of the large particles are 100 to $200 \mu \mathrm{m}$ greater than those of the previous micrograph (Fig. III-6). A possible explanation is that the polymer is absorbing the liquid. This is similar to the results that Bradtec obtained when trying to extract ${ }^{137} \mathrm{Cs}$ from milk, where the absorption of liquid into the particles produced milk enriched in calcium. 


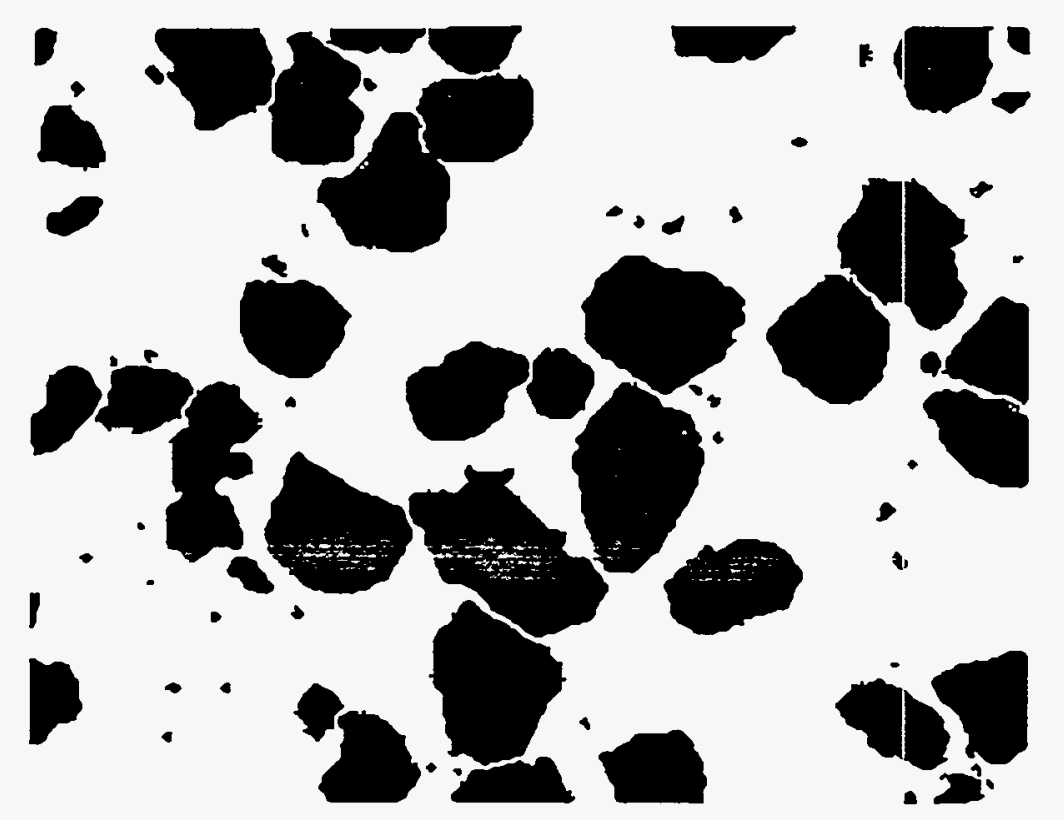

Fig. III-24. Micrograph of Swelled Resorcinol Sample (US form)

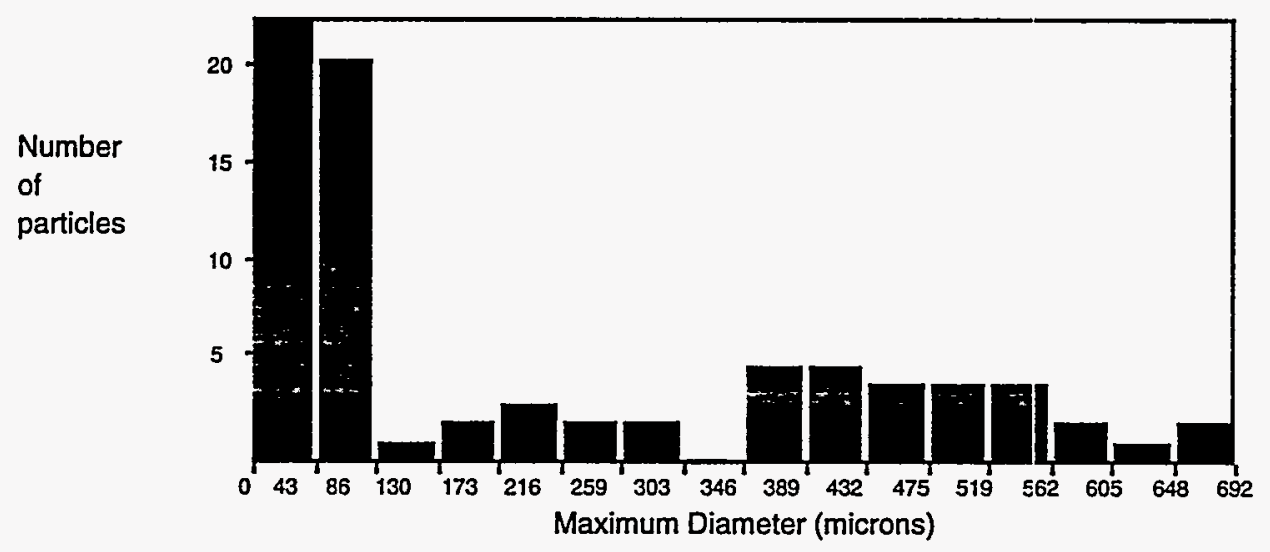

Fig. III-25. Particle Distribution of Resorcinol Sample in Fig. III-24 as Function of Diameter (average value, $197 \mu \mathrm{m}$ ) 


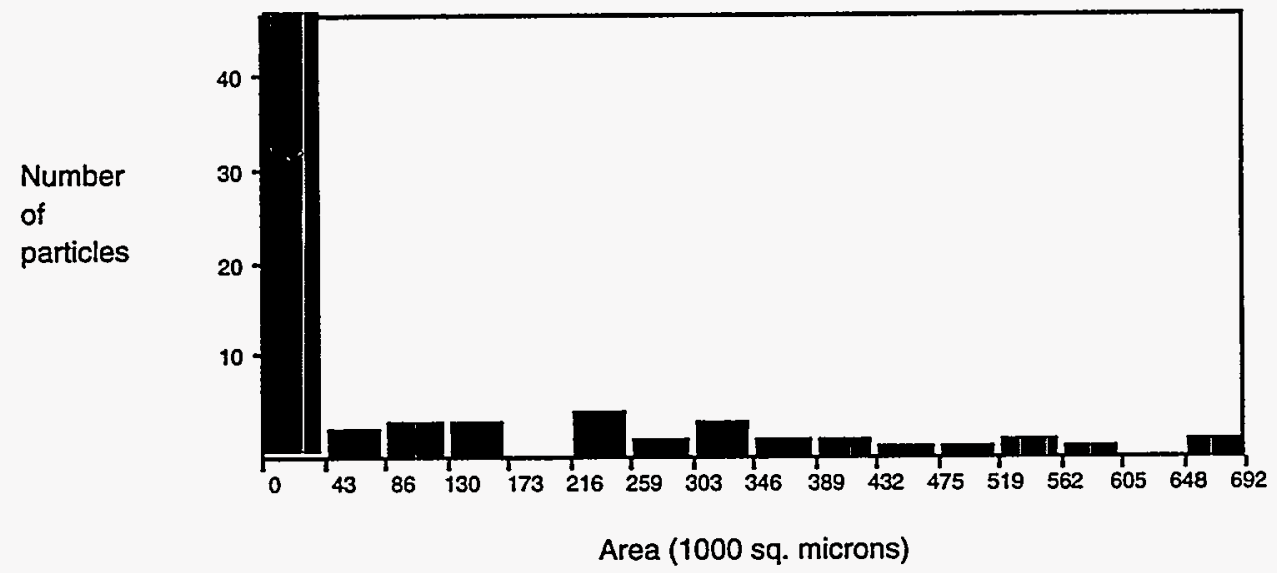

Fig. III-26. Particle Distribution of Resorcinol Sample in Fig. III-24 as Function of Area (average value, $60,000 \mu \mathrm{m}$ )

The particles in the resorcinol sample after 10 cycles of irradiation are very tightly packed (Fig. II-27). This makes it difficult to determine the size distribution. It was necessary to separate particles using the software when a natural break (gain boundary contact) was suggested by the micrograph (Figs. III-28 and III-29).

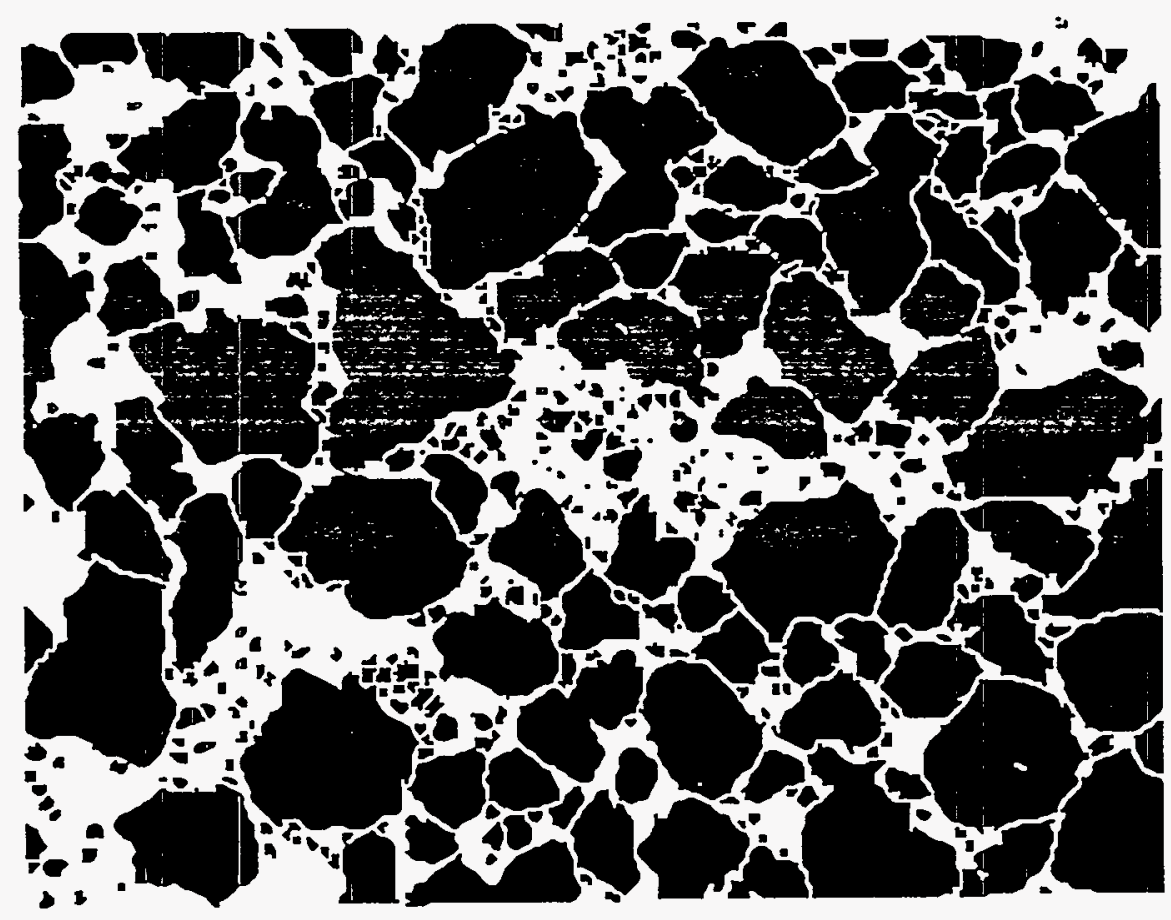

Fig. III-27. Micrograph of Resorcinol Sample (US form) after 10 Cycle Irradiation 


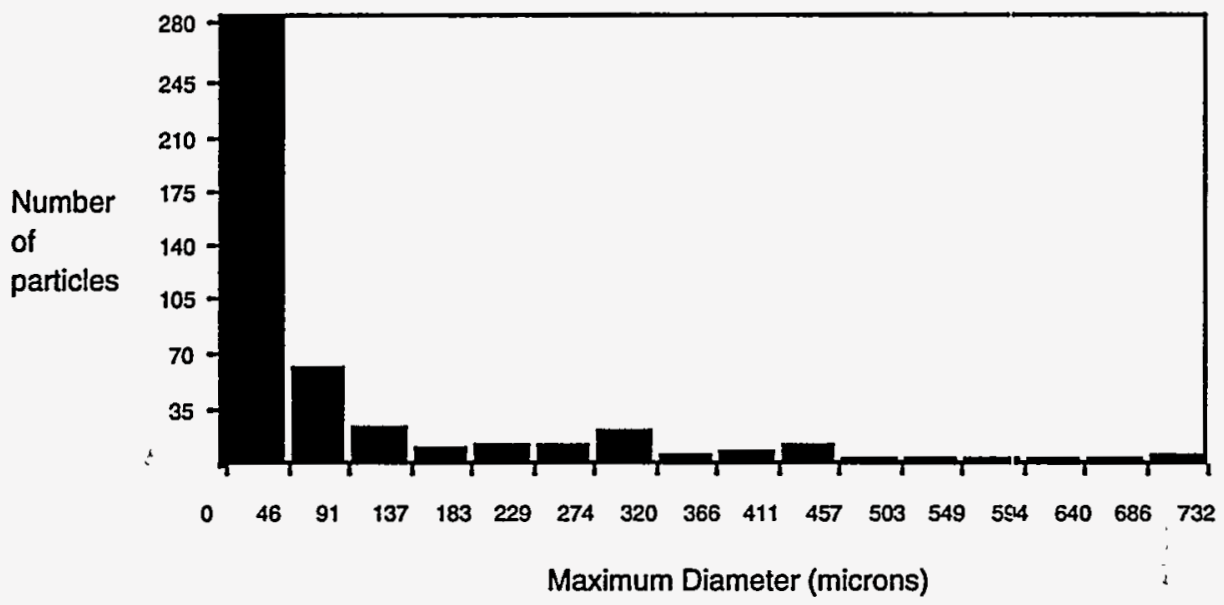

Fig. III-28. Particle Distribution of Resorcinol Sample in Fig. III-27 as Function of Diameter (average value, $95 \mu \mathrm{m}$ )

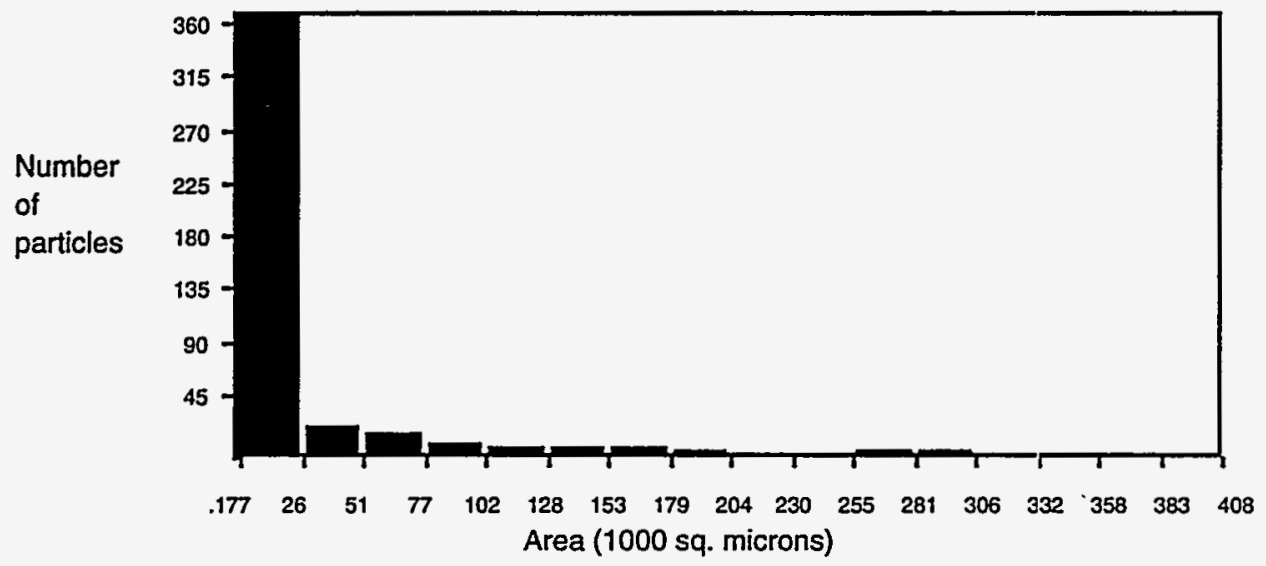

Fig. III-29. Particle Distribution of Resorcinol Sample in Fig. III-27 as Function of Area (average value, $21,000 \mu \mathrm{m}^{2}$ )

In the micrograph of the resorcinol sample after the 100 cycle irradiation (Fig. III-30), the number of fine particles increased compared with Figs. III-24 and III-27. This suggests that the irradiation is breaking up the particles and creating these tiny fragments (fines), which may or may not have magnetite and cesium-extraction components (Figs. III-31 and III-32). 


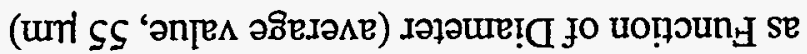

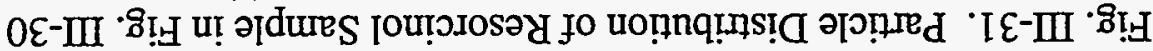

(suosọw) dәрәше! unu!̣xw

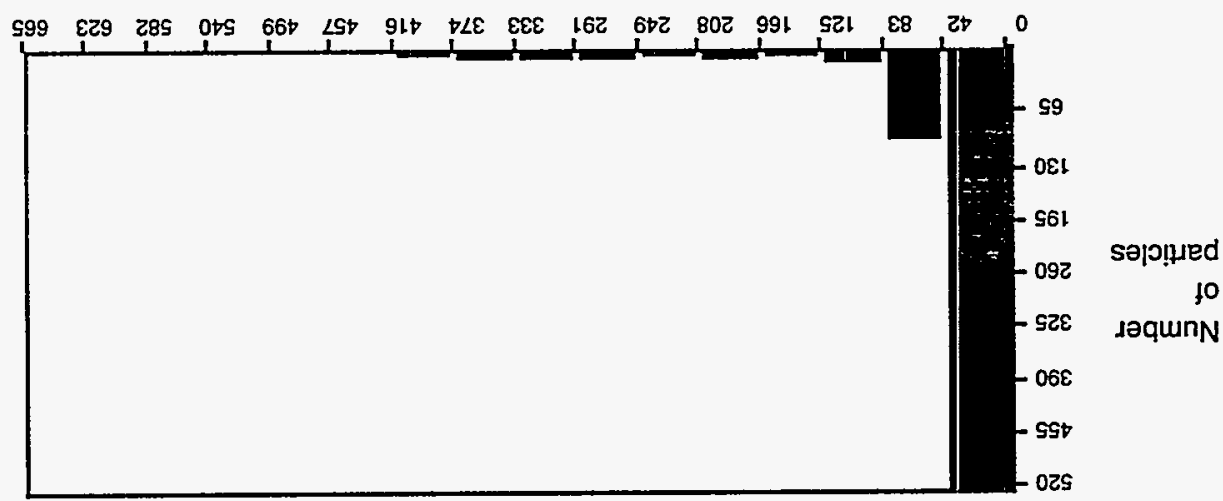

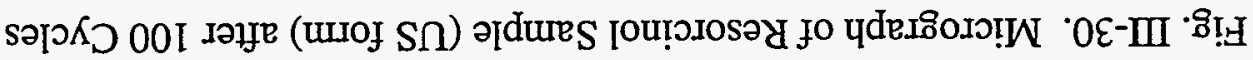

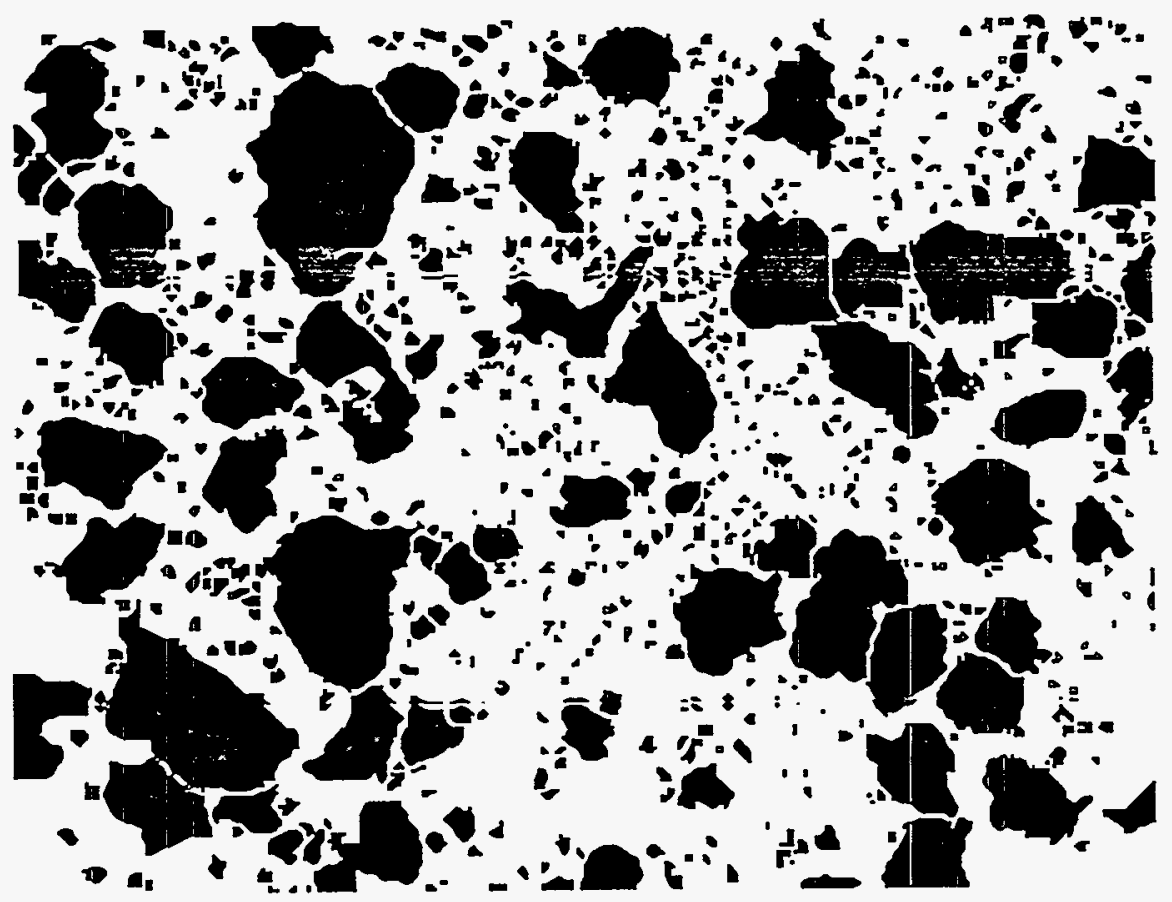




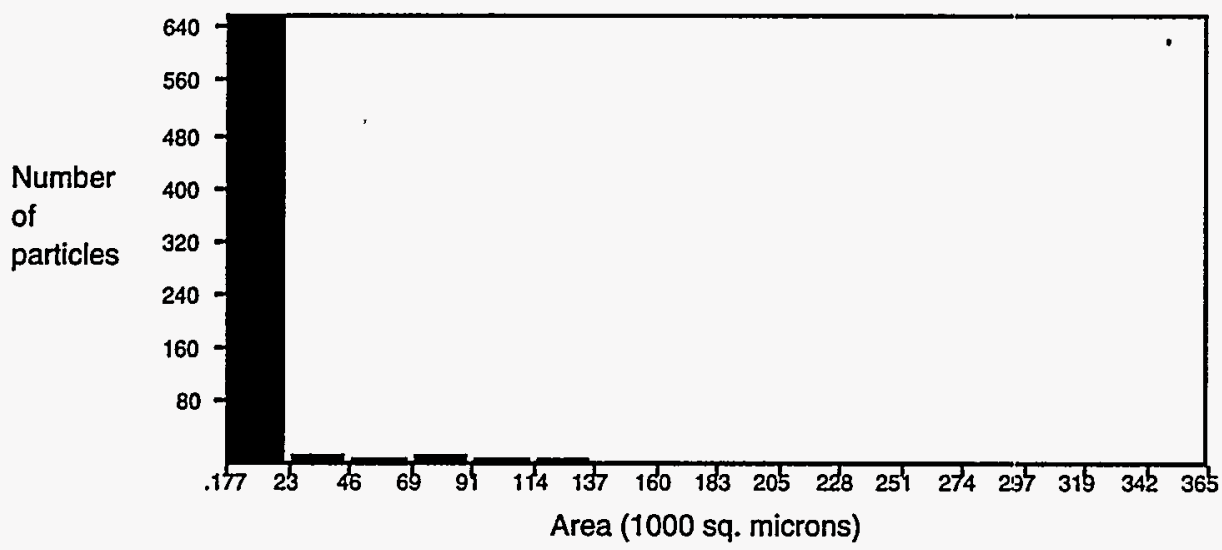

Fig. III-32. Particle Distribution of Resorcinol Sample in Fig. III-30 as Function of Area (average value, $8000 \mu \mathrm{m}^{2}$ )

\section{Conclusion}

The overall effect of gamma radiation on the silico-titanate particles was a drastic increase in the particle size. This will cause a significant decrease in extraction efficiency due to the decreased surface area.

The resorcinol (US form) was also greatly affected by the radiation. As the irradiation dose increased, the number of smaller particles or fines increased. These smaller fragments may or may not have both the magnetic- and cesium-extracting components.

For the entire sample, the extent of the radiation damage and its result on the extraction efficiency cannot be determined; however, it is obvious through $\mathrm{K}_{d}$ measurements that the irradiation of the particles is decreasing their extraction performance. 
APPENDIX A.

\section{GAMMA RRADIATION FACILITY}

\section{Facility Description}

The gamma facility is located in the Chemistry Division at ANL. The gamma cell is approximately $4.3 \mathrm{~m} \mathrm{x} 4.9 \mathrm{~m}$ (14 ft x $16 \mathrm{ft}$ ), with a $0.3 \mathrm{~m}$ (12.5 in.) ceiling. Most of the cell shown in Fig. A-1 can be used to irradiate samples depending on the dose requirements. All the reserved areas in Fig A-1 are available for short-term experiments such as particle irradiation (time frame of a few months). The atmosphere is once-through air, with a total of $34 \mathrm{~m}^{3} / \mathrm{min}$ $(1200 \mathrm{cfm})$ being exhausted. This produces an air change about every two minutes. The cobalt source is stored under the floor of the cell when not in use. The source is drawn out of the floor by means of an " $\mathrm{A}$ " frame mechanism to expose items placed in the cell. The shielding walls are $1.2-\mathrm{m}(3.7-\mathrm{ft})$ thick magnetite concrete and should shield against $1 \mathrm{MCi}$ of $1 \mathrm{MeV}$ gamma energy. Viewing into the cell is provided by two zinc bromide windows, which normally are covered with six-inch shielding shutters. The shutters can be raised for a short time during irradiations to make observations.

\section{Cobalt Source}

The source array is comprised of six rods, $2.5-\mathrm{cm}$ (1-in.) dia by $20-\mathrm{cm}(8-\mathrm{in}$.$) length.$ Four of the rods are located on a $6.3-\mathrm{cm}(2.5$-in.) radius from the center of the array. The other two rods are located on a $9.5-\mathrm{cm}$ (3.75-in.) radius from the center of opposing corners of the array. The rods, when raised into the cell, are $40.6 \mathrm{~cm}$ (16 in.) from the floor to the centerline of the rod length. The original strength of the source was $70,000 \mathrm{Ci}$ of cobalt- 60 as of November 1990. There is a $0.8 \%$ reduction in strength per month.

\section{Dosimeter}

Dosimetry in the facility is performed using cobalt-doped glass dosimeters. The glass plate absorbency at $450 \mu \mathrm{m}$ is measured before and after irradiation, and the difference in absorbency is used to determine absorbed doses. The glass plates have been calibrated against a ferrous sulfate dosimeter to determine the calibration curve for the glass. The response of the glass is linear from $1 \times 10^{5}$ to $5 \times 10^{6}$ rads. Dosimetry runs are timed to fall in this linear portion of the curve. The plates are read immediately after irradiation so that no corrections are necessary for fade characteristics. The accuracy of the glass dosimeter is $\pm 10 \%$. 


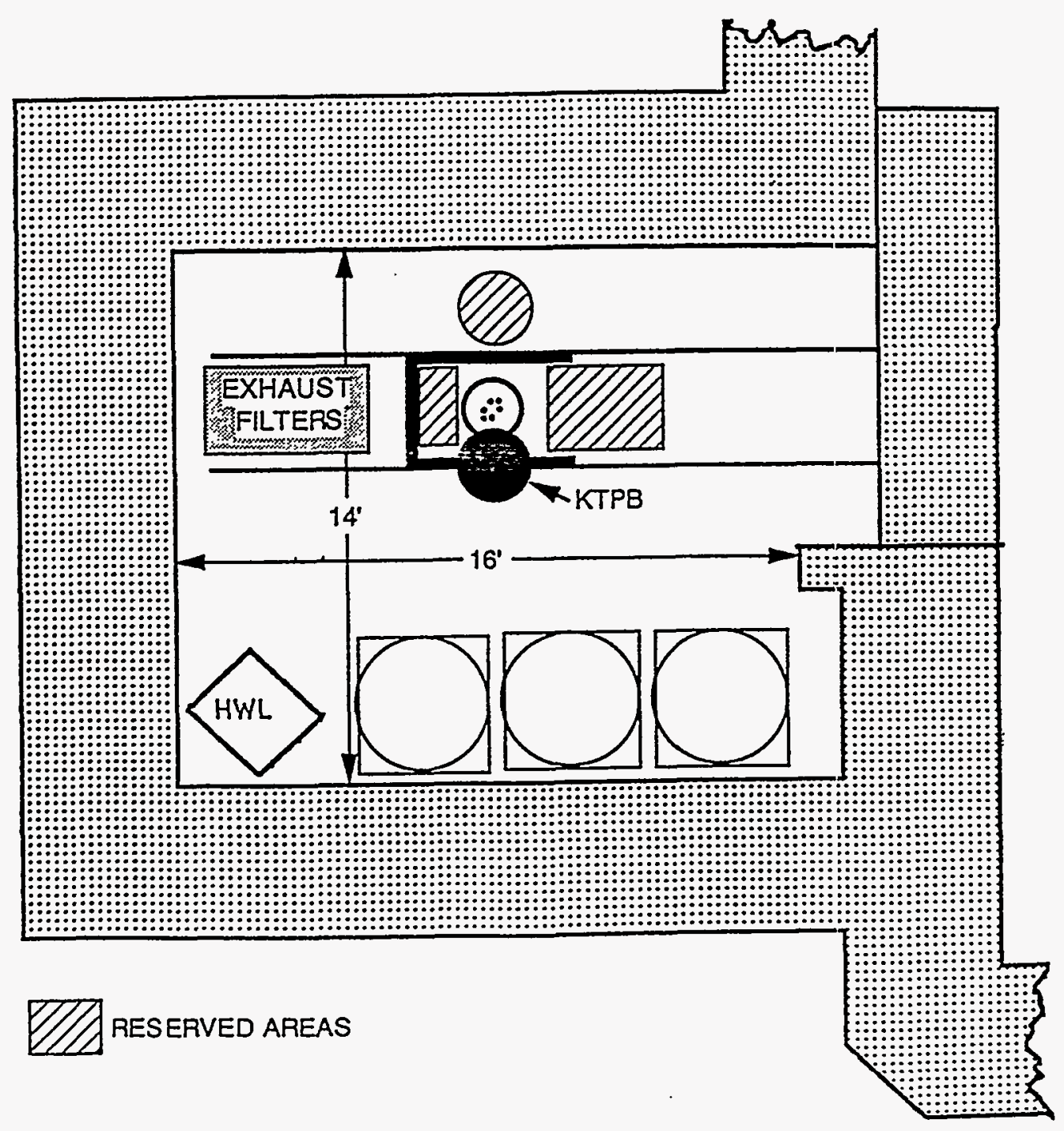

Fig. A-1. Layout of Gamma Facility 


\section{REFERENCES}

1. H. Cember, Introduction to Health Physics, 2nd Ed., Pergamon Press, New York, pp. 97-131 (1988). 
Distribution for ANL-94/47

Internal:

S. Asse

J. E. Battles

B. A. Buchholz

G. Dyrkacz

J. E. Harmon
M. D. Kaminski

J. J. Laidler

L. Nunez (20)

M. J. Steindler
C. E. Till

H. E. Tuazon

G. F. Vandegrift

TIS Files

\section{External:}

DOE-OSTI (2)

ANL-E Library (2)

ANL-W Library

Manager, Chicago Operations Office, DOE

J. Haugen, DOE-CH

Chemical Technology Division Review Committee Members:

E. R. Beaver, Monsanto Company, St. Louis, MO

D. L. Douglas, Consultant, Bloomington, MN

R. K. Genung, Oak Ridge National Laboratory, Oak Ridge, TN

J. G. Kay, Drexel University, Philadelphia, PA

G. R. St. Pierre, Ohio State University, Columbus, $\mathrm{OH}$

J. Stringer, Electric Power Research Institute, Palo Alto, CA

J. B. Wagner, Arizona State University, Tempe, AZ

K. J. Atkins, Bradtec, Inc., Atlanta, GA

F. M. Bos, Bradtec, Inc., Atlanta, GA

C. R. Bradley, Bolingbrook, IL

P. Colton, Pacific Northwest Laboratory, Richland, WA

G. R. Elder, Bradtec, Inc., Atlanta, GA

T. Fryberger, USDOE, Office of Environmental Management, Germantown, MD

W. L. Kuhn, Battelle Pacific Northwest Laboratory, Richland, WA

C. A. Swift, Bradtec, Inc., Atlanta, GA

I. R. Tasker, Waste Policy Institute, Gaithersburg, MD

J. Watson, Oak Ridge National Laboratory, Oak Ridge, TN 